\title{
VARIÁVEIS LATENTES EM ANÁLISE DE SOBREVIVÊNCIA E CURVAS DE CRESCIMENTO
}

\author{
SUELY RUIZ GIOLO
}

Tese apresentada à Escola Superior de Agricultura "Luiz de Queiroz", Universidade de São Paulo, para obtenção do título de Doutor em Agronomia, Área de Concentração: Estatística e Experimentação Agronômica.

P I R A C I C A B A

Estado de São Paulo - Brasil

Janeiro - 2003 


\title{
VARIÁVEIS LATENTES EM ANÁLISE DE SOBREVIVÊNCIA E CURVAS DE CRESCIMENTO
}

\author{
SUELY RUIZ GIOLO \\ Estatístico
}

Orientadora: Prof $\stackrel{\underline{a}}{-}$ Dr $^{\underline{a}}$ CLARICE GARCIA BORGES DEMÉTRIO

Tese apresentada à Escola Superior de Agricultura "Luiz de Queiroz", Universidade de São Paulo, para obtenção do título de Doutor em Agronomia, Área de Concentração: Estatística e Experimentação Agronômica.

P I R A C I C A B A

Estado de São Paulo - Brasil

Janeiro - 2003 


\section{Dados I nternacionais de Catalogação na Publicação (CI P) DI VISÃO DE BI BLIOTECA E DOCUMENTAÇÃO - ESALQ/ USP}

\section{Giolo, Suely Ruiz}

Variáveis latentes em análise de sobrevivência e curvas de crescimento / Suely

Ruiz Giolo. - - Piracicaba, 2002.

$100 \mathrm{p}$.

Dissertação (doutorado) - - Escola Superior de Agricultura Luiz de Queiroz, 2003.

Bibliografia.

1. Análise de dados 2. Análise de sobrevivência 3. Curvas de crescimento 4. Melhorc mento genético animal 5 . Variável latente I. Título

CDD 519.53

"Permitida a cópia total ou parcial deste documento, desde que citada a fonte - $\mathrm{O}$ autor" 


\section{DEDICATÓRIA}

A Deus a vida, as oportunidades e

os ensinamentos.

À minha família, em especial aos meus pais,

o carinho e o apoio incondicionais. 


\section{AGRADECIMENTOS}

À Prof $\underline{a}^{a}$ Dr $\underline{a}$ Clarice Garcia Borges Demétrio a orientação, o constante estímulo, a amizade e a confiança depositada no meu trabalho.

Ao Prof. Dr. Robin Henderson a supervisão, o estímulo, a paciência e os ensinamentos transmitidos durante o meu período de estudos no Department of Mathematics and Statistics da Lancaster University, Inglaterra.

À CAPES o fundamental suporte financeiro concedido.

À Universidade Federal do Paraná e aos professores do Departamento de Estatística o afastamento concedido para a realização desse trabalho.

Aos professores e funcionários do Departamento de Ciências Exatas da ESALQ/USP que me propiciaram condições para a realização desse trabalho.

Aos colegas e amigos de doutorado, em especial à Mํㅡㄹ Cristina Neves de Oliveira, Silvano Cesar da Costa e Claudia Cristina Paro de Paz a amizade, a troca de conhecimentos e a atenção recebida em todos os momentos.

Aos colegas e amigos da Universidade de Lancaster, Rosemeire, Inês, Isabel, Jó, Rui, Ana Lúcia, Paulo, Vera, Guilherme, Meire, Rodrigo, Carol e tantos outros, os bons momentos compartilhados em terra tão distante.

Ao Paulo Justiniano Ribeiro Junior e Silvia Emiko Shimakura a amizade, o incentivo e a ajuda durante meu período de estudos em Lancaster.

Ao Prof. Dr. Luiz Alberto Fries do Gensys Consultores Associados S/C Ltda e à Embrapa de São Carlos por terem cedido os dados utilizados nesse trabalho.

A todos aqueles que, direta ou indiretamente, colaboraram para a realização deste trabalho. 


\section{SUMÁRIO}

Página

LISTA DE FIGURAS . . . . . . . . . . . . . . . . . . vii

LISTA DE TABELAS ......................... ix

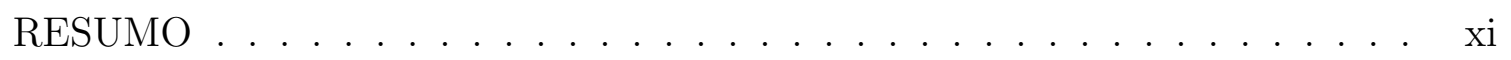

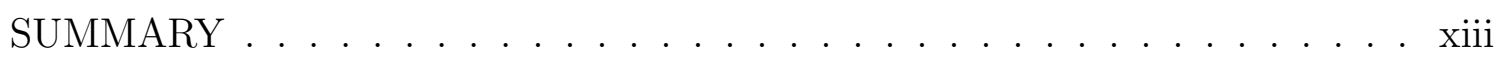

1 INTRODUÇत̃ $\ldots \ldots \ldots \ldots \ldots \ldots$

2 REVISÃO DE LITERATURA . . . . . . . . . . . . . . . . 4

2.1 Análise de dados de sobrevivência univariados . . . . . . . . . . . . . 4

2.2 Análise de dados de sobrevivência multivariados . . . . . . . . . . . 6

2.2.1 Notação de processos de contagem . . . . . . . . . . . . . . . 8

2.2.2 Algumas generalizações do modelo de fragilidade . . . . . . . . . . . . 9

2.2.3 Modelos de fragilidade aditivos . . . . . . . . . . . . . 11

2.2.4 Algoritmos de estimação . . . . . . . . . . . . . . . . . . . . . 14

2.2.5 Testes de hipóteses . . . . . . . . . . . . . . . . . . . . . 21

2.3 Interpretação dos parâmetros . . . . . . . . . . . . . . . . . . 24

2.3.1 Ajuste dos modelos de fragilidade . . . . . . . . . . . . . 25

2.4 Análise de dados de sobrevivência multivariados em um contexto de censura intervalar . . . . . . . . . . . . . . . . . . . . . . . . . . 29

3 MATERIAL E MÉTODOS . . . . . . . . . . . . . . . 32

3.1 Material . . . . . . . . . . . . . . . . . . . . 32

3.1 .1 Estudo para a seleção de touros da raça Nelore . . . . . . . . . . . . . 32

3.1.2 Estudo para a seleção de touros da raça Canchim . . . . . . . . . . . 34

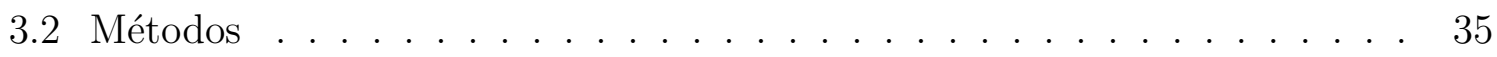


3.2.1 Modelos de fragilidade gama com censura intervalar . . . . . . . . . . 35

3.2.2 Estudo de simulação . . . . . . . . . . . . . . . . . . . . . . . . 42

3.2.3 Modelos de curvas de crescimento com efeitos aleatórios . . . . . . . . . 43

3.2.4 Comparação por meio de simulação entre os resultados do modelo de fragilidade gama com censura intervalar e os do modelo de curvas de crescimento com efeitos aleatórios . . . . . . . . . . . . . . . 46

4 RESULTADOS E DISCUSSÃO . . . . . . . . . . . . . . 48

4.1 Estudo realizado com bovinos Nelore . . . . . . . . . . . . . . . . . . . . 48

4.1.1 Resultados do modelo de fragilidade gama com censura intervalar . . . 50

4.1.1.1 Resultados do estudo de simulação . . . . . . . . . . . . . . . . 54

4.1.2 Resultados do modelo de curvas de crescimento com efeitos aleatórios . 55

4.2 Estudo realizado com bovinos Canchim . . . . . . . . . . . . . . 60

4.3 Comparação dos critérios de seleção . . . . . . . . . . . . . . . 67

4.3.1 Comparação dos critérios de seleção por meio de simulação . . . . . . . 67

5 CONCLUSÕES . . . . . . . . . . . . . . . . . . . 72

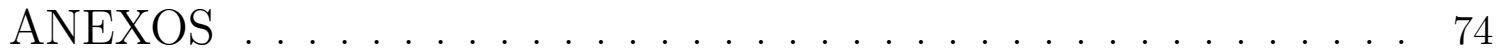

REFERÊNCIAS BIBLIOGRÁFICAS . . . . . . . . . . . . 96 


\section{LISTA DE FIGURAS}

Página

1 Médias e intervalos de credibilidade a posteriori dos $z_{j}$ 's associados aos 64 touros Nelore. . . . . . . . . . . . . . . . . . . . . 52

2 Distribuições a posteriori das classificações de uma amostra de 16 touros Nelore. 53

3 Curvas de sobrevivência a posteriori para os descendentes machos e fêmeas dos

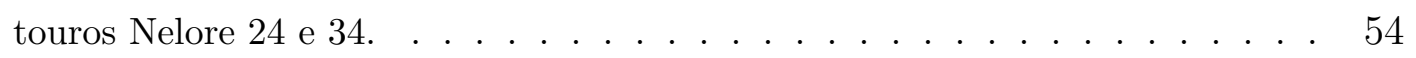

4 Gráficos de caixas das estimativas do parâmetro $\beta_{1}$ obtidas em 500 simulações considerando-se o modelo de fragilidade gama com censura intervalar sem, e com, efeito aleatório. . . . . . . . . . . . . . . . 55

5 Médias e intervalos de credibilidade a posteriori $\operatorname{dos} f_{j}$ 's associados aos 64 touros Nelore. . . . . . . . . . . . . . . . . . . . 57

6 Distribuições a posteriori das classificações de uma amostra de 12 touros Nelore. 58

7 Curvas de crescimento a posteriori para três descendentes machos dos touros

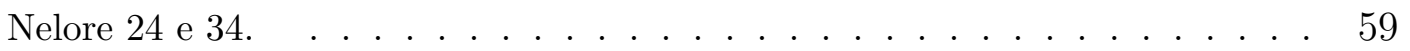

8 Médias e intervalos de credibilidade a posteriori dos $z_{j}$ 's associados aos 241 touros Canchim. . . . . . . . . . . . . . . . . . 64

9 Distribuições a posteriori das classificações de 12 touros Canchim. . . . . . . . 65

10 Curvas de sobrevivência a posteriori dos descendentes machos e fêmeas do touro 234 e da vaca 1504 da raça Canchim nas quatro estações do ano. . . . 65

11 Curvas de sobrevivência a posteriori dos machos e fêmeas, nascidos no inverno, descendentes do touro 234 e da vaca 1504 da raça Canchim considerando-se diferentes idades da vaca no parto. . . . . . . . . . . . . . 66

12 Pesos simulados para 1000 animais nos tempos 0,220 e 600 dias. . . . . . . 67 
13 Classificações dos touros obtidas em uma das simulações realizadas com 10 e 20 touros, respectivamente. . . . . . . . . . . . . . . . 69

14 Distribuição dos tempos até um ganho de peso de $160 \mathrm{~kg}$. . . . . . . . . . . . 70 


\section{LISTA DE TABELAS}

Página

1 Estatísticas resumo para as covariáveis quantitativas observadas nos descendentes de 64 touros da raça Nelore. . . . . . . . . . . . . . . . . . 48

2 Distribuição de freqüências do número de descendentes de 64 touros da raça Nelore. . . . . . . . . . . . . . . . . . . . . . . . . . . . 49

3 Características dos fatores qualitativos observados nos descendentes de 64 touros da raça Nelore. . . . . . . . . . . . . . . . . . . . . . . . . 49

4 Estatísticas resumo das distribuições a posteriori dos parâmetros do modelo de fragilidade gama com censura intervalar e de alguns $z_{j}$ 's - bovinos Nelore. . . . . . . . . . . . . . . . . . . . . . 51

5 Estatísticas resumo para os pesos observados nos descendentes de 64 touros da raça Nelore. . . . . . . . . . . . . . . . . . 56

6 Parâmetros e desvios padrões a posteriori obtidos pelo método MCMC. . 56

7 Estatísticas resumo para os tempos, em dias, até os descendentes dos touros 24 e 34 da raça Nelore alcançarem 190kg. . . . . . . . . . . . . . . 59

8 Distribuição de freqüências do número de descendentes de 1687 vacas Canchim. ...................... 60

9 Distribuição de freqüências do número de nascimentos por mês e estação do ano dos descendentes de 1687 vacas e 241 touros Canchim. . . . . . . 61

10 Estatísticas resumo dos pesos e idades observadas nos descendentes de 241 touros da raça Canchim. . . . . . . . . . . . . . . . . . . . 61

11 Estatísticas resumo das distribuições a posteriori dos parâmetros do modelo de fragilidade gama com censura intervalar - bovinos Canchim. . . . 
12 Estatísticas resumo das distribuições a posteriori dos parâmetros do modelo de curvas de crescimento e do modelo de fragilidade gama e dos $f_{j}$ 's e $z_{j}$ 's obtidos em uma das simulações. . . . . . . . . . . . . . . . 68

13 Classificações obtidas para os 10 touros usando-se o modelo de curvas de crescimento (modelo I) e o modelo de fragilidade gama com censura intervalar $($ modelo II) . . . . . . . . . . . . . . . . . . . . . . 69 


\section{VARIÁVEIS LATENTES EM ANÁLISE DE SOBREVIVÊNCIA E CURVAS DE CRESCIMENTO}

Autora: SUELY RUIZ GIOLO

Orientadora: $\operatorname{Prof}^{\underline{a}} \operatorname{Dr}^{\underline{a}}$ CLARICE GARCIA BORGES DEMÉTRIO

\section{RESUMO}

Em um contexto de análise de dados de sobrevivência univariados ou multivariados, dados de tempos de falha caracterizam-se pela possibilidade de poderem ser censurados. Embora comum na prática, a censura impede o uso de alguns procedimentos estatísticos covencionais o que vem motivando, em especial após a publicação do artigo de Cox (1972), o desenvolvimento de métodos estatísticos nessa área. Uma linha de estudo recente é a de que, em algumas situações, a variável resposta esteja sendo influenciada por variáveis latentes, variáveis estas que são usadas, em um sentido estatístico, para descreverem efeitos genéticos ou ambientais compartilhados pelos indivíduos ou, ainda, covariáveis não consideradas no estudo. Nesse trabalho, ênfase é dada aos modelos de sobrevivência que consideram tempos de falha multivariados e variáveis latentes. Esses tempos aparecem quando, por exemplo, cada indivíduo em estudo está sujeito a diversos eventos ou, quando existe um agrupamento natural ou artificial o qual induz dependência entre os tempos dos 
indivíduos do mesmo grupo. Modelos com variáveis latentes em que tais tempos de falha ocorrem em intervalos de tempo, ou seja, em um contexto de censura intervalar são especialmente considerados nesse trabalho. O modelo de fragilidade gama para dados de sobrevivência com censura intervalar é proposto, nesse trabalho, como um critério para a seleção de bovinos. Como uma alternativa para esta seleção, o modelo de curvas de crescimento com efeitos aleatórios é também considerado. Para a estimação dos parâmetros envolvidos em ambos os modelos propostos, programas computacionais são apresentados. Uma abordagem Bayesiana é considerada no processo de estimação sendo, o método de Markov chain Monte Carlo (MCMC) utilizado e as distribuições a posteriori obtidas, usando-se o amostrador de Gibbs. O modelo de fragilidade gama com censura intervalar e o de curvas de crescimento com efeitos aleatórios são comparados por meio de um estudo de simulação. Para ilustrar ambos os modelos propostos, estudos com bovinos das raças Nelore e Canchim são utilizados. 


\title{
LATENT VARIABLES IN SURVIVAL ANALYSIS AND GROWTH CURVES
}

\author{
Author: SUELY RUIZ GIOLO \\ Adviser: $\operatorname{Prof}^{\underline{a}} \operatorname{Dr}^{\underline{a}}$ CLARICE GARCIA BORGES DEMÉTRIO
}

\section{SUMMARY}

In a context of univariate or multivariate survival data analysis, failure times data are characterized by the possibility to be censored. Although common in practice, censoring precludes the use of some conventional statistical procedures and it has been motivating, specially after the publication of the Cox's paper (1972), the development of statistical methods in this area. A recent topic of study is concerned with some situations where the response variable is influenced by latent variables which are used in a statistical sense to describe genetic or environmental effects shared by individuals or also covariates not considered in the study. In this work emphasis is given to survival models which consider multivariate failure times and latent variables. Such times occur when, for instance, each individual under study is exposed to several events or when there is a natural or artificial clustering that causes dependence among times of those individuals at the same cluster. Models with latent variables where such failure times lie in intervals 
of time, i.e. in an interval censored context are specially considered in this work. The gamma frailty interval censored survival model is proposed in this work as a selection criterion for cattle. As an alternative selection criterion the growth curves model with random effects is also considered. To estimate the involved parameters in both proposed models, computational programs are presented. A Bayesian approach is considered in the estimation process so that the Markov chain Monte Carlo (MCMC) method is used and the posterior distributions are obtained using Gibbs sampling. The gamma frailty interval-censored survival model and the growth curves model with random effects are compared using a simulation study. To illustrate both proposed models studies with Nelore and Canchim cattle are used. 


\section{INTRODUÇÃO}

Dados de tempos de falha são comumente encontrados em diversas áreas de pesquisa (biomédicas, agricultura, sociologia etc.). Por falha entende-se a ocorrência de um evento pré-especificado e, por tempo de falha, o período de tempo decorrido para o evento ocorrer. Uma característica importante dos dados de tempos de falha é a possibilidade de poderem ser censurados. Isso refere-se a circunstâncias em que alguns indivíduos encontram-se livres do evento por terem, por exemplo, sido retirados mais cedo do estudo ou pelo término do experimento. Enquanto comum na prática, a censura impede o uso de alguns procedimentos estatísticos convencionais. Em conseqüência, métodos nessa área têm sido desenvolvidos e, o interesse pelo assunto, crescido significativamente após a publicação do artigo de Cox (1972).

Uma linha de estudo recente é a de que, em algumas situações, a variável resposta, tempo de falha, possa estar sendo afetada por variáveis latentes. Estas são variáveis aleatórias não-observadas, as quais são usadas em um sentido estatístico, para descreverem influências ambientais ou efeitos genéticos não-observados ou, ainda, covariáveis não consideradas no estudo.

Modelos com variáveis latentes vêm sendo utilizados, por exemplo, em estudos envolvendo tempos de falha multivariados. Tais tempos aparecem quando cada indivíduo em estudo está sujeito a diversos eventos ou, quando existe algum agrupamento natural ou artificial de indivíduos o qual induz dependência entre os tempos do mesmo grupo. Em estudos com animais, por exemplo, é natural supor que haja correlação entre os tempos dos animais de uma mesma ninhada, enquanto que, em estudos com humanos é razoável que exista correlação entre os tempos para a ocorrência de um evento dos membros de uma mesma família. As associações 
aparecem devido a influências genéticas ou ambientais compartilhadas e, se forem ignoradas, inferências incorretas poderão ser obtidas. Para esse fim, uma classe de modelos denominada modelos de fragilidade (frailty models) para dados de sobrevivência multivariados vem sendo estudada por diversos pesquisadores, dentre os quais, Clayton (1978), Oakes (1982), Hougaard (1986), Hougaard et al. (1992), McGilchrist (1993), Paik et al. (1994) e Hougaard (2000). A suposição mais comum é a de que cada membro do grupo tenha a mesma variável latente afetando a sobrevivência. Contudo, essa suposição é forte, sendo razoável argumentar que, em adição aos efeitos aleatórios compartilhados, efeitos aleatórios específicos a cada indivíduo possam também estar atuando. Isso leva à possibilidade de efeitos aleatórios correlacionados dentro do grupo, admitindo-se tanto componentes compartilhados quanto componentes a nível individual.

O uso de modelos com variáveis latentes na descrição da associação entre tempos de falha e medidas repetidas de alguma característica também vem sendo pesquisado. Muitas pesquisas científicas geram dados longitudinais com medidas repetidas de uma variável resposta em um número de pontos no tempo e, dados de tempos de falha, em que o tempo para algum evento é registrado. Um exemplo é o de pesquisas sobre a AIDS em que a contagem de linfócitos CD4 ou outro elemento é feita intermitentemente juntamente com o tempo para conversão HIV/AIDS ou morte. Um segundo exemplo é o de tratamento de pacientes com esquizofrenia em que características de saúde mental são medidas regularmente enquanto o paciente está sob estudo, mas com alguns pacientes retirados (ou perdidos) do estudo após um período de tempo aleatório. Em ambos os exemplos, a interação entre os processos é de grande interesse científico. Essa é uma área de pesquisa atual com contribuições recentes dadas por Faucett \& Thomas (1996), Wulfsohn \& Tsiatis (1997), Hogan \& Laird (1997a,b), Finkelstein \& Shoenfeld (1999), Henderson et al. (2001) dentre outros.

No presente trabalho destacam-se como objetivos principais:

- a extensão dos modelos de fragilidade para situações em que ocorram dados de 
sobrevivência multivariados com censura intervalar e em que, variáveis latentes são incorporadas ao modelo para descreverem a associação entre os tempos de falha. O interesse por esses modelos, se deve à ocorrência freqüente de dados dessa natureza, ou seja, de estudos em que se sabe que os tempos de sobrevivência dos indivíduos ocorrem em intervalos de tempo. Contribuições importantes para a divulgação desses modelos, em um contexto univariado, foram dadas por Peto (1973), Turnbull (1976), Filkelstein (1986), Klein \& Moeschberger (1997) e Lindsey \& Ryan (1998), dentre outros;

- a elaboração de programas computacionais para a estimação dos parâmetros envolvidos uma vez que, esses modelos, embora sendo uma extensão dos modelos para dados de sobrevivência com censura intervalar na ausência de variáveis latentes, não foram amplamente utilizados na literatura até o momento. Isso provavelmente se deve às dificuldades encontradas no processo de estimação dos parâmetros e à necessidade de programas computacionais que viabilizem a sua utilização;

- a ilustração dos modelos propostos fazendo-se uso de conjunto de dados reais na área de melhoramento genético animal. 


\section{REVISÃO DE LITERATURA}

Estudos que envolvam dados de tempos de falha multivariados são de interesse nesse trabalho. Para fixar os conceitos básicos em análise de sobrevivência bem como apresentar a notação que será assumida, é, inicialmente, apresentada uma breve revisão para dados de sobrevivência univariados. Dados de sobrevivência multivariados bem como diversos modelos propostos para a sua análise são, então, apresentados em maiores detalhes considerando-se as situações que envolvam, ou não, censura intervalar.

\subsection{Análise de dados de sobrevivência univariados}

Considere $n$ indivíduos, indexados por $i=1, \ldots, n$, em que, para o i-ésimo indivíduo, observam-se: um único tempo de sobrevivência, $t_{i}$, um correspondente indicador de censura, $\delta_{i}$, em que $\delta_{i}=1$ se o tempo observado corresponde a uma falha ou $\delta_{i}=0$ se corresponde a uma censura e um vetor p-dimensional de covariáveis $\mathbf{x}_{i}=\left(x_{i 1}, x_{i 2}, \ldots, x_{i p}\right)^{\prime}$. Sejam, ainda, $\Im$ o conjunto de todos os indivíduos com $\delta_{i}=1$ e $R_{i}$ o conjunto dos indivíduos em risco anterior ao tempo $t_{i}$. Assumindo-se que os tempos têm distribuição contínua, definem-se a função de densidade de probabilidade e a função de sobrevivência, a qual fornece a probabilidade de um indivíduo sobreviver a um tempo $t$, por:

$$
f(t \mid \mathbf{x})=\lim _{\delta t \rightarrow 0} \frac{P(t<T<t+\delta t \mid \mathbf{x})}{\delta t}, \quad t \geq 0
$$

e

$$
S(t \mid \mathbf{x})=P(T>t \mid \mathbf{x})=\int_{t}^{\infty} f(u \mid \mathbf{x}) d u
$$


respectivamente. A função de risco acumulada é expressa por:

$$
A(t \mid \mathbf{x})=\int_{0}^{t} \alpha(u \mid \mathbf{x}) d u
$$

e, em termos das funções definidas anteriormente, têm-se as relações:

$$
\alpha(t \mid \mathbf{x})=\frac{f(t \mid \mathbf{x})}{S(t \mid \mathbf{x})}=-\frac{d}{d t} \log S(t \mid \mathbf{x})
$$

$\mathrm{e}$

$$
S(t \mid \mathbf{x})=\exp \{-A(t \mid \mathbf{x})\}=\exp \left\{-\int_{0}^{t} \alpha(u \mid \mathbf{x}) d u\right\}
$$

Na análise de dados de sobrevivência univariados, o modelo de riscos proporcionais de Cox (1972) é um dos mais populares. Assume-se, nesse modelo, que os tempos $t_{i}, i=1, \ldots, n$, são independentes e que o risco do indivíduo $i$ é dado por:

$$
\alpha\left(t \mid \mathbf{x}_{i}\right)=\alpha_{0}(t) \exp \left\{\boldsymbol{\beta}^{\prime} \mathbf{x}_{i}\right\}
$$

em que, $\alpha_{0}$ é conhecida como a função de risco base, ou seja, o risco de um indivíduo com covariáveis $\mathbf{x}=\mathbf{0}, \boldsymbol{\beta}$ é o vetor de dimensão $p$ de coeficientes de regressão desconhecidos e $\mathbf{x}_{i}$ é o vetor de dimensão $p$ de covariáveis observadas para o indivíduo $i$.

O modelo de Cox, definido em (1), é conhecido como sendo semiparamétrico por assumir que as covariáveis atuam multiplicativamente no risco pela relação $\exp \left\{\boldsymbol{\beta}^{\prime} \mathbf{x}_{i}\right\}$ e por considerar $\alpha_{o}(t)$ arbitrária, ou seja, por não ser assumida nenhuma distribuição de probabilidade para os tempos. A denominação desse modelo como sendo de riscos proporcionais se deve ao fato de a razão entre as funções de risco de dois indivíduos, 


$$
\frac{\alpha_{i}\left(t \mid \mathbf{x}_{i}\right)}{\alpha_{\ell}\left(t \mid \mathbf{x}_{\ell}\right)}=\exp \left\{\boldsymbol{\beta}^{\prime}\left(\mathbf{x}_{i}-\mathbf{x}_{\ell}\right)\right\}
$$

$(i, \ell=1, \ldots, n$ e $i \neq \ell)$, não depender de $t$.

Para a estimação do vetor de parâmetros desconhecidos $\boldsymbol{\beta}$, Cox (1975) propôs a função de verossimilhança parcial, $\mathrm{L}(\boldsymbol{\beta})$, a qual é dada por:

$$
L(\boldsymbol{\beta})=\prod_{j \in \Im}\left(\frac{\exp \left\{\boldsymbol{\beta}^{\prime} \mathbf{x}_{i}\right\}}{\sum_{j \in R_{i}} \exp \left\{\boldsymbol{\beta}^{\prime} \mathbf{x}_{i}\right\}}\right)=\prod_{i=1}^{n}\left(\frac{\exp \left\{\boldsymbol{\beta}^{\prime} \mathbf{x}_{i}\right\}}{\sum_{j \in R_{i}} \exp \left\{\boldsymbol{\beta}^{\prime} \mathbf{x}_{i}\right\}}\right)^{\delta_{i}} .
$$

Os indivíduos censurados entram na função de verossimilhança parcial $\mathrm{L}(\boldsymbol{\beta})$ através do conjunto de risco $R_{i}$ e contribuem, para esta função, somente enquanto permanecem em risco. Os parâmetros $\boldsymbol{\beta}$ são estimados maximizando-se o logaritmo da função $\mathrm{L}(\boldsymbol{\beta})$, isto é, resolvendo-se o sistema de equações escores

$$
0=\frac{\partial \ell(\boldsymbol{\beta})}{\partial \boldsymbol{\beta}}=\sum_{i=1}^{n} \delta_{i}\left[\mathbf{x}_{i}-\frac{\sum_{j \in R_{i}} \mathbf{x}_{i} \exp \left\{\boldsymbol{\beta}^{\prime} \mathbf{x}_{i}\right\}}{\sum_{j \in R_{i}} \exp \left\{\boldsymbol{\beta}^{\prime} \mathbf{x}_{i}\right\}}\right]
$$

em que $\ell(\boldsymbol{\beta})=\log \mathrm{L}(\boldsymbol{\beta})$.

Versões paramétricas do modelo de Cox são obtidas especificando-se uma função paramétrica para a função de risco base $\alpha_{0}(t)$, ou seja, assumindo-se uma distribuição de probabilidade para os tempos $t_{i}, i=1, \ldots, n$. Distribuições usuais nas versões paramétricas são, dentre outras, a Weibull, a exponencial e a log-normal.

\subsection{Análise de dados de sobrevivência multivariados}

Uma abordagem comumente usada para o problema de modelar dados multivariados é a de especificar independência entre os dados observados condicional- 
mente a um conjunto de variáveis não-observáveis ou "latentes". Modelos de fragilidade para dados de sobrevivência multivariados são usualmente obtidos sob essa abordagem de independência condicional. Esses modelos são caracterizados pela especificação de variáveis latentes as quais são incluídas no modelo de riscos proporcionais como fatores multiplicativos. As variáveis latentes representam informações que não podem ser observadas tais como fatores genéticos e ambientais e outras informações que por alguma razão não puderam ser consideradas no delineamento.

Várias distribuições de probabilidade para as variáveis latentes (frailties) têm sido propostas, incluindo a gama, a estável positiva (positive stable) e a log-normal. A mais comumente usada tem sido a gama por ser não negativa, extremamente flexível e algebricamente conveniente. Para, por exemplo, diferentes escolhas dos parâmetros de forma e escala, a distribuição gama varia desde uma exponencial até uma curva em forma de um sino, similar à Normal. Ainda, se a distribuição gama é assumida, é possível obter expressões explicitas para as funções marginais $f(t), S(t)$ etc. após integração em relação à variável latente.

O modelo semiparamétrico de fragilidade gama é formulado pela introdução de um efeito aleatório no modelo de Cox. Esse efeito aleatório (variável latente) é incorporado ao modelo como um fator multiplicativo na função de risco. O fato de a variável latente atuar de maneira multiplicativa na função de risco é, em princípio arbitrária, mas tem sido usada na maioria dos trabalhos com dados de sobrevivência multivariados. Desta forma, quanto maior for o valor da variável latente, maior será a chance de uma falha ocorrer, isto é, mais frágeis os indivíduos do grupo $j(j=1, \ldots, m)$ estarão para falhar e daí o nome de modelo de fragilidade. Formalmente, considere $\mathbf{T}_{j}=\left(T_{1 j}, T_{2 j}, \ldots, T_{n_{j} j}\right)^{\prime}$ os $n_{j}$ tempos de falha ou censura do j-ésimo grupo e seja $z_{j}$ uma variável latente não-observada associada a esse j-ésimo grupo. Será assumido que, condicionalmente a $z_{j}$, os componentes de $\mathbf{T}_{j}$ são independentes com as distribuições dos $T_{i j}$ modeladas por:

$$
\alpha_{i j}\left(t \mid \mathbf{x}_{i j}, z_{j}\right)=z_{j} \alpha_{0}(t) \exp \left\{\boldsymbol{\beta}^{\prime} \mathbf{x}_{i j}\right\}
$$


com $i=1, \ldots, n_{j} ; j=1, \ldots, m$ e em que $\alpha_{i j}$ é a função de risco para $T_{i j}$ condicionalmente a $z_{j}$ e um vetor $\mathbf{x}_{i j}$ de dimensão $p$ de covariáveis; $\alpha_{0}$ é uma função de risco base, desconhecida; $\boldsymbol{\beta}$ é um vetor de dimensão $p$ de coeficientes de regressão desconhecidos e $z_{j}$ é uma variável aleatória com distribuição gama de média 1 e variância qualquer.

Nesta formulação, a variável latente não varia com o tempo, o que representa uma das limitações desse modelo. Se for assumido para $j=1, \ldots, m$, que:

$$
z_{j} \sim \operatorname{gama}(\eta, v) \text { independentes com } \eta \geq 0, v \geq 0 \text { e } \eta=v=\xi^{-1}
$$

tem-se, $\mathrm{E}\left(z_{j}\right)=1$ e $\operatorname{Var}\left(z_{j}\right)=\xi$. Nos modelos semiparamétricos de fragilidade é necessário assumir que a família de distribuições da variável latente tenha média 1 para que haja identificabilidade. Se $\xi=0$, todas as variáveis latentes serão iguais a 1, ou seja, a distribuição gama fica degenerada no ponto 1, obtendo-se assim o modelo usual de riscos proporcionais de Cox (para dados independentes). Versões paramétricas do modelo (2) são obtidas pela especificação de uma função paramétrica para a função de risco base $\alpha_{0}(t)$. No modelo semiparamétrico de fragilidade gama $(2), \alpha_{0}(t)$ são funções arbitrárias e não-especificadas.

\subsubsection{Notação de processos de contagem}

A abordagem de processos de contagem tem sido usada para caracterizar o modelo (2). Neste contexto dois processos são necessários. O primeiro é o processo multivariado $\mathbf{N}(t)=\left\{N_{i j}(t), i=1, \ldots, n_{j}\right.$ e $\left.j=1, \ldots, m\right\}, t \geq 0$, contando o número observado de eventos até o tempo $t$ para o indivíduo $i$ do grupo j . Então,

$$
N_{i j}(t)= \begin{cases}1 & \text { para } \mathrm{t} \geq \mathrm{t}_{i j}, \delta_{i j}=1 \\ 0 & \text { caso contrário }\end{cases}
$$


em que $t_{i j}$ denota o tempo do indivíduo $i$ do grupo $j$ e $\delta_{i j}$ indica se este tempo é uma falha $\left(\delta_{i j}=1\right)$ ou uma censura $\left(\delta_{i j}=0\right)$. Assim, $N_{i j}(t)=0$ enquanto uma falha não ocorre mas $N_{i j}(t)$ salta para 1 quando esta ocorre. O segundo processo é contínuo à esquerda e identifica a intensidade correspondente a $\mathbf{N}(t)$ e é definido por:

$$
H_{i j}(t)= \begin{cases}1 & \text { para } \mathrm{t} \leq \mathrm{t}_{i j} \\ 0 & \text { caso contrário }\end{cases}
$$

ou seja, $H_{i j}(t)=1$ se o indivíduo $i$ do grupo $j$ está em risco até $t^{-}$(tempo imediatamente anterior a $t$ ) ou igual a 0 , em caso contrário. O processo $H_{i j}$ é previsível, o que significa que seu valor é conhecido no instante $t^{-}$.

O processo de intensidade é obtido multiplicando-se a função de risco pelo processo previsível sendo, portanto, expresso por:

$$
\lambda_{i j}\left(t \mid \mathbf{x}_{i j}, z_{j}\right)=H_{i j}(t) \alpha_{i j}(t) .
$$

Então, usando-se (2),

$$
\lambda_{i j}\left(t \mid \mathbf{x}_{i j}, z_{j}\right)=H_{i j}(t) z_{j} \alpha_{0}(t) \exp \left\{\boldsymbol{\beta}^{\prime} \mathbf{x}_{i j}\right\}
$$

\subsubsection{Algumas generalizações do modelo de fragilidade}

O modelo de fragilidade apresentado em (3), também referido, por alguns autores, como modelo de fragilidade compartilhado, foi generalizado em diversas direções importantes, conforme descrito em Liang et al. (1995):

i) versão estratificada: neste modelo funções de risco base diferentes, uma para cada um dos $k$ estratos de um mesmo agrupamento de indivíduos, são assumidas. O modelo de riscos condicional torna-se: 


$$
\lambda_{i j}\left(t \mid \mathbf{x}_{i j}, z_{j}\right)=H_{i j}(t) z_{j} \alpha_{0 h}(t) \exp \left\{\boldsymbol{\beta}^{\prime} \mathbf{x}_{i j}\right\}
$$

para $i=1, \ldots, n_{j}, j=1, \ldots, m$ e $h=1, \ldots, k$. Esse modelo pode ser aplicado, por exemplo, em estudos com famílias ou ninhadas no qual funções de risco base diferentes para machos e fêmeas $(k=2)$ de uma mesma família ou ninhada são desejadas;

ii) padrões de associações mais complexos: se a estrutura de dependência é suposta ser proveniente de fatores genéticos comuns, o modelo deveria estar apto para acomodar um padrão de associação no qual a associação entre primos é metade daquela entre irmãos completos. Tal modelo pode ser formulado por:

$$
\lambda_{i j}\left(t \mid \mathbf{x}_{i j}, \mathbf{z}_{j}\right)=H_{i j}(t) z_{i j} \alpha_{0}(t) \exp \left\{\boldsymbol{\beta}^{\prime} \mathbf{x}_{i j}\right\}
$$

para $i=1, \ldots, n_{j}$ e $j=1, \ldots, m$ e em que $\mathbf{z}_{j}=\left(z_{1 j}, \ldots, z_{n_{j} j}\right)^{\prime}$ é um vetor de variáveis latentes não-observadas associadas à j-ésima família;

iii) mais de um tipo de variável latente: essa generalização ocorre quando, por exemplo, a dependência entre os membros de uma família aparece não somente por fatores genéticos compartilhados, mas também por fatores ambientais compartilhados. Em tais situações, modelos com múltiplas variáveis latentes não-observadas e independentes podem ser representados por:

$$
\lambda_{i j}\left(t \mid \mathbf{x}_{i j}, \mathbf{z}_{E, j}, \mathbf{z}_{G, j}\right)=z_{E, i j} z_{G, i j} H_{i j}(t) \alpha_{0}(t) \exp \left\{\boldsymbol{\beta}^{\prime} \mathbf{x}_{i j}\right\}
$$

$\operatorname{com} \mathbf{z}_{E, j}$ e $\mathbf{z}_{G, j}$ vetores de variáveis latentes associadas à família $j$ representando fatores ambientais e genéticos não-observados, respectivamente. Alternativamente, 
modelos aditivos foram considerados por Petersen (1998) e

iv) versão tempo-dependente: o modelo de fragilidade (3) não descreve situações em que a variável latente não-observada é tempo-dependente. Versões tempodependente têm sido desenvolvidas e podem ser descritas por:

$$
\lambda_{i j}\left(t \mid \mathbf{x}_{i j}, z_{j}\right)=H_{i j}(t) z_{j}(t) \alpha_{0}(t) \exp \left\{\boldsymbol{\beta}^{\prime} \mathbf{x}_{i j}\right\}
$$

em que $z_{j}(t)$ é uma variável latente tempo-dependente.

\subsubsection{Modelos de fragilidade aditivos}

$\mathrm{Na}$ teoria usual de modelos de fragilidade, um único componente aleatório não-observado é introduzido na função intensidade. Isso é feito para modelar duas fontes de variação diferentes, mas relacionadas, dos tempos de falha. Uma fonte de variação é das covariáveis individuais não-observadas. A outra provém de covariáveis comuns não-observadas e que, quando não consideradas, geram dependência entre os eventos. Uma abordagem geral para tempos de falha multivariados deve, então, levar em consideração variações devidas a características não-observadas compartilhadas e não-compartilhadas.

De acordo com Petersen (1998), o modelo de fragilidade apresentado em (3), possui um único componente aleatório não-observável que representa as características comuns não-observadas. Além disso, é assumido neste modelo, que indivíduos compartilhando o mesmo efeito aleatório (e covariáveis) possuem exatamente o mesmo risco e isto nem sempre é verdadeiro. Como um modo de contornar esse problema, Petersen (1998) considerou modelos em que a associação entre os respectivos tempos de falha dos indivíduos de cada família é devida, em parte, a relações familiares (fatores genéticos compartilhados) e, em parte, ao ambiente que esses indivíduos compartilham (fatores ambientais). Tais modelos correspondem ao 
conhecido modelo de componentes de variância para dados normalmente distribuídos no sentido que, a associação entre os tempos de falha é induzida por assumir que os indivíduos compartilham alguns, mas não todos, os componentes da variância. Contudo, ao invés de descrever os tempos de sobrevivência (ou uma transformação destes) diretamente em um modelo de componentes de variância, componentes de fragilidade são combinados aditivamente e, então, atuam multiplicativamente nas taxas de risco dos indivíduos. Este modelo foi denominado "modelo de fragilidade aditivo".

Considerando, $\mathbf{N}=\left\{N_{i j} ; i=1, \ldots, n_{j}, j=1, \ldots, m\right\}$ um processo de contagem multivariado, o modelo de fragilidade aditivo tem por finalidade especificar um processo de intensidade $\boldsymbol{\lambda}=\left(\lambda_{i j} ; i=1, \ldots, n_{j}, j=1, \ldots, m\right)$ para os tempos de falha em que,

$$
\lambda_{i j}\left(t \mid \mathbf{x}_{i j}, \mathbf{z}\right)=\left(\mathbf{A}_{i j}\right)^{\prime} \mathbf{z} H_{i j}(t) \alpha_{i j h}(t)
$$

com $H_{i j}(t)$ um processo não-negativo e previsível; z um vetor $k$-dimensional de efeitos individuais desconhecidos; $\mathbf{A}_{i j}=\left[\begin{array}{lll}\mathrm{a}_{i 1} & \ldots & \mathrm{a}_{i k}\end{array}\right]^{\prime}$ um vetor de delineamento conhecido e $\alpha_{i j h}$ a função de risco (usualmente a de Cox) considerada para o i-ésimo indivíduo da j-ésima família no h-ésimo estrato.

Os componentes aleatórios $z_{1}, \ldots, z_{k}$ são assumidos serem independentes e com distribuição gama de parâmetros $\left(v_{h}, \eta\right), h=1, \ldots, k$. Para que a função de risco seja identificável é assumido que os $z_{h}(h=1, \ldots, k)$ têm média $1 \mathrm{e}$ variância qualquer $\xi_{h}$.

Análogo ao que é feito com componentes de variância para variáveis distribuídas normalmente, o modelo (4) é interpretado como o processo de intensidade condicional dos tempos de falha dadas as variáveis latentes $z_{h}$. Assim, os tempos de falha dos indivíduos são correlacionados através das variáveis latentes mas, dadas as variáveis latentes, os tempos de falha são independentes. Algumas aplicações desse modelo, apresentadas por Petersen (1998), bem como sua conexão 
com outros modelos de fragilidade, são mostradas a seguir:

1. modelo de fragilidade compartilhado: esse modelo é representado por:

$$
\lambda_{i j}(t)=z_{0 j} H_{i j}(t) \alpha_{i j h}(t)
$$

para $i=1, \ldots, n_{j}, j=1, \ldots, m$ e $h=1, \ldots, k$. Com $k=4$, correspondendo a, por exemplo, pai, mãe, filho e filha, essa abordagem permite acessar a variabilidade interfamiliar. Na notação de Petersen, o modelo é definido usando-se $\left(\mathbf{A}_{i j}\right)^{\prime}=\left[\begin{array}{ll}1 & 1\end{array} \ldots 1\right]$, de dimensão $1 \times n_{j}$, para cada família. O vetor $\mathbf{z}$, de dimensão $\mathrm{n}_{j} \times 1$, é dado, por exemplo, para $j=1$, por $\mathbf{z}=\left[\begin{array}{lll}z_{01} & 0 \ldots 0\end{array}\right]^{\prime}$;

2. modelo de super-dispersão: esse modelo é definido por,

$$
\lambda_{i j}(t)=z_{i j} H_{i j}(t) \alpha_{i j}(t),
$$

$i=1, \ldots, n_{j}$ e $j=1, \ldots, m$. Nesse caso, cada indivíduo tem sua própria variável latente associada atuando multiplicativamente na função de risco. As variáveis latentes e os tempos de falha associados a diferentes indivíduos são independentes. A noção de família nesse modelo não tem significado porque são todas de tamanho 1 . Os índices $i j$ são mantidos somente para concordar com a notação apresentada. Nesse modelo, $\left(\mathbf{A}_{i j}\right)^{\prime}$ bem como $\mathbf{z}$ contêm um único elemento, isto é, $\left(\mathbf{A}_{i j}\right)^{\prime}=[1]$ e $\mathbf{z}=\left[z_{i j}\right]$;

3. modelo para gêmeos: esse modelo aplica-se a estudos clássicos, envolvendo gêmeos idênticos e não-idênticos. O modelo é dado por:

$$
\begin{aligned}
& \lambda_{1 j}(t)=\left(z_{0 j}+z_{1 j}\right) H_{1 j}(t) \alpha_{1 j h}(t) \\
& \lambda_{2 j}(t)=\left(z_{0 j}+z_{2 j}\right) H_{2 j}(t) \alpha_{2 j h}(t),
\end{aligned}
$$


$j=1, \ldots, m$. As variáveis latentes representam genes e ambientes compartilhados $\left(z_{o j}\right)$ e, genes e ambientes não compartilhados $\left(z_{1 j}, z_{2 j}\right)$. Esse modelo permite funções de risco diferentes para gêmeos do sexo feminino e masculino. Para esse modelo, $\left(\mathbf{A}_{1 j}\right)^{\prime}=\left[\begin{array}{lll}1 & 1 & 0\end{array}\right],\left(\mathbf{A}_{2 j}\right)^{\prime}=\left[\begin{array}{lll}1 & 0 & 1\end{array}\right]$ e $\mathbf{z}=\left[\begin{array}{lll}z_{0 j} & z_{1 j} & z_{2 j}\end{array}\right]^{\prime}$ para cada par de gêmeos;

4. modelo para ninhadas: esse modelo definido por:

$$
\begin{array}{rcc}
\lambda_{1 j}(t)= & \left(z_{0 j}+z_{1 j}\right) H_{1 j}(t) \alpha_{1 j}(t) \\
& \ldots & \cdots \\
\lambda_{i j}(t)= & \left(z_{0 j}+z_{i j}\right) H_{i j}(t) \alpha_{i j}(t) \\
& \cdots & \cdots \\
\lambda_{n_{j} j}(t) & = & \left(z_{0 j}+z_{n_{j} j}\right) H_{n_{j} j}(t) \alpha_{n_{j} j}(t),
\end{array}
$$

$i=1, \ldots, n_{j}$ e $j=1, \ldots, m$, representa uma extensão do modelo de fragilidade compartilhado permitindo heterogeneidade entre indivíduos dentro de uma mesma ninhada. Para cada ninhada, têm-se $\left(\mathbf{A}_{1 j}\right)^{\prime}=\left[\begin{array}{lllll}1 & 1 & 0 & \ldots\end{array}\right], \ldots$, $\left(\mathbf{A}_{n_{j} j}\right)^{\prime}=\left[\begin{array}{llll}1 & 0 & 0 & \ldots\end{array}\right]$, todos de dimensão $1 \times\left(n_{j}+1\right)$. O vetor $\mathbf{z}$, de dimensão $\left(n_{j}+1\right) \times 1$, é dado por $\mathbf{z}=\left[\begin{array}{lll}z_{0 j} & z_{1 j} \ldots & z_{n_{j} j}\end{array}\right]^{\prime}$.

\subsubsection{Algoritmos de estimação}

Procedimentos de estimação têm sido baseados na construção de uma função de verossimilhança e sua otimização. Em particular, o algoritmo EM (Dempster et al., 1977) pode ser aplicado, sendo os valores latentes não observados considerados como dados perdidos (missing). Os dados completos, mas parcialmente observados, consistem dos componentes $\mathbf{z}, \mathbf{N}$ e $\mathbf{H}$, isto é, do vetor de variáveis de fragilidade $\mathbf{z}$, composto de variáveis não observáveis; do processo de contagem multivariado $\mathbf{N}$, que conta o número observado de eventos para cada indivíduo e, do 
processo de risco $\mathbf{H}$, que denota se o indivíduo está, ou não, em risco no tempo $t$. Os dados incompletos e observados consistem somente dos dois últimos componentes. Então, o algoritmo EM trabalha com a função de verossimilhança como se os dados z fossem observados. Em cada iteração o algoritmo consiste em um passo de esperança (passo E) seguido por um passo de maximização (passo M) e daí o nome "algoritmo EM". Nielsen et al. (1992) e Klein (1992), independentemente, desenvolveram estimadores de máxima verossimilhança generalizados para o modelo semiparamétrico de fragilidade gama com a suposição de distribuição gama, facilitando grandemente a execução do passo E. No passo M, com as variáveis latentes fixas e conhecidas, o modelo torna-se essencialmente o modelo de Cox. Nielsen et al. (1992) e Klein (1992) usam, então, a caracterização de Johansen (1983) do estimador de verossimilhança parcial de $\boldsymbol{\beta}$ e o estimador de Nelson-Aalen modificado para $\alpha_{0}$ como um estimador de máxima verossimilhança generalizado para o parâmetro do modelo. O algoritmo EM é, então, usado para maximizar a função de verossimilhança sobre $\boldsymbol{\beta}$ e $\alpha_{0}$ com a variância da variável latente, $\xi$, fixa. O perfil de verossimilhança em $\xi$ é, então, otimizado para a obtenção conjunta dos estimadores de máxima verossimilhança de $\left(\boldsymbol{\beta}, \alpha_{0}, \xi\right)$.

A suposição de distribuição gama é usada por Nielsen et al. (1992) e Klein (1992) somente no passo E do algoritmo EM. Então, fornecido um mecanismo para a realização do passo E, estimadores de máxima verossimilhança dos parâmetros em modelos semiparamétricos de fragilidade mais gerais podem ser obtidos.

Serão descritos, a seguir, os algoritmos de Nielsen et al. (1992) e Klein (1992).

\section{a) Algoritmo de Nielsen et al. (1992)}

Para a utilização do algoritmo de Nielsen et al. (1992), as seguintes suposições são necessárias:

i) condicionalmente a $z$, falha e censura são independentes e, 
ii) condicionalmente a $z$, a censura é não-informativa.

Para iniciar o processo, é considerada a seguinte função de verossimilhança parcial condicional, baseada em $\mathbf{N}$ :

$$
L(\boldsymbol{\beta}, \xi \mid \mathbf{z})=\prod_{j=1}^{m} \prod_{i=1}^{n_{j}} \exp \left\{-\int_{0}^{\tau} \lambda_{i j}\left(u \mid z_{j}, \mathbf{x}_{i j}\right) d u\right\} \prod_{t \in[0, \tau)}\left(\lambda_{i j}\left(t \mid z_{j}, \mathbf{x}_{i j}\right)\right)^{d N_{i j}(t)}
$$

em que $\lambda_{i j}($.$) é dada por (3) ; d N_{i j}(t)$ é o incremento para $\mathbf{N}$ no tempo $t$, isto é, $d N_{i j}(t)=1$ se ocorreu um salto (ou seja, uma falha) em $t$ e $d N_{i j}(t)=0$, em caso contrário, e $\tau$ é o tempo estabelecido para o término do experimento. Então, a função de verossimilhança completa baseada em $\mathbf{z}, \mathbf{N}$ e $\mathbf{H}$ será:

$$
L(\boldsymbol{\beta}, \xi, \mathbf{z})=L(\boldsymbol{\beta}, \xi \mid \mathbf{z}) \prod_{j=1}^{m} f\left(z_{j}, \xi\right)
$$

Sendo $z_{j} \sim$ gama e usando-se (5), segue que:

$$
\begin{aligned}
L(\boldsymbol{\beta}, \xi, \mathbf{z})= & L(\boldsymbol{\beta}, \xi \mid \mathbf{z}) \prod_{j=1}^{m}\left(\frac{z_{j}^{\frac{1}{\xi}-1}\left(\frac{1}{\xi}\right)^{\frac{1}{\xi}} \exp \left\{-z_{j} \frac{1}{\xi}\right\}}{\Gamma\left(\frac{1}{\xi}\right)}\right) \\
= & \prod_{j=1}^{m}\left[z_{j}^{\frac{1}{\xi}-1}\left(\frac{1}{\xi}\right)^{\frac{1}{\xi}} \exp \left\{-z_{j} \frac{1}{\xi}\right\} \frac{1}{\Gamma\left(\frac{1}{\xi}\right)}\right. \\
& \prod_{i=1}^{n_{j}} \exp \left\{-\int_{0}^{\tau} z_{j} H_{i j}(u) \alpha_{0}(u) \exp \left\{\boldsymbol{\beta}^{\prime} \mathbf{x}_{i j}\right\} d u\right\} \\
& \left.\prod_{t \in[0, \tau)}\left(z_{j} H_{i j}(t) \alpha_{0}(t) \exp \left(\boldsymbol{\beta}^{\prime} \mathbf{x}_{i j}\right)\right)^{d N_{i j}(t)}\right]
\end{aligned}
$$

Esta função, se olhada como função de $\mathbf{z}$, resultará em:

$$
L(\boldsymbol{\beta}, \xi, \mathbf{z}) \propto \prod_{j=1}^{m} z_{j}^{\frac{1}{\xi}+N_{j}-1} \exp \left\{-z_{j}\left[\frac{1}{\xi}+\sum_{i=1}^{n_{j}} \int_{0}^{\tau} H_{i j}(u) \alpha_{0}(u) \exp \left\{\boldsymbol{\beta}^{\prime} \mathbf{x}_{i j}\right\} d u\right]\right\}
$$


em que $\mathbf{N}_{j}=\sum_{i=1}^{n_{j}} N_{i j}$ é o número de falhas no grupo $j$. Em outras palavras, olhando como função de $\mathbf{z},(6)$ corresponde à função de verossimilhança de uma distribuição gama com parâmetros $\left(\frac{1}{\xi}+N_{j}, \frac{1}{\xi}+\Lambda_{j}(\boldsymbol{\beta})\right)$ sendo que, para $j=1, \ldots, m$,

$$
\Lambda_{j}(\boldsymbol{\beta})=\int_{0}^{\tau} S_{j}^{(0)}(\boldsymbol{\beta}, u) \alpha_{0}(u) d u
$$

$\mathrm{e}$

$$
S_{j}^{(0)}(\boldsymbol{\beta}, t)=\sum_{i=1}^{n_{j}} H_{i j}(t) \exp \left\{\boldsymbol{\beta}^{\prime} \mathbf{x}_{i j}\right\}
$$

Assim, integrando-se (6) em relação a z, obtém-se a função de verossimilhança parcial marginal baseada nas observações $\mathbf{N}$ e $\mathbf{H}$. Como resultado desta integração, tem-se:

$$
\begin{aligned}
L(\boldsymbol{\beta}, \xi) & =\int_{0}^{\infty} L(\boldsymbol{\beta}, \xi, \mathbf{z}) d \mathbf{z}=\int_{0}^{\infty} L(\boldsymbol{\beta}, \xi \mid \mathbf{z}) \prod_{j=1}^{m} f\left(z_{j}, \xi\right) d z_{j} \\
& =\prod_{j=1}^{m} \frac{\left(\frac{1}{\xi}\right)^{\frac{1}{\xi}}}{\Gamma\left(\frac{1}{\xi}\right)} \frac{\Gamma\left(\frac{1}{\xi}+N_{j}\right)}{\left[\frac{1}{\xi}+\Lambda_{j}(\boldsymbol{\beta})\right]^{N_{j}+\frac{1}{\xi}}} \prod_{j=1}^{m} \prod_{i=1}^{n_{j}} \prod_{t \in[0, \tau)}\left[H_{i j}(t) \alpha_{0}(t) \exp \left\{\boldsymbol{\beta}^{\prime} \mathbf{x}_{i j}\right\}\right]^{d N_{i j}(t)}(8)
\end{aligned}
$$

Fixado o valor de $\xi$, calculam-se, no passo E, as estimativas de $z_{j}$ para serem usadas no passo M do algoritmo, já que as variáveis latentes foram eliminadas por integração. Desse modo, o processo iterativo resume-se aos seguintes passos:

Passo E: Calcular

$$
\hat{z}_{j}=\frac{\frac{1}{\xi}+N_{j}}{\frac{1}{\xi}+\Lambda_{j}(\boldsymbol{\beta})}
$$

o que corresponde à esperança matemática de uma variável aleatória com distribuição gama de parâmetros $\left(\frac{1}{\xi}+N_{j}, \frac{1}{\xi}+\Lambda_{j}(\boldsymbol{\beta})\right)$.

Passo M: Maximizar (8), obtida após o passo E, substituindo-se também o 
parâmetro nuisance $\alpha_{0}(t)=d \Lambda_{0}(t)$ pelo estimador de Nelson-Aalen modificado, assumindo-se que $z_{j}$ seja igual a $\hat{z}_{j}$,

$$
\hat{\Lambda}_{0}(t)=\int_{0}^{\infty} \frac{\mathrm{J}(\mathrm{s})}{\sum_{\mathrm{j}} \hat{\mathrm{z}}_{\mathrm{j}} \mathrm{S}_{\mathrm{j}}^{(0)}(\boldsymbol{\beta}, \mathrm{s})} d N . .(s),
$$

sendo que $d N . .(s)=\sum_{i, j} d N_{i j}(s)$ e $J(s)=I(H . .(s)>0)$. Ver Johansen (1983) para maiores detalhes sobre o estimador de Nelson-Aalen.

Como valor inicial para o processo, considera-se $z_{j}=1(j=1, \ldots, m)$, o que corresponde a ajustar um modelo de regressão de Cox para dados independentes. Com isso, têm-se os valores iniciais do vetor $\boldsymbol{\beta}$ dados pelas estimativas obtidas pelo modelo usual de Cox. O parâmetro $\xi$ pode assumir qualquer valor maior do que zero. O algoritmo converge quando, na k-ésima iteração $(k=1, \ldots)$ :

i) $\Delta \log L(\boldsymbol{\beta}, \xi)=\log L\left(\boldsymbol{\beta}^{(k)}, \xi\right)-\log L\left(\boldsymbol{\beta}^{(k-1)}, \xi\right)<\varepsilon_{1} \quad$ e,

ii) $\sum_{j} \Delta z_{j}=\sum_{j}\left|z_{j}^{(k)}-z_{j}^{(k-1)}\right|<\varepsilon_{2}$

sendo que, $\varepsilon_{1}$ e $\varepsilon_{2}$ são constantes iguais a, por exemplo, $10^{-8}$.

Para obter as estimativas finais dos parâmetros, é necessário empregar o algoritmo EM para vários valores de $\xi$ e fazer o gráfico da função de verossimilhança (8) como uma função de $\xi$. A partir daí, escolhe-se numericamente ou graficamente o EMV (estimador de máxima verossimilhança) $\hat{\xi}$ e calcula-se o correspondente $\hat{\boldsymbol{\beta}}$. Este procedimento é conhecido como "método do perfil de verossimilhança", ou "da verossimilhança perfilada".

\section{b) Algoritmo de Klein (1992)}

Nesse método, o algoritmo EM é aplicado diretamente, usando-se a função de verossimilhança conjunta (6), que como já foi visto, tem a forma de uma distribuição gama. O processo consiste, então, em usar o logaritmo da função de 
verossimilhança (6), isto é,

$$
\begin{aligned}
\log L(\boldsymbol{\beta}, \xi, \mathbf{z})= & \sum_{j=1}^{m}\left[\left(\frac{1}{\xi}-1\right) \log z_{j}-\frac{1}{\xi} \log \xi-\frac{z_{j}}{\xi}-\log \Gamma\left(\frac{1}{\xi}\right)\right. \\
& +\sum_{i=1}^{n_{j}}\left[-\int_{0}^{\tau} z_{j} H_{i j}(u) \alpha_{0}(u) \exp \left\{\boldsymbol{\beta}^{\prime} \mathbf{x}_{i j}\right\} d u\right. \\
& \left.\left.+\sum_{t \in[0, \tau)]} d N_{i j}(t)\left(\log z_{j}+\log \left[H_{i j}(t) \alpha_{0}(t)\right]+\boldsymbol{\beta}^{\prime} \mathbf{x}_{i j}\right)\right]\right]
\end{aligned}
$$

expressão que pode ser separada em duas partes: uma que só depende de $\xi$ e outra que depende de $\boldsymbol{\beta}$ e do parâmetro nuisance $\alpha_{0}$. Dessa forma tem-se $\log L(\boldsymbol{\beta}, \xi, \mathbf{z})=$ $L_{1}(\xi)+L_{2}\left(\boldsymbol{\beta}, \alpha_{0}\right)$ em que:

$$
L_{1}(\xi)=-m\left[\frac{1}{\xi} \log \xi+\log \Gamma\left(\frac{1}{\xi}\right)\right]+\sum_{j=1}^{m}\left[\left(\frac{1}{\xi}-1+N_{j}\right) \log z_{j}-\frac{z_{j}}{\xi}\right]
$$

$\mathrm{e}$

$$
L_{2}\left(\boldsymbol{\beta}, \alpha_{0}\right)=\sum_{j=1}^{m}\left(-z_{j} \Lambda_{j}(\boldsymbol{\beta})+\sum_{i=1}^{n_{j}} \sum_{t \in[0, \tau)} d N_{i j}(t)\left[\boldsymbol{\beta}^{\prime} \mathbf{x}_{i j}+\log \alpha_{0}(t)\right]\right)
$$

Os passos E e M do processo iterativo sugerido por Klein (1992) consistem, então, em:

Passo E: Obter a esperança dessa função de verossimilhança em relação aos dados observados. Substituindo-se então, $\mathrm{E}\left(z_{j}\right)=A_{j} / C_{j}$ e $\mathrm{E}\left(\log z_{j}\right)=\psi\left(A_{j}\right)-\log \left(C_{j}\right) \operatorname{com}$ $A_{j}=\frac{1}{\xi}+N_{j}$ e $C_{j}=\frac{1}{\xi}+\Lambda_{j}(\boldsymbol{\beta})$ os parâmetros da distribuição gama obtidos da função de verossimilhança (6) e $\psi($.$) a função digama, têm-se, após o Passo E, as seguintes$ expressões:

$$
\begin{aligned}
E\left(L_{1}(\xi)\right)= & \sum_{j=1}^{m}\left[\left(\frac{1}{\xi}-1+N_{j}\right)\left[\psi\left(A_{j}-\log \left(C_{j}\right)\right]-\frac{A_{j}}{\xi C_{j}}\right]\right. \\
& -m\left[\frac{1}{\xi} \log \xi+\log \Gamma\left(\frac{1}{\xi}\right)\right]
\end{aligned}
$$


e

$$
E\left(L_{2}\left(\boldsymbol{\beta}, \alpha_{0}\right)\right)=\sum_{j=1}^{m}\left(-\frac{A_{j}}{C_{j}} \Lambda_{j}(\boldsymbol{\beta}) \sum_{i=1}^{n_{j}} \sum_{t \in[0, \tau)} d N_{i j}(t)\left[\boldsymbol{\beta}^{\prime} \mathbf{x}_{i j}+\log \alpha_{0}(t)\right]\right)
$$

Passo M: Consiste em maximizar as expressões (9) e (10) em relação aos parâmetros $\boldsymbol{\beta}$ e $\xi$. Nesse passo, o parâmetro nuisance $\alpha_{0}$ é obtido pelo estimador de Nelson-Aalen modificado da mesma forma que no método de Nielsen et al. (1992).

Em síntese, o processo iterativo descrito por Klein (1992) segue os seguintes passos:

Passo 1: Obter as estimativas iniciais de $\boldsymbol{\beta}$ pelo ajuste de uma regressão de Cox padrão e a de $\alpha_{0}$ pelo estimador de Nelson-Aalen modificado, considerando-se $\hat{z}_{j}=1$; Passo 2: (Passo E) Calcular $A_{j}, C_{j}$ e $\hat{z}_{j},(j=1, \ldots, m)$ baseado nos valores atuais dos parâmetros;

Passo 3: (Passo M) Atualizar as estimativas de $\boldsymbol{\beta}$ e $\alpha_{0}$ bem como a de $\xi$, usando-se as expressões (10) e (9), respectivamente;

Passo 4: Repetir os passos 2 e 3 até a convergência ser obtida.

O programa desenvolvido por Nielsen et al. (1992), que implementa o algoritmo descrito, encontra-se disponível no endereço ftp://ftp.ime.usp.br/ pub/acarlos/frailty. Este programa é composto de rotinas em linguagem $\mathrm{C}$ e Fortran e pode ser executado no sistema UNIX. Quanto ao algoritmo de Klein (1992), este encontra-se implementado em uma macro do SAS e disponível no endereço www.bioestat.mcw.edu/SoftMenu.html. Para obtenção das estimativas dos parâmetros do modelo de Cox para dados independentes, pode-se usar, por exemplo, o Proc Phreg do SAS.

Estimativas das variâncias para $\hat{\boldsymbol{\beta}}$ e $\hat{\xi}$ podem ser obtidas por meio da inversa da matriz de informação observada, isto é, por:

$$
[I(\boldsymbol{\eta})]^{-1}=\left[\frac{\partial^{2}}{\partial \boldsymbol{\eta}^{2}} \log L(\boldsymbol{\eta})\right]^{-1}
$$


com $\boldsymbol{\eta}=\left(\alpha_{0}, \boldsymbol{\beta}, \xi\right)$ e L $(\boldsymbol{\eta})$ a função de verossimilhança correspondente ao modelo (3). As expressões dos elementos da matriz $I(\boldsymbol{\eta})$ podem ser encontradas em Andersen et al. (1997).

\subsubsection{Testes de hipóteses}

Para testar a existência de dependência entre as observações, ou seja, testar a hipótese nula $H_{0}: \xi=0$, três estatísticas de teste são comumente usadas: a de Wald, a da razão de verossimilhanças e a estatística escore. Assintoticamente, as três estatísticas têm distribuição $\chi_{1}^{2}$. Como, no entanto, o valor do parâmetro encontra-se na borda do espaço paramétrico, problemas podem ocorrer ao se testar a hipótese nula mencionada. Nielsen et al. (1992) ao discutirem esses problemas, apresentaram os resultados de um estudo de simulação usado para verificar a distribuição amostral de $\hat{\xi}$ bem como a validade do teste da razão de verossimilhanças. Concluíram que, para dados de tempos não-censurados e amostras pequenas, a distribuição da estatistística de teste não concorda muito bem com a distribuição $\chi_{1}^{2}$. Concluíram, ainda, que para dados de tempos censurados e considerando-se testes bilaterais, a distribuição amostral de $\hat{\xi}$ é mais próxima da Normal e, conseqüentemente, a distribuição da estatística de teste mais próxima da $\chi_{1}^{2}$. A aproximação $\chi_{1}^{2}$ foi considerada mais pobre quando testes unilaterais foram considerados.

As três estatísticas mencionadas são apresentadas a seguir.

a) Estatística de Wald:

$$
W_{\xi}=\left(\hat{\xi}-\xi_{0}\right)^{\prime} I(\hat{\xi})\left(\hat{\xi}-\xi_{0}\right)
$$

em que $I(\hat{\xi})$ é a matriz de informação observada. Sob $H_{0}$ e para $\hat{\xi}$ de dimensão 1 , tem-se:

$$
W_{\xi}=\frac{\hat{\xi}^{2}}{\hat{V} \operatorname{ar}(\hat{\xi})} .
$$


b) Estatística da Razão de Verossimilhanças:

$$
R V_{\xi}=2 \log \frac{L\left(\hat{\alpha}_{0}, \hat{\boldsymbol{\beta}}, \hat{\xi}\right)}{L\left(\hat{\alpha}_{0}^{*}, \hat{\boldsymbol{\beta}}^{*}\right)}=2\left(\log L\left(\hat{\alpha}_{0}, \hat{\boldsymbol{\beta}}, \hat{\xi}\right)-\log L\left(\hat{\alpha}_{0}^{*}, \hat{\boldsymbol{\beta}}^{*}\right)\right)
$$

em que $\mathrm{L}\left(\hat{\alpha}_{0}, \hat{\boldsymbol{\beta}}, \hat{\xi}\right)$ é dada por (6) sendo $\hat{\alpha}_{0}, \hat{\boldsymbol{\beta}}$ e $\hat{\xi}$ as estimativas obtidas usando-se o modelo de fragilidade (3) e, $\mathrm{L}\left(\hat{\alpha}_{0}^{*}, \hat{\boldsymbol{\beta}}^{*}\right)$ considerando-se o modelo (3) com todos os $z_{j}, j=1, \ldots, m$, iguais a 1 .

c) Estatística Escore:

A estatística escore foi obtida por Commenges \& Andersen (1995) e é válida para qualquer distribuição da variável latente e não apenas para a distribuição gama. De acordo com os autores, a estatística escore é dada por:

$$
S_{\theta}=\frac{T^{2}}{V}
$$

sendo:

$$
T=\sum_{j=1}^{m}\left(\sum_{i=1}^{n_{j}} M_{i j}\right)^{2}-D+C
$$

com, $\mathrm{D}=\sum_{l=1}^{m} m_{l}$ o número total de falhas; $m_{l}$ o número de falhas no tempo ordenado $t_{l}(l=1, \ldots, r) ; M_{i j}=\delta_{i j}-\hat{\Lambda}_{0}\left(t_{i j}\right) ; \hat{\Lambda}_{0}(t)$ e $\hat{\boldsymbol{\beta}}$ obtidos do ajuste do modelo de Cox para dados independentes e,

$$
\begin{gathered}
C=\sum_{j=1}^{m} \sum_{i=1}^{n_{j}} \frac{\delta_{i j}}{S^{0}\left(t_{i j}\right)^{2}} \sum_{j=1}^{m}\left(\sum_{i=1}^{n_{j}} H_{i j}\left(t_{i j}\right) \exp \left\{\hat{\boldsymbol{\beta}}^{\prime} \mathbf{x}_{i j}\right\}\right)^{2}, \\
\operatorname{com} S^{0}(t)=\sum_{j=1}^{m} S_{j}^{0}(\hat{\boldsymbol{\beta}}, t)=\sum_{j=1}^{m} \sum_{i=1}^{n_{j}} H_{i j}(t) \exp \left\{\hat{\boldsymbol{\beta}}^{\prime} \mathbf{x}_{i j}\right\} .
\end{gathered}
$$

Para estimar V, a variância de T, tem-se: 


$$
V=V(T)=\sum_{j=1}^{m} \sum_{l=1}^{r} Q_{j}\left(t_{l}\right)^{2} \bar{p}_{j}\left(t_{l}\right) m_{l}+\sum_{h=1}^{p} \sum_{k=1}^{p} \gamma_{h} \gamma_{k} \hat{\sigma}_{h k}
$$

em que $t_{l},(l=1, \ldots, r)$, são os $m$ tempos de falha distintos e ordenados; $\hat{\sigma}_{h k}$ $(h, k=1, \ldots, p)$ são os elementos da matriz de variância-covariância de $\hat{\boldsymbol{\beta}}$ e,

$$
\bar{p}_{j}(t)=\sum_{i=1}^{n_{j}} p_{i j}(t)=\sum_{i=1}^{n_{j}} \frac{H_{i j}(t) \exp \left\{\hat{\boldsymbol{\beta}}^{\prime} \mathbf{x}_{i j}\right\}}{S^{0}(t)}
$$

e

$$
Q_{j}\left(t_{l}\right)=2\left(\bar{M}_{i j}\left(t_{l-1}\right)-\sum_{g=1}^{m} \bar{M}_{g}\left(t_{l-1}\right) \bar{p}_{i}\left(t_{l}\right)+\sum_{g=1}^{m} \bar{p}_{g}\left(t_{l}\right)^{2}\right)
$$

Ainda, $\bar{M}\left(t_{l}\right)=\sum_{i=1}^{n_{j}} M_{i j}\left(t_{l}\right) \operatorname{com} M_{i j}\left(t_{l}\right)=\delta_{i j}-\hat{\Lambda}_{0}\left(t_{i j}\right) \exp \left\{\hat{\boldsymbol{\beta}}^{\prime} \mathbf{x}_{i j}\right\}$ se $T_{i j} \leq t_{l}$ ou $M_{i j}\left(t_{l}\right)=-\hat{\Lambda}_{0}\left(t_{i j}\right) \exp \left\{\hat{\boldsymbol{\beta}}^{\prime} \mathbf{x}_{i j}\right\}$ se $T_{i j}>t_{l}$. Para $j=1, \ldots, m, \bar{M}_{j}\left(t_{0}\right)=0 \mathrm{e}$,

$$
\gamma_{h}=\sum_{j=1}^{m} \sum_{l=1}^{r} Q_{j}\left(t_{l}\right) m_{l}\left(\sum_{i=1}^{n_{j}} p_{i j}\left(t_{l}\right) \mathbf{x}_{i j h}\right), \quad h=1, \ldots, p
$$

Se $H_{0}: \xi=0$ é rejeitada, há interesse em testar hipóteses do tipo $H_{0}: \boldsymbol{\beta}=\boldsymbol{\beta}_{0}$. As estatísticas de Wald ou da razão de verossimilhanças podem ser usadas e são dadas por:

$$
W_{\boldsymbol{\beta}}=\left(\hat{\boldsymbol{\beta}}-\boldsymbol{\beta}_{0}\right)^{\prime} I(\hat{\boldsymbol{\beta}})\left(\hat{\boldsymbol{\beta}}-\boldsymbol{\beta}_{0}\right)
$$

e

$$
R V_{\boldsymbol{\beta}}=2 \log \frac{L(\hat{\alpha}, \hat{\boldsymbol{\beta}}, \hat{\theta})}{L\left(\hat{\alpha}, \boldsymbol{\beta}_{0}, \hat{\theta}\right)},
$$

respectivamente. Assintoticamente, $W_{\boldsymbol{\beta}}$ e $R V_{\boldsymbol{\beta}}$ têm distribuição $\chi_{p}^{2}$. 


\subsection{Interpretação dos parâmetros}

Para dados independentes, isto é, para $\xi=0$, tem-se que a razão entre as funções de risco de dois indivíduos com vetores de covariáveis $\mathbf{x}_{1}$ e $\mathbf{x}_{2}$ não depende de $t$, ou seja, o risco do indivíduo com vetor de covariáveis $\mathbf{x}_{1}$ falhar, relativo ao risco do indivíduo com vetor de covariáveis $\mathbf{x}_{2}$ é dado por:

$$
R(t)=\frac{\alpha_{0}(t) \exp \left\{\boldsymbol{\beta}^{\prime} \mathbf{x}_{1}\right\}}{\alpha_{0}(t) \exp \left\{\boldsymbol{\beta}^{\prime} \mathbf{x}_{2}\right\}}=\exp \left\{\boldsymbol{\beta}^{\prime}\left(\mathbf{x}_{1}-\mathbf{x}_{2}\right)\right\}
$$

Devido à suposição de proporcionalidade dos riscos, esta razão depende somente das estimativas de $\boldsymbol{\beta}$. Para $\xi \neq 0$, ou seja, para dados correlacionados, o vetor $\boldsymbol{\beta}$ tem interpretação diferente daquela em que os dados são independentes. A interpretação só é a mesma se forem comparados dois indivíduos de um mesmo grupo, ou seja, dois indivíduos com variáveis latentes iguais. De fato, neste caso tem-se:

$$
R(t)=\frac{z_{j} \alpha_{0}(t) \exp \left\{\boldsymbol{\beta}^{\prime} \mathbf{x}_{1}\right\}}{z_{j} \alpha_{0}(t) \exp \left\{\boldsymbol{\beta}^{\prime} \mathbf{x}_{2}\right\}}=\exp \left\{\boldsymbol{\beta}^{\prime}\left(\mathbf{x}_{1}-\mathbf{x}_{2}\right)\right\}
$$

Agora, se forem comparados dois indivíduos com os mesmos valores das covariáveis mas pertencentes a grupos distintos, o risco relativo de falha não é 1 mas sim a razão entre as variáveis latentes não-observadas, isto é:

$$
R(t)=\frac{z_{k} \alpha_{0}(t) \exp \left\{\boldsymbol{\beta}^{\prime} \mathbf{x}_{1}\right\}}{z_{j} \alpha_{0}(t) \exp \left\{\boldsymbol{\beta}^{\prime} \mathbf{x}_{1}\right\}}=\frac{z_{k}}{z_{j}}
$$

Finalmente, se forem comparados dois indivíduos com covariáveis diferentes e pertencentes a grupos distintos tem-se, de acordo com Klein (1992), que:

$$
R(t)=\exp \left\{\boldsymbol{\beta}^{\prime}\left(\mathbf{x}_{1}-\mathbf{x}_{2}\right)\right\}\left[\frac{1+\xi \hat{\Lambda}_{0}(t) \exp \left\{\boldsymbol{\beta}^{\prime} \mathbf{x}_{2}\right\}}{1+\xi \hat{\Lambda}_{0}(t) \exp \left\{\boldsymbol{\beta}^{\prime} \mathbf{x}_{1}\right\}}\right]
$$


O risco relativo, diferentemente dos casos anteriores, depende agora não somente das estimativas de $\boldsymbol{\beta}$ mas também do tempo $t$. Para visualizar o comportamento do risco de um tratamento relativo ao de outro, à medida que $t$ cresce, podem ser construídos gráficos de $t$ versus $\mathrm{R}(t)$. Com tais gráficos pode-se avaliar, por exemplo, a igualdade, ou não, de dois tratamentos no decorrer do tempo.

\subsubsection{Ajuste dos modelos de fragilidade}

Em se tratando de modelagem, este é um aspecto importante que está começando a ser pesquisado. Em um artigo recente, Glidden (1999) apresentou técnicas gráficas e numéricas para pesquisar o ajuste do modelo de fragilidade gama. Muito ainda deve ser feito nessa área a fim de que se possa avaliar adequadamente o ajuste dos modelos propostos.

As técnicas propostas por Glidden (1999), para a verificação do modelo semiparamétrico de fragilidade gama, foram baseadas na esperança a posteriori da variável latente $z_{j}$ dado o conhecimento dos dados até o tempo $t$. Glidden (1999) supôs $m$ grupos independentes, cada qual com $n_{j}$ tempos $T_{i j}=\min \left(F_{i j}, C_{i j}\right)$,

$i=1, \ldots, n_{j} ; j=1, \ldots, m$, em que $F_{i j}$ denota os tempos de falha e $C_{i j}$ os tempos censurados. Na notação de processos de contagem, os dados são representados por $N_{i j}(t)=\mathrm{I}\left(T_{i j} \leq t, \delta_{i j}=1\right)$ e $H_{i j}(t)=\mathrm{I}\left(T_{i j} \geq t\right)$. As distribuições de $T_{i j}$ foram assumidas serem modeladas por (3), isto é,

$$
\lambda_{i j}\left(t \mid \mathbf{x}_{i j}, z_{j}\right)=H_{i j}(t) z_{j} \alpha_{0}(t) \exp \left\{\boldsymbol{\beta}^{\prime} \mathbf{x}_{i j}\right\}
$$

Considerando $\Im_{t}=\left\{\mathrm{N}_{i j}(\mathrm{~s}), \mathrm{H}_{i j}(\mathrm{~s}): 0 \leq \mathrm{s} \leq t ; i=1, \ldots, n_{j} \mathrm{e}\right.$ $j=1, \ldots, m\}$, o qual representa a história de falhas e censuras até o tempo $t$ e, denotando por $\tau$, o tempo máximo de seguimento, segue que a esperança a posteriori da variável latente $z_{j}$, dado o conhecimento dos dados até o tempo $t$, é, de acordo com Nielsen et al. (1992), 


$$
E\left[z_{j} \mid \Im_{t}\right]=z_{0 j}(t)=\frac{1+\xi N_{j . .}(t)}{R_{j}(t ; \xi)}, \quad j=1, \ldots, m
$$

em que, $N_{j . .}(t)$ é o número de falhas no grupo $j$ antes do tempo $t$ e, $R_{j}(t ; \xi)=$ $1+\sum_{i=1}^{n_{j}} \exp \{\xi \Lambda(t)\}-n_{j}$. Foi, ainda, observado por Glidden (1999) que,

$$
M_{j}(t)=N_{j . .}(t)-\sum_{i=1}^{n_{j}} \int_{0}^{t} z_{0 j}\left(s^{-}\right) H_{i j}(s) \exp \{\xi \Lambda(s)\} d \Lambda(s)
$$

é o número observado de eventos em $t$ no j-ésimo grupo menos seu valor esperado sob o modelo de fragilidade gama.

Como os processos $z_{01}(t), z_{02}(t), \ldots, z_{0 m}(t)$ são independentes e identicamente distribuídos com média 1 , a soma normalizada dos $z_{0 j}$ 's foi denotada por:

$$
W_{m}(t):=m^{-1 / 2} \sum_{j=1}^{m}\left[\frac{1+\xi N_{j . .}(t)}{R_{j}(t ; \xi)}-1\right]
$$

o que produziu:

$$
W_{m}(t)=m^{-1 / 2} \sum_{j=1}^{m} \int_{0}^{t} P_{j}(s) d M_{j}(s),
$$

com $P_{j}(s)=\frac{\xi}{R_{j}(s, \xi)}$ funções peso previsíveis. Glidden (1999) mostrou, então, que $W_{m}(\cdot)$ converge para um processo gaussiano de média zero. Assim, $W_{m}(\cdot)$ fornece uma base natural para procedimentos de verificação do modelo semiparamétrico de fragilidade gama.

Não é possível, contudo, usar $W_{m}(t)$ diretamente devido a parâmetros desconhecidos estarem envolvidos. Glidden (1999) substituiu, então, os parâmetros desconhecidos em $W_{m}(t)$ por seus respectivos estimadores amostrais, obtendo: 


$$
\hat{W}_{m}(t):=m^{-1 / 2} \sum_{j=1}^{m}\left[\frac{1+\hat{\xi} N_{j . .}(t)}{\hat{R}_{j}(t ; \hat{\xi})}-1\right]
$$

em que, $\hat{R}_{j}(t, \xi)=1+\sum_{i=1}^{n_{j}} \exp \{\xi \hat{\Lambda}(t)\}-n_{j}$ com $\hat{\Lambda}(\cdot)$ os estimadores do tipo NelsonAalen de $\Lambda(\cdot)$ e, $\hat{\xi}$, o estimador pseudo-verossimilhança de $\xi$, obtido pela maximização do logaritmo da função pseudo-verossimilhança:

$$
\begin{aligned}
\hat{\ell}_{m}= & \sum_{j=1}^{m} \int_{0}^{t} \log \left[1+\xi N_{j . .}\left(u^{-}\right)\right] d N_{j . .}(u)+\xi \sum_{i=1}^{n_{j}} \hat{\Lambda}\left(X_{i j}\right) N_{i j}(\tau) \\
& -\left[\xi^{-1}+N_{j . .}(\tau)\right] \log \left(\hat{R}_{j}(\tau, \xi)\right) .
\end{aligned}
$$

Glidden (1999) obteve, então, a distribuição assintótica de $\hat{W}_{m}(\cdot)$ sob o modelo de fragilidade gama. Para isto definiu,

$$
\tilde{f}(t)=\frac{1}{m} \sum_{j=1}^{m}\left(R_{j}(t ; \xi)\right)^{-1}\left[N_{j . .}(t)-Z_{0 j}(t) \sum_{i=1}^{n_{j}} \Lambda(t) \exp \{\xi \Lambda(t)\}\right]
$$

e

$$
\tilde{g}(s ; t)=-\frac{1}{m} \sum_{j=1}^{m} \sum_{i=1}^{n_{j}} \xi\left(R_{j}(t ; \xi)\right)^{-1} Z_{0 j}(t) \exp \{\xi \Lambda(t)\} Y_{i j}(s)
$$

e considerou $\mathrm{f}(\cdot)$ e $\mathrm{g}(\cdot)$ os limites de $\tilde{f}(\cdot)$ e $\tilde{g}(\cdot)$. Mostrou, que sob a hipótese nula, $\hat{W}_{m}(\mathrm{t})$ é assintoticamente equivalente a

$$
\hat{W}_{m}(t)=m^{-1 / 2} \sum_{j=1}^{m} \phi_{j}(t)+o_{p}(1)
$$

em que,

$$
\phi_{j}(t)=\int_{0}^{t} P_{j}(s) d M_{j}(s)+\epsilon_{j} f(t)+\int_{0}^{t} g(s ; t) d \phi_{j}(s) .
$$


Sob $H_{0}$ os $\phi_{j}$ 's são variáveis aleatórias independentes e identicamente distribuídas de média zero para qualquer $t$ fixo. Assim, sob $H_{0}, \hat{W}_{n}(t)$ converge fracamente para um processo gaussiano $G(t)$ de média zero e função de covariância $\operatorname{cov}\{G(s), G(t)\}$.

Devido às distribuições assintóticas de quantidades tal como o supremo de $G(\cdot)$ serem analiticamente intratáveis, Glidden (1999) estendeu a idéia de reamostragem de Lin et al. (1993) para aproximar a distribuição do processo G(·) por simulação. Definiu, então,

$$
\tilde{W}_{m}(t)=m^{-1 / 2} \sum_{j=1}^{m} \hat{\phi}_{j}(t) S_{j}
$$

com $S_{1}, \ldots, S_{m}$ variáveis aleatórias independentes e identicamente distribuídas com distribuição normal padrão e independentes dos dados e, mostrou que $\tilde{W}_{m}(t)$ também converge fracamente para $\mathrm{G}(\cdot)$. Desse modo, aproximou a distribuição nula de $\hat{W}_{m}(t)$ com a de $\tilde{W}_{m}(t)$, gerando, repetidamente, as variáveis normais $S_{1}, \ldots, S_{m}$, fixando os dados $N_{i j}$ e $H_{i j}$ em seus valores observados.

Assim, um método para verificação da qualidade do modelo semiparamétrico de fragilidade gama, apresentado por Glidden (1999), é o de construir o gráfico de $\hat{W}_{m}(t)$ em relação ao tempo $t$. Quando o modelo for apropriado, o processo $\hat{W}_{m}(t)$ estará centrado em torno de zero. Para verificar o quão não usual é o padrão de $\hat{W}_{m}(t)$, Glidden (1999) sugere plotar, nesse mesmo gráfico, em torno de 20 realizações da distribuição de $\tilde{W}_{m}(t)$.

Um teste formal, que complementa o procedimento gráfico, também foi proposto por Glidden (1999). O teste é baseado em $\hat{Q}_{m}=\sup _{t}\left|\hat{W}_{m}(t)\right|$. A probabilidade associada a $\hat{Q}_{m}$ é estimada, novamente por simulação, pela probabilidade empírica que $\sup _{t}\left|\tilde{W}_{m}(t)\right|$ excede o valor observado de $\hat{Q}_{m}$. 


\subsection{Análise de dados de sobrevivência multivariados em um contexto de censura intervalar}

Dados censurados aparecem por uma variedade de razões e, para fazerse uma distinção entre os diversos tipos de censura (à direita, à esquerda, intervalar etc.), deve-se considerar a forma pela qual os dados são obtidos. Qualquer combinação dos tipos de censura (Klein \& Moeschberger, 1997) pode ocorrer em um estudo. Usa-se o termo censura intervalar para a descrição de situações em que se sabe que o tempo de sobrevivência de um indivíduo, $T_{i}$, ocorre entre dois valores, isto é, $T_{i} \in\left[L_{i}, U_{i}\right]$, sendo que $L_{i} \leq T_{i} \leq U_{i}$. Para indivíduos que experimentaram o evento de interesse entre esses dois valores, sabe-se que seu respectivo tempo de sobrevivência é no mínimo $L_{i}$ e no máximo $U_{i}$. Por outro lado, sabe-se, para aqueles indivíduos que não experimentaram o evento de interesse, que seu tempo de sobrevivência é no mínimo $U_{i}$.

Note que tempos de falha (tempos exatos) bem como tempos censurados à direita e à esquerda, são casos especiais de dados com censura intervalar com $L_{i}=U_{i}$ para tempos de falha, $U_{i}=\infty$ para censuras à direita e $L_{i}=0$ para censuras à esquerda. Desse modo, a função de verossimilhança para os vários tipos de censura pode ser construída incorporando-se as seguintes contribuições:

1. tempos exatos: $\mathrm{f}(t)$

2. tempos censurados à direita: $\mathrm{S}(\ell)$

3. tempos censurados à esquerda: $1-\mathrm{S}(u)$

4. tempos ocorrendo em intervalos: $\mathrm{S}(\ell)-\mathrm{S}(u)$

sendo que, $f(\cdot)$ denota a função de densidade de probabilidade e $S(\cdot)$ a função de sobrevivência.

Diferentes autores assumem distintas convenções para representar dados de sobrevivência com censura intervalar. Peto (1973) e Turnbull (1976), por 
exemplo, assumem intervalos de tempos fechados, ou seja, $\left[L_{i}, U_{i}\right]$ para, segundo eles, facilitar a acomodação de tempos exatos, isto é, de observações em que $L_{i}=U_{i}$. Para permitir uma contribuição não nula para a função de verossimilhança, desses tempos exatos, usam a notação $\mathrm{S}(\ell)-\mathrm{S}\left(u^{+}\right)$com $\mathrm{S}\left(u^{+}\right)=\lim _{\Delta \rightarrow 0} \mathrm{~S}\left(u_{i}+\Delta\right)$, em vez de $\mathrm{S}(\ell)$ - S $(u)$. Outros autores como, por exemplo, Filkelstein (1986), assumem intervalos semi-abertos e convencionam que a contribuição de qualquer tempo exato de falha, $t_{i}$, é $\mathrm{S}\left(t_{i}\right)$. De acordo com Lindsey \& Ryan (1998), a escolha por qualquer uma das convenções é razoável uma vez que, na prática, a escolha por qualquer uma delas traz um impacto muito pequeno nos resultados.

Considere, por exemplo, um estudo com $n$ indivíduos $(i=1, \ldots, n)$ em que, para cada um deles, observam-se um intervalo de tempo $\left[L_{i}, U_{i}\right]$, uma variável indicadora, $\delta$, indicando se o evento ocorreu, ou não, no respectivo intervalo e um vetor de covariáveis $\mathbf{x}_{i}$ o qual está associado um vetor de parâmetros desconhecidos $\boldsymbol{\beta}$. Adotando-se a convenção de intervalos fechados, tem-se, para esse estudo, que a contribuição para a função de verossimilhança dos indivíduos com $\delta_{i}=1$ é de $S\left(\ell_{i}\right)-S\left(u_{i}^{+}\right)$e a contribuição dos indivíduos com $\delta_{i}=0$ (assumindo serem censurados à direita) é de $S\left(\ell_{i}\right)$. Assim, a função de verossimilhança é dada por:

$$
L=\prod_{i=1}^{n}\left[S\left(\ell_{i}, \mathbf{x}_{i}, \boldsymbol{\beta}\right)-S\left(u_{i}^{+}, \mathbf{x}_{i}, \boldsymbol{\beta}\right)\right]^{\delta_{i}}\left[S\left(\ell_{i}, \mathbf{x}_{i}, \boldsymbol{\beta}\right)\right]^{1-\delta_{i}}
$$

em que, $\delta_{i}=1$ se o evento de interesse ocorreu no intervalo observado e $\delta_{i}=0$ em caso contrário. Assim, tem-se que o logaritmo da função de verossimilhança é dado por:

$$
\ell=\log L=\sum_{i=1}^{n} \delta_{i} \log \left[S\left(\ell_{i}, \mathbf{x}_{i}, \boldsymbol{\beta}\right)-S\left(u_{i}^{+}, \mathbf{x}_{i}, \boldsymbol{\beta}\right)\right]+\left(1-\delta_{i}\right) \log \left[S\left(\ell_{i}, \mathbf{x}_{i}, \boldsymbol{\beta}\right)\right] .
$$

Klein \& Moeschberger (1997) apresentam detalhes para a construção da função de verosimilhança para várias combinações de censuras. Versões semiparamétricas e paramétricas são possíveis para $\mathrm{S}(\cdot)$. A estimação dos parâmetros é 
feita maximizando-se (14). Programas estatísticos tais como, por exemplo, o R e o SAS podem ser utilizados para essa finalidade.

Modelos semi-paramétricos e paramétricos para dados de sobrevivência multivariados com censura intervalar e com variáveis latentes seguem o mesmo raciocínio dos modelos sem variáveis latentes. A estimação dos parâmetros é, contudo, algebricamente mais complexa e não se encontra disponível nos programas estatísticos até o momento. 


\section{MATERIAL E MÉTODOS}

A identificação de animais, ou plantas, geneticamente superiores é provavelmente um dos objetivos mais importantes em pesquisas que envolvam o melhoramento genético animal ou vegetal. Muitas pesquisas vêm sendo realizadas nessa área e as análises estatísticas apresentam-se, em geral, não triviais. A motivação desse trabalho concentra-se nos estudos de melhoramento genético animal cuja variável resposta de interesse seja o tempo observado entre dois eventos específicos. Como a suposição de Normalidade dessa variável não é usualmente satisfeita, problemas vêm sendo encontrados pelos pesquisadores no momento da análise estatística. Nesse trabalho, métodos que vêm sendo pesquisados em análise de sobrevivência são considerados para a análise dos dados de bovinos descritos nos estudos a seguir.

\subsection{Material}

\subsubsection{Estudo para a seleção de touros da raça Nelore}

Os dados descritos nesse estudo foram cedidos por GenSys Consultores Associados S/C Ltda. Os mesmos referem-se a registros de 6602 animais da raça Nelore nascidos na primavera, no período de 1990 a 1998, e que foram gerados por 64 touros. Para cada animal as seguintes informações encontram-se disponíveis:

1. identificação do animal;

2. identificação do touro que gerou o animal;

3. identificação da vaca que gerou o animal; 
4. ano de nascimento da vaca;

5. tipo de reprodução (0 se natural, 1 se artificial);

6. peso do animal ao nascer;

7. sexo do animal (0 se fêmea, 1 se macho);

8. peso do animal na desmama;

9. grupo de manejo na desmama;

10. tempo (em dias) desde o nascimento até a desmama;

11. peso do animal no sobreano;

12. status: 1 se o ganho de peso entre o nascimento e a desmama foi $\geq 160 \mathrm{~kg}$ e 0 em caso contrário e

13. grupo de manejo no sobreano.

A variável tempo desde o nascimento até a desmama, é apresentada em dias e indica o período observado entre dois eventos (o nascimento e a desmama). Covariáveis relacionadas ao peso são dadas em quilogramas sendo que, a covariável "peso no sobreano" significa o peso do animal registrado entre 380 e 685 dias após os mesmos terem nascido. As covariáveis grupo de manejo na desmama e grupo de manejo no sobreano indicam o local de permanência do animal bem como a suplementação alimentar por ele recebida. Foi registrado, para cada animal observado na desmama, um correspondente indicador de censura, denominado status, indicando se o ganho de peso no período do nascimento até a desmama, foi, ou não, maior do que 160kg. Nesse estudo, nenhum animal ganhou 160kg antes de 120 dias e, portanto, por simplicidade, esse valor foi subtraído do tempo observado desde o nascimento até a desmama.

O objetivo principal desse estudo concentra-se na identificação dos touros geneticamente superiores, visando sua utilização na reprodução animal. Para 
a avaliação e conseqüente identificação dos touros será considerado, como variável resposta de interesse, os tempos, desde o nascimento até a desmama, que os animais gerados por eles levaram para atingirem um específico ganho de peso. Tempos não muito longos são economicamente desejáveis e, de acordo com pesquisadores de gado de corte da raça Nelore (Albuquerque \& Fries, 1998), um ganho de peso realístico para esse período está em torno de $160 \mathrm{~kg}$. Serão também considerados na avaliação, além das covariáveis (efeitos fixos) descritas, efeitos aleatórios representando, em um sentido estatístico, fatores genéticos compartilhados pelos animais e que, contudo, não são observáveis. O objetivo de se colocarem no modelo esses efeitos é levar em consideração que os tempos observados em animais gerados pelo mesmo touro são provavelmente associados.

\subsubsection{Estudo para a seleção de touros da raça Canchim}

Os dados desse estudo são similares aos do estudo anterior e foram cedidos pela Embrapa - Empresa Brasileira de Pesquisa Agropecuária localizada em São Carlos no Estado de São Paulo. Os bovinos, contudo, são da raça Canchim sendo que, as observações, foram coletadas em 4509 animais gerados por 241 touros. As informações disponíveis para cada animal são:

1. identificação do animal;

2. identificação do touro que gerou o animal;

3. identificação da vaca que gerou o animal;

4. idade da vaca no parto;

5. sexo (0 se fêmea, 1 se macho);

6. mês de nascimento do animal;

7. ano de nascimento do animal;

8. peso ao nascer; 
9. idade na desmama e

10. peso na desmama.

A variável idade na desmama, indicando o período observado entre o nascimento e a desmama, é apresentada em dias e os pesos são apresentados em quilogramas. A covariável mês de nascimento foi categorizada nas estações do ano, isto é, verão, outono, inverno e primavera e, a idade da vaca no parto, apresentada em dias, foi categorizada nos intervalos (750, 1650]; (1650, 2550]; [2550, 3450); $[3450,4500)$ e $[4500,6700)$ dias. A identificação dos touros geneticamente superiores, em termos da taxa de crescimento dos animais gerados por eles, é também de interesse nesse estudo. Para a raça Canchim, contudo, considera-se que $175 \mathrm{~kg}$ seja um ganho de peso realístico no período do nascimento até a desmama. A variável resposta de interesse é, portanto, o tempo até um ganho de peso de $175 \mathrm{~kg}$ no período do nascimento até a desmama.

\subsection{Métodos}

Embora, as informações disponíveis em ambos os estudos não sejam exatamente as mesmas, nota-se a existência de um objetivo comum, ou seja, a seleção de touros baseada nos tempos até um ganho específico de peso dos seus descendentes. Para a análise de ambos os estudos, os modelos de fragilidade gama com censura intervalar e os modelos de curvas de crescimento com efeitos aleatórios foram propostos.

\subsubsection{Modelos de fragilidade gama com censura intervalar}

Para a análise dos dados descritos, propôs-se, inicialmente, o uso de técnicas que vêm sendo pesquisadas em análise de sobrevivência. Note que, devido à inviabilidade, na prática, de se pesarem os animais diariamente, não se pode observar o tempo exato, $T_{i}$, que um animal leva para ganhar um peso específico $(160 \mathrm{~kg}$ no caso dos bovinos da raça Nelore e $175 \mathrm{~kg}$ no da raça Canchim). Sabe-se, contudo, 
que esse ganho de peso ocorre em um intervalo de tempo denotado aqui por $\left[\mathrm{L}_{i}, \mathrm{U}_{i}\right]$ em que $\mathrm{L}_{i} \leq \mathrm{T}_{i} \leq \mathrm{U}_{i}$. Sabe-se, também, que alguns animais atingem o ganho de peso desejado até a desmama, enquanto outros não e, portanto, tudo o que se sabe a respeito desses últimos é que eles devem atingir tal ganho de peso em algum momento após aquela data.

De um modo geral, as seguintes considerações necessitam ser feitas para uma análise adequada dos dados apresentados em ambos os estudos:

1. os tempos $T_{i}$ ocorrem em intervalos de tempos denotados por $\left[\mathrm{L}_{i}, \mathrm{U}_{i}\right]$;

2. existem animais que alcançam o ganho de peso desejado até a desmama e animais que o fazem após a desmama e

3. os tempos dos animais gerados pelo mesmo touro são, provavelmente, associados.

Uma classe de modelos estatísticos propostos nesse trabalho, e que incorporam tais considerações, são os modelos de fragilidade gama com censura intervalar. Esses modelos consideram que os tempos $T_{i}$ ocorrem em intervalos bem como que cada $T_{i}$ pode ser, um tempo de falha, se o ganho de peso desejado ocorreu no intervalo $\left[\mathrm{L}_{i}, \mathrm{U}_{i}\right]$, ou um tempo censurado, em caso contrário. Uma variável indicadora que indica se o animal alcançou, ou não, o ganho de peso no respectivo intervalo de tempo, é usada para considerar essa informação nos modelos. Efeitos aleatórios são também possíveis permitindo, assim, que variáveis não observáveis como, por exemplo, a associação entre os tempos dos indivíduos de um mesmo grupo, sejam consideradas.

Nos modelos de componentes de variância para dados normalmente distribuídos, o efeito aleatório é, em geral, aditivamente incorporado. O modelo aqui proposto incorpora tal efeito multiplicativamente na taxa de risco individual (Hougaard, 2000) e, como esse efeito aleatório não é observável, uma distribuição de probabilidade deve ser considerada. A distribuição gama, por sua simplicidade, flexibilidade e popularidade nessa área, foi assumida. 
O modelo proposto permite que covariáveis, isto é, efeitos fixos sejam considerados e, condicional ao efeito aleatório e às covariáveis, assume-se que os tempos $\mathrm{T}_{i}$ são independentes e seguem a distribuição Weibull com parâmetros $\gamma \mathrm{e}$ $z_{j} \exp \left\{\alpha+\boldsymbol{\beta}^{\prime} \mathbf{x}_{i j}\right\}$. Portanto, a probabilidade de um animal $i(i=1, \ldots, n)$ gerado pelo touro $j(j=1, \ldots, m)$ com vetor p-dimensional de covariáveis $\mathbf{x}_{i j}$ ganhar o peso desejado após o tempo $t$, é representada por:

$$
S\left(t \mid \mathbf{x}_{i j}, z_{j}\right)=\exp \left\{-z_{j} \exp \left\{\alpha+\boldsymbol{\beta}^{\prime} \mathbf{x}_{i j}\right\} t^{\gamma}\right\}
$$

sendo que $\alpha$ é uma constante; $\boldsymbol{\beta}$ denota o vetor p-dimensional de coeficientes desconhecidos associados aos efeitos fixos $\mathbf{x}_{i j} ; z_{j}$ representa os fatores genéticos compartilhados por animais gerados pelo touro $j$ e que não são mensuráveis e $\gamma$ é o parâmetro de forma da distribuição Weibull. Um animal com função de sobrevivência $\mathrm{S}(\mathrm{t} \mid \cdot$ ) decrescendo rapidamente ao longo do tempo ganha peso rapidamente. Em termos de riscos, o modelo (15) é representado por:

$$
\lambda\left(t \mid \mathbf{x}_{i j}, z_{j}\right)=z_{j} \exp \left\{\alpha+\boldsymbol{\beta}^{\prime} \mathbf{x}_{i j}\right\} \gamma t^{\gamma-1}
$$

Pode-se ver mais claramente em (16) do que em (15) que o efeito aleatório atua multiplicativamente nos riscos individuais. Assim, se a função de risco para um determinado animal cresce rapidamente isso indica que o peso do animal está aumentando rapidamente. O interesse estará, portanto, naqueles touros com animais cuja função de sobrevivência decresce rapidamente ou, eqüivalentemente, cuja função de risco cresce rapidamente.

Os componentes aleatórios $z_{j}, j=1, \ldots, m$, são assumidos independentes e com distribuição gama com parâmetros $(1 / \xi, 1 / \xi)$ de modo que $\mathrm{E}\left(z_{j}\right)=1$ e $\operatorname{Var}\left(z_{j}\right)=\xi$, chamada variância genética. Cada touro tem, portanto, um valor $z_{j}$ associado o que permite uma comparação entre eles. Valores grandes de $z_{j}$ indicam 
touros cujos descendentes ganham peso rapidamente. O modelo proposto em (15) permite diferentes números de descendentes por touro. Conclusões sobre aqueles touros com poucos descendentes deveriam, no entanto, ser olhadas com cuidado.

A função de verossimilhança para o modelo proposto é expressa por:

$$
\begin{aligned}
L= & \prod_{i=1}^{n}\left[S\left(\ell_{i}, \mathbf{x}_{i}, \boldsymbol{\beta}\right)-S\left(u_{i}^{+}, \mathbf{x}_{i}, \boldsymbol{\beta}\right)\right]^{\delta_{i}}\left[S\left(\ell_{i}, \mathbf{x}_{i}, \boldsymbol{\beta}\right)\right]^{1-\delta_{i}} \\
= & \prod_{i=1}^{n}\left[\exp \left\{-z_{j} \exp \left\{\alpha+\boldsymbol{\beta}^{\prime} \mathbf{x}_{i j}\right\} \ell_{i}^{\gamma}\right\}-\exp \left\{-z_{j} \exp \left\{\alpha+\boldsymbol{\beta}^{\prime} \mathbf{x}_{i j}\right\}\left(u_{i}^{+}\right)^{\gamma}\right\}\right]^{\delta_{i}} \\
& {\left[\exp \left\{-z_{j} \exp \left\{\alpha+\boldsymbol{\beta}^{\prime} \mathbf{x}_{i j}\right\} \ell_{i}^{\gamma}\right\}\right]^{1-\delta_{i}} }
\end{aligned}
$$

sendo que, $\delta_{i}=1$ se o evento de interesse ocorreu no intervalo observado e $\delta_{i}=0$, em caso contrário. Assim, tem-se que o logaritmo da função de verossimilhança é dado por:

$$
\begin{aligned}
\ell= & \sum_{i=1}^{n} \delta_{i} \log \left[S\left(\ell_{i}, \mathbf{x}_{i}, \boldsymbol{\beta}\right)-S\left(u_{i}^{+}, \mathbf{x}_{i}, \boldsymbol{\beta}\right)\right]+\left(1-\delta_{i}\right) \log \left[S\left(\ell_{i}, \mathbf{x}_{i}, \boldsymbol{\beta}\right)\right] \\
= & \sum_{i=1}^{n} \delta_{i} \log \left[\exp \left\{-z_{j} \exp \left\{\alpha+\boldsymbol{\beta}^{\prime} \mathbf{x}_{i j}\right\} \ell_{i}^{\gamma}\right\}-\exp \left\{-z_{j} \exp \left\{\alpha+\boldsymbol{\beta}^{\prime} \mathbf{x}_{i j}\right\}\left(u_{i}^{+}\right)^{\gamma}\right\}\right] \\
& +\left(1-\delta_{i}\right)\left[\exp \left\{-z_{j} \exp \left\{\alpha+\boldsymbol{\beta}^{\prime} \mathbf{x}_{i j}\right\} \ell_{i}^{\gamma}\right\}\right]
\end{aligned}
$$

Para a implementação computacional do modelo proposto, optou-se pela abordagem Bayesiana devido às dificuldades encontradas sob a abordagem clássica. Sob uma perpectiva Bayesiana, não existe distinção fundamental entre variáveis e parâmetros de um modelo estatístico. Todos são considerados quantidades aleatórias sendo, a distribuição a posteriori, o objeto da inference Bayesiana que, em geral, não pode ser obtida em uma forma exata devido às integrações envolvidas. Um modo de tratar com esse problema é estimar as distribuições a posteriori usando-se o método de Markov chain Monte Carlo (MCMC). MCMC 
é um método computacionalmente intensivo no qual uma cadeia estocástica dos valores dos parâmetros é gerada de modo que, após um número conveniente de iterações (burn in), os valores da cadeia são assumidos serem amostras de uma distribuição de probabilidades específica. Essas cadeias podem ser construídas de diferentes maneiras, dentre elas, o amostrador de Gibbs usado nesse trabalho. Uma breve introdução ao conceito de cadeia de Markov bem como ao amostrador de Gibbs são apresentados a seguir.

\section{a) Cadeias de Markov}

Suponha uma seqüência de variáveis aleatórias $\left\{X_{0}, X_{1}, X_{2}, \ldots, X_{h}\right\}$, tal que para cada tempo $t \geq 0$, o próximo estado $X_{t+1}$ seja amostrado da distribuição $\mathrm{P}\left(X_{t+1} \mid X_{t}\right)$ a qual depende somente do estado atual $X_{t}$, isto é, dado $X_{t}$, o estado seguinte $X_{t+1}$ não depende da história da cadeia $\left\{X_{0}, X_{1}, \ldots, X_{t-1}\right\}$. Essa seqüência é chamada cadeia de Markov e $\mathrm{P}(\cdot \mid \cdot)$ é chamada de Kernel de transição da cadeia. Sujeita à condições de regularidade (Gilks et al., 1996), a cadeia esquecerá gradualmente seu estado inicial e $P^{(t)}\left(\cdot \mid X_{0}\right)$ convergirá para uma única distribuição estacionária, denotada aqui por $\varphi(\cdot)$, a qual não dependerá de $t$ ou de $X_{0}$. Após um longo e suficiente período de $m$ iterações (burn in period), os pontos $\left\{X_{t}: t=m+1, . ., n\right\}$ serão amostras aproximadas da distribuição $\varphi(\cdot)$. As amostras obtidas no burn in period são, usualmente, descartadas da cadeia de Markov para calcular a esperança, $\mathrm{E}[f(X)]$, de quaisquer funções da variável $X$ tais como, por exemplo, a média, a variância e outros momentos. Assim, o estimador para essa esperança é dado por:

$$
\bar{f}=\frac{1}{n-m} \sum_{t=m+1}^{n} f\left(X_{t}\right)
$$

MCMC é, portanto, um método para explorar a distribuição $\varphi(\cdot)$ em que uma cadeia de Markov com distribuição estacionária $\varphi(\cdot)$ é construída e médias 
amostrais dessa cadeia são usadas para estimar características de $\varphi(\cdot)$.

Em síntese, MCMC é uma técnica Bayesiana que requer informacão a priori dos parâmetros de interesse. Se existir pouca, ou nenhuma informação a respeito dos parâmetros, então, usar prioris com variâncias grandes (prioris não informativas) permitirá que os dados dominem a análise, como ocorre sob a abordagem clássica. Para detalhes adicionais ver Gilks et al. (1996).

\section{b) Amostrador de Gibbs}

Foi descrito brevemente na seção anterior como uma cadeia de Markov pode ser usada para estimar $\mathrm{E}[f(X)]$, em que a esperança é tomada de uma distribuição estacionária $\varphi(\cdot)$. É de interesse, no entanto, saber como construir essa cadeia de modo que sua distribuição estacionária seja a distribuição de interesse, denotada aqui por $\pi(\cdot)$. Entre os diversos métodos propostos na literatura, será considerado o amostrador de Gibbs. A idéia, em linhas gerais, desse amostrador é a de, sucessivamente, retirar amostras da distribuição de cada i-ésimo componente de $\mathbf{X}$, condicionando a todos os componentes remanescentes, em que $\mathbf{X}$ tenha distribuição $\pi(\cdot)$, ou seja, retirar amostras das distribuições:

$$
\pi\left(X_{i} \mid \mathbf{X}_{\{-i\}}\right)=\frac{\pi(\mathbf{X})}{\int \pi(\mathbf{X}) d X_{i}}
$$

sendo que $\mathbf{X}_{\{-i\}}$ inclui todos os componentes de $\mathbf{X}$, exceto $X_{i}$. Essas distribuições são conhecidas como "distribuições condicionais completas". Assim, o amostrador de Gibbs consiste em, simplemente, amostrar de distribuições condicionais completas e seu algoritmo pode ser escrito por:

0. iniciar com $\mathbf{X}=\left(X_{1}^{(0)}, X_{2}^{(0)}, \ldots, X_{h}^{(0)}\right)$

1. obter $X_{1}^{(1)}$ da distribuição condicional de $X_{1} \mid\left(X_{2}^{(0)}, \ldots, X_{h}^{(0)}\right)$ 
1.1. obter $X_{2}^{(1)}$ da distribuição condicional de $X_{2} \mid\left(X_{1}^{(1)}, X_{3}^{(0)}, \ldots, X_{h}^{(0)}\right)$

1.h. obter $X_{h}^{(1)}$ da distribuição condicional de $X_{h} \mid\left(X_{1}^{(1)}, \ldots, X_{h-1}^{(1)}\right)$

2. fazer a iteração desses passos até obter a cadeia de Markov $\left(X_{1}^{(1)}, \ldots, X_{h}^{(1)}\right)$, $\ldots,\left(X_{1}^{(n)}, \ldots, X_{h}^{(n)}\right)$.

Sob condições de regularidade, convergência da cadeia de Markov para uma distribuição estacionária multivariada $\mathrm{P}\left(X_{1}, \ldots, X_{h}\right)$ é garantida (Gilks et al., 1996), de modo que, após um período de $m$ iterações, as observações $\left(X_{1}^{(m+1)}, \ldots, X_{h}^{(m+1)}\right), \ldots,\left(X_{1}^{(n)}, \ldots, X_{h}^{(n)}\right)$ podem ser consideradas realizações dessa distribuição. Estatísticas resumo empíricas podem, então, ser obtidas dessas amostras e usadas para a retirada de inferências sobre seus valores verdadeiros.

Usando, portanto, o método MCMC, programas computacionais como, por exemplo, os apresentados nos Anexos F e H, foram escritos para serem utilizados no WinBUGS. Nesses programas, distribuições a priori bem como valores iniciais para os parâmetros de interesse são requeridos de modo que:

a) para os parâmetros $\alpha, \gamma, \beta_{1}$ e $\xi_{f}$, de interesse no ajuste do modelo de fragilidade gama com censura intervalar aos dados dos bovinos Nelore, assumiram-se as prioris: $\alpha \sim N\left(0,10^{5}\right), \gamma \sim \Gamma\left(1,10^{-5}\right), \beta_{1} \sim N\left(0,10^{5}\right)$ e $1 / \xi_{f} \sim \Gamma\left(10^{-4}, 10^{-4}\right)$. Os respectivos valores iniciais considerados foram: $\alpha=0, \gamma=1, \beta_{1}=1$, $1 / \xi_{f}=0,1, \mathrm{z}_{j}=1$ para $j=1, \ldots, 64$ e $t_{i j}$ igual aos tempos até a desmama subtraído do valor 120 dias e,

b) para os parâmetros $\alpha, \gamma, \beta_{1}, \ldots, \beta_{8}, \xi_{f}$ e $\xi_{v}$, de interesse no ajuste do modelo de fragilidade gama com censura intervalar aos dados dos bovinos Canchim, assumiram-se as prioris: $\alpha \sim N\left(0,10^{5}\right), \gamma \sim \Gamma\left(1,10^{-5}\right), \beta_{k} \sim N\left(0,10^{5}\right)$ para $k=1, \ldots, 8,1 / \xi_{f} \sim \Gamma\left(10^{-4} ; 10^{-4}\right)$ e $1 / \xi_{v} \sim \Gamma\left(10^{-4} ; 10^{-4}\right)$. Nesse caso, os valores iniciais foram: $\alpha=0, \gamma=1, \beta_{1}=\ldots=\beta_{8}=1,1 / \xi_{f}=0,1,1 / \xi_{v}=0,1$, 
$\mathrm{z}_{j}=1$ para $j=1, \ldots, 241, \mathrm{z}_{v}=0,1$ para $v=1, \ldots, 1687$ e $t_{i j}$ igual aos tempos até a desmama.

As conclusões quanto à seleção dos touros foram, então, obtidas baseadas nas distribuições a posteriori dos parâmetros.

\subsubsection{Estudo de simulação}

Para avaliar o impacto nas estimativas dos parâmetros do modelo proposto, quando o efeito aleatório é ignorado, foi realizado um estudo de simulação. Nesse estudo, foram simulados tempos com censura intervalar e foram considerados uma covariável binária e para cada simulação, dentre as 500 realizadas, 500 tempos e 50 touros. Os valores usados para os parâmetros do modelo considerado para a simulação e expresso por

$$
S\left(t \mid \mathbf{x}_{i j}, z_{j}\right)=\exp \left\{-z_{j} \exp \left\{\alpha+\beta_{1} x_{i j}\right\} t^{\gamma}\right\}
$$

foram $\alpha=-50, \beta_{1}=7, \gamma=10$ e dois valores para a variância genética $\xi=1,0$ e 0,5 . O programa apresentado no anexo I foi usado para a simulação dos tempos.

Para a obtenção das estimativas dos parâmetros do modelo sem efeito aleatório e com efeito aleatório conhecido, foram escritos (R-versão 1.5) os programas apresentados nos Anexos J e K, respectivamente. Nesses programas foi considerado $Y_{i}=\log \left(T_{i}\right)$ que tem distribuição valor extremo (Lawless, 1982) em vez de $T_{i}$ devido à questões de convergência do procedimento iterativo de Newton-Raphson o qual é extremamente sensível aos valores que iniciam o processo. As funções de sobrevivência para $Y_{i}$ sem, e com, efeito aleatório, são expressas, respectivamente, por:

$$
S\left(y \mid \mathbf{x}_{i j}\right)=\exp \left\{-\exp \left\{\frac{\log (t)-\mu-\boldsymbol{\lambda}^{\prime} \mathbf{x}_{i j}}{\sigma}\right\}\right\}
$$


e

$$
S\left(y \mid \mathbf{x}_{i j}, z_{j}\right)=\exp \left\{-z_{j} \exp \left\{\frac{\log (t)-\mu-\boldsymbol{\lambda}^{\prime} \mathbf{x}_{i j}}{\sigma}\right\}\right\}
$$

Os correspondentes logaritmos das funções de verossimilhanças são, portanto, respectivamente,

$$
\begin{aligned}
\ell= & \sum_{i=1}^{n} \delta_{i} \log \left[\exp \left\{-\exp \left\{k_{1}\right\}\right\}-\exp \left\{-\exp \left\{k_{2}\right\}\right\}\right] \\
& +\left(1+\delta_{i}\right) \log \left[\exp \left\{-\exp \left\{k_{1}\right\}\right\}\right]
\end{aligned}
$$

e

$$
\begin{aligned}
\ell= & \sum_{i=1}^{n} \delta_{i} \log \left[\exp \left\{-z_{j} \exp \left\{k_{1}\right\}\right\}-\exp \left\{-z_{j} \exp \left\{k_{2}\right\}\right\}\right] \\
& +\left(1+\delta_{i}\right) \log \left[\exp \left\{-z_{j} \exp \left\{k_{1}\right\}\right\}\right]
\end{aligned}
$$

sendo que:

$$
k_{1}=\frac{\log \left(\ell_{i}\right)-\mu-\boldsymbol{\lambda}^{\prime} \mathbf{x}_{i j}}{\sigma} \quad \text { e } \quad k_{2}=\frac{\log \left(u_{i}\right)-\mu-\boldsymbol{\lambda}^{\prime} \mathbf{x}_{i j}}{\sigma} .
$$

As funções de sobrevivência dadas por (18) e (19) têm uma correspondência direta com a expressão (15), no sentido que, $\alpha=-\mu / \sigma, \gamma=1 / \sigma \mathrm{e}$ $\beta_{k}=-\lambda_{k} / \sigma(k=1, \ldots, p)$ permitindo, assim, a obtenção das estimativas dos parâmetros de interesse.

\subsubsection{Modelos de curvas de crescimento com efeitos aleatórios}

Um outro critério para a seleção dos touros, alternativo ao modelo de fragilidade gama com censura intervalar, é baseado no ajuste de funções não lineares tais como a logística, a de Gompertz e a de Richard (Perotto, 1992). Estas curvas são usuais no estudo de crescimento de bovinos (em termos de peso) sendo, os pesos, 
observados em algumas idades tais como nascimento, desmama etc. Nesse trabalho, considerou-se apenas a curva de crescimento logística mas a extensão para qualquer outra é direta. Para a curva logística sem efeito aleatório, o peso corporal do animal no tempo $t$, denotado aqui por $W(t)$, é representado por:

$$
W(t)=\frac{A}{(1+b \exp \{-k t\})}
$$

sendo que A é o peso assintótico do animal, usualmente denominado de peso adulto; o parâmetro $b$ é uma constante de integração que se ajusta para situações em que $W(0)$ e, ou, $t_{0}$ são diferentes de zero. O parâmetro $k$ é uma constante que expressa a taxa, segundo a qual uma função logarítmica de $W$ muda linearmente com o tempo e é interpretado biologicamente como índice de maturação e serve como medida da taxa de mudança na velocidade do ganho de peso.

O modelo proposto para a seleção de touros e, também, de seus descendentes é baseado na função logística apresentada em (20) incorporando-se os efeitos aleatórios de touro e dos descendentes. Os efeitos aleatórios incorporados levam em consideração que os pesos dos animais gerados pelo mesmo touro são associados bem como que, os pesos observados no mesmo animal, também o são. O peso no tempo $t$ para o animal $i$, descendente do touro $j$, com efeitos fixos $\mathbf{x}_{i j}$ é, portanto, expresso por:

$$
W_{i}(t)=\frac{A_{i}}{(1+b \exp \{-k t\})}+\epsilon_{i}
$$

sendo que $\mathrm{A}_{i}$ é o peso adulto do animal $i(i=1, \ldots, n)$ descendente do touro $j, b$ é uma constante de integração e $k$ é uma constante que serve como medida da taxa de mudança na velocidade do ganho de peso.

Admitiu-se que $\mathrm{A}_{i} \sim \mathrm{N}\left(\mu+\boldsymbol{\beta}^{\prime} \mathbf{x}_{i j}+f_{j(i)}, \sigma_{a}^{2}\right)$ sendo $\mu$ uma constante, $\boldsymbol{\beta}$ um vetor p-dimensional de coeficientes desconhecidos associados aos efeitos fixos 
$\mathbf{x}_{i j}, f_{j(i)}$ o efeito genético do touro $j$ que gerou o animal $i$ e $\sigma_{a}^{2}$ a variância do efeito genético do animal. Para o efeito aleatório paterno $f_{j}(j=1, \ldots, m)$ e para os erros aleatórios $\epsilon_{i}(i=1, \ldots, n)$ também foram assumidas a distribuição Normal, ou seja, $f_{j} \sim N\left(0, \sigma_{f}^{2}\right)$ e $\epsilon_{i} \sim N\left(0, \sigma_{e}^{2}\right)$ com $\sigma_{f}^{2}$ denotando a variância do efeito genético paterno, $\sigma_{e}^{2}$ a variância residual, $n=\sum_{j=1}^{m} n_{j}$ o número de animais e $m$ o número de touros. A covariância entre os efeitos genéticos paterno e do animal foi assumida ser zero. Em conseqüência, tem-se que os pesos $W_{i}(t)$, seguem a distribuição Normal com média $A_{i} /(1+b \exp \{-k t\})$ e variância $\sigma_{e}^{2}$.

O modelo definido em (21) também permite diferentes números de descendentes por touro, porém, conclusões sobre aqueles touros com poucos descendentes deveriam ser olhadas com cautela.

O tempo para atingir um determinado peso, por exemplo $190 \mathrm{~kg}$, o que eqüivale ao tempo até um ganho de peso de $160 \mathrm{~kg}$ para animais com peso ao nascer de $30 \mathrm{~kg}$, pode ser obtido, para cada animal, por:

$$
T_{i}=\frac{\log (190 b)-\log \left(A_{i}-190\right)}{k}, \quad A_{i}>190
$$

Programas usando o pacote WinBUGS foram escritos (um deles apresentado no Anexo G), para a realização da análise. O método MCMC foi, assim como no modelo de fragilidade gama com censura intervalar, usado no processo de estimação assumindo-se prioris não informativas para os parâmetros de interesse. No ajuste do modelo de curvas de crescimento aos dados dos bovinos Nelore, assumiramse as prioris: $b \sim \mathrm{N}\left(0,10^{5}\right), k \sim \Gamma\left(10^{-4} ; 10^{-4}\right), \beta_{1} \sim \mathrm{N}\left(0,10^{5}\right), \tau_{a} \sim \Gamma\left(10^{-4} ; 10^{-4}\right)$, $\tau_{f} \sim \Gamma\left(10^{-4} ; 10^{-4}\right)$ e $\tau_{e} \sim \Gamma\left(10^{-4} ; 10^{-4}\right)$ sendo que, $\sigma_{a}^{2}=1 / \tau_{a}, \sigma_{f}^{2}=1 / \tau_{f}$ e $\sigma_{e}^{2}=1 / \tau_{e}$.

Comparações entre os touros foram feitas usando-se as médias a posteriori de $f_{j}, j=1, \ldots, m$. Os touros foram classificados em ordem decrescente e, então, os melhores, de acordo com o critério proposto, foram selecionados. Como uma ferramenta adicional no processo de seleção, usaram-se as distribuições a posteriori das classificações que fornecem a incerteza associada à classificação atribuída 
a cada touro.

O modelo de curvas de crescimento não foi ajustado para os dados do estudo realizado com bovinos da raça Canchim pelo fato de os pesos terem sido observados somente em duas idades inviabilizando, assim, o ajuste desse modelo.

\subsubsection{Comparação por meio de simulação entre os resultados do mo- delo de fragilidade gama com censura intervalar e os do modelo de curvas de crescimento com efeitos aleatórios}

Foi realizada uma comparação, por meio de simulação, entre os dois critérios propostos nesse trabalho para a seleção de touros. Concordância entre as classificações, obtidas por ambos os critérios, indica que eles se eqüivalem e, portanto, um, ou outro, pode ser escolhido sem grande impacto na decisão final.

Os procedimentos usados na simulação e análise dos dados simulados podem ser resumidos do seguinte modo:

1. usando-se a função logística apresentada em (21) com parâmetros $b=7,5$, $k=0,013$ e assumindo-se $A_{i} \sim \mathrm{N}\left(\mu+f_{j}, 700\right)$ em que $\mu=274, f_{j} \sim \mathrm{N}(0,300)$ e $\epsilon_{i} \sim \mathrm{N}(0,25), 1000$ pesos foram simulados nos tempos $t=0,220$ e 600 dias totalizando, em cada simulação, 3000 pesos (3 para cada animal);

2. para cada simulação, ajustou-se o modelo de curvas de crescimento logístico com efeito aleatório obtendo-se as classificações dos touros;

3. para cada simulação e fazendo-se as devidas adaptações dos dados ao contexto de análise de sobrevivência, ajustou-se também, o modelo de fragilidade gama com censura intervalar. No ajuste desse modelo, considerou-se que status $=1$ se o ganho de peso observado entre os tempos $t=0$ e $t=220$ foi $\geq 160 \mathrm{~kg}$ e status $=0$, em caso contrário. Se status $=1$ foi assumido que o ganho de peso desejado ocorreu no intervalo [120,220] dias e, em caso contrário, no intervalo [220, 500] dias. Após o ajuste, as classificações dos touros foram, então, obtidas; 
4. para cada simulação verificou-se a concordância entre as classificações dos touros obtidas pelos dois modelos propostos e

5. os passos de 1 a 4 foram repetidos um número razoável de vezes considerando-se 10 touros $(j=1, \ldots, 10)$ com 100 descendentes cada, bem como considerandose 20 touros com 50 descendentes cada. Nenhum efeito fixo foi considerado na simulação dos dados.

No ajuste do modelo de fragilidade gama com censura intervalar (item 3) foi assumido, condicionalmente ao efeito aleatório $\mathbf{z}$, que os tempos $T_{i j}$, até um ganho de peso de 160kg seguem a distribuição Weibull com parâmetros $\gamma$ e $z_{j} \exp \{\alpha\}$. Como uma forma simplista de verificar tal suposição utilizou-se de uma análise gráfica, sugerida na literatura para dados de sobrevivência sem efeito aleatório (Lee, 1980; Lawless, 1982). Esse procedimento gráfico, ignorando-se o efeito aleatório e o efeito das covariáveis, consiste basicamente em:

1. sabendo-se que:

$$
S(t)=\exp \left\{-\exp \{\alpha\} t^{\gamma}\right\}
$$

então, tem-se que:

$$
\log [-\log (S(t))]=\alpha+\gamma \log (t) \quad \mathrm{e}
$$

2. assim, se $\log [-\log (\hat{S}(t))]$ versus $\log (t)$ for aproximadamente uma reta, a distribuição Weibull é razoável para os dados sendo que, o intercepto e a inclinação da reta ajustada, fornecem uma idéia dos valores dos parâmetros da distribuição Weibull. Para $\hat{S}(t)$ utiliza-se, em geral, o estimador nãoparamétrico de Kaplan-Meier (1958).

O programa apresentado no Anexo M foi usado para a obtenção dos pesos utilizados nesse estudo de simulação. 


\section{RESULTADOS E DisCUSSÃO}

\subsection{Estudo realizado com bovinos Nelore}

Para o estudo realizado com bovinos da raça Nelore introduzido no capítulo anterior, são apresentadas, inicialmente, algumas estatísticas descritivas para uma análise exploratória dos mesmos.

Para esse estudo, a variável tempo, observada do nascimento até a desmama, variou de 134 a 276 dias. Pela Tabela 1 observa-se uma grande variação do peso ao nascer, na desmama e no sobreano.

Tabela 1. Estatísticas resumo para as covariáveis quantitativas observadas nos descendentes de 64 touros da raça Nelore.

\begin{tabular}{lcccc}
\hline Covariável quantitativa & Valor mínimo & Valor máximo & Média & Variância \\
\hline peso ao nascer & 15 & 46 & 30,3 & 12,1 \\
peso na desmama & 100 & 289 & 176,5 & 561,4 \\
peso no sobreano & 170 & 470 & 272,6 & 1879,9 \\
\hline
\end{tabular}

A partir da Tabela 2, observa-se que os 64 touros geraram diferentes números de descendentes, variando de 3 a 460. Dos 6602 animais sob estudo, podese ainda notar, pela Tabela 3, que em torno de $35 \%$ eram machos e a reprodução natural foi mais usual do que a artificial, $74 \%$ e $26 \%$, respectivamente.

Os números de descendentes por grupo de manejo na desmama e no sobreano são apresentados nos Anexos A e B, respectivamente. Em torno de 80\% dos descendentes foram gerados por vacas distintas e foram considerados somente 
Tabela 2. Distribuição de freqüências do número de descendentes de 64 touros da raça Nelore.

\begin{tabular}{|c|c|c|c|c|c|c|c|c|c|c|c|c|}
\hline Número de descendentes & 3 & 4 & 6 & 7 & 11 & 13 & 16 & 22 & 27 & 31 & 32 & 36 \\
\hline Número de touros & 1 & 2 & 1 & 1 & 1 & 3 & 1 & 1 & 2 & 3 & 1 & 2 \\
\hline Número de descendentes & 37 & 39 & 43 & 47 & 48 & 49 & 56 & 57 & 61 & 62 & 65 & 70 \\
\hline Número de touros & 1 & 2 & 1 & 2 & 1 & 1 & 1 & 1 & 2 & 1 & 1 & 1 \\
\hline Número de descendentes & 71 & 74 & 78 & 79 & 95 & 99 & 127 & 135 & 136 & 137 & 142 & 153 \\
\hline Número de touros & 1 & 1 & 1 & 1 & 1 & 1 & 1 & 1 & 1 & 1 & 1 & 1 \\
\hline Número de descendentes & 159 & 162 & 165 & 169 & 174 & 179 & 194 & 200 & 208 & 211 & 220 & 235 \\
\hline Número de touros & 1 & 1 & 1 & 1 & 1 & 1 & 1 & 1 & 1 & 1 & 1 & 1 \\
\hline Número de descendentes & 251 & 252 & 260 & 296 & 337 & 460 & & & & & & \\
\hline Número de touros & 1 & 1 & 1 & 1 & 1 & 1 & & & & & & \\
\hline
\end{tabular}

aqueles nascidos na primavera uma vez que, encontra-se disponível uma quantidade muito pequena daqueles nascidos em outras estações do ano.

Tabela 3. Características dos fatores qualitativos observados nos descendentes de 64 touros da raça Nelore.

\begin{tabular}{lcc}
\hline \multicolumn{1}{c}{ Covariáveis } & \multicolumn{3}{c}{ Freqüências } \\
\hline reprodução & natural $=4884$ & artificial $=1718$ \\
sexo & fêmeas $=4305$ & machos $=2297$ \\
status & falha $=1789$ & censura $=4813$ \\
\hline \multicolumn{1}{c}{ Grupos de manejo } & Número de grupos \\
\hline na desmama & \multicolumn{2}{c}{102} \\
no sobreano & \multicolumn{3}{c}{38} \\
\hline
\end{tabular}

Na desmama, foi observado que em torno de $30 \%$ dos descendentes tiveram ganho de peso igual ou superior a $160 \mathrm{~kg}$, indicando que os $160 \mathrm{~kg}$ foram atingidos até aquela data. Além disso, nenhum descendente atingiu o peso desejado antes de 120 dias. Por outro lado, 70\% dos descendentes não ganharam 160kg até a desmama e, portanto, tudo o que se sabe a respeito desses animais é que eles 
alcançaram tal ganho de peso em algum tempo após aquela data e, supôs-se, no máximo 500 dias após o nascimento. Isso significa, portanto, que os tempos exatos, $\mathrm{T}_{i}(i=1, \ldots, n)$, dos $n$ descendentes são desconhecidos. Sabe-se, contudo, que tais tempos $\mathrm{T}_{i}$ ocorreram em intervalos de tempo denotados por $\left[\mathrm{L}_{i}, \mathrm{U}_{i}\right]$ em que $\mathrm{L}_{i} \leq \mathrm{T}_{i} \leq \mathrm{U}_{i}$. Para o descendente que ganhou pelo menos $160 \mathrm{~kg}$ até a desmama, foi assumido que o mesmo atingiu os $160 \mathrm{~kg}$ no intervalo [120 dias, $\mathrm{U}_{i}$ ] em que, neste caso, $\mathrm{U}_{i}=$ tempo em dias, do animal $i$, observado desde o nascimento até a desmama. Caso contrário, o intervalo assumido foi $\left[\mathrm{U}_{i}, 500\right.$ dias]. Para cada descendente, foi utilizada uma variável indicadora, denominada status, tal que status $=1$ se um ganho de peso igual ou superior a $160 \mathrm{~kg}$ foi observado e status $=0$, em caso contrário.

Os resultados obtidos no ajuste do modelo de fragilidade gama com censura intervalar, descrito na seção 3.2.1, são apresentados a seguir.

\subsubsection{Resultados do modelo de fragilidade gama com censura intervalar}

Para ilustrar o modelo de sobrevivência com fragilidade gama e censura intervalar definido em (15), foram considerados a covariável sexo e o efeito aleatório de touro de modo que, o modelo para o animal $i$ gerado pelo touro $j$ ficou representado por:

$$
S\left(t \mid \mathbf{x}_{i j}, z_{j}\right)=\exp \left\{-z_{j} \exp \left\{\alpha+\beta_{1} \operatorname{sex}_{\{i j\}}\right\} t^{\gamma}\right\}
$$

O programa escrito no pacote WinBUGS (Spiegelhalter et al., 2000) para realizar a análise dos dados, usando o modelo (23), bem como seu respectivo fluxograma encontram-se apresentados no Anexo F.

Um resumo das distribuições a posteriori dos parâmetros e de alguns $z_{j}$ 's, baseado no método MCMC, é apresentado na Tabela 4, enquanto que, na Figura 1 e Anexo D, podem-se observar as médias a posteriori de todos os $z_{j}$, $j=1, \ldots, 64$, bem como seus intervalos de credibilidade. 
Tabela 4. Estatísticas resumo das distribuições a posteriori dos parâmetros do modelo de fragilidade gama com censura intervalar e de alguns $z_{j}$ 's - bovinos Nelore.

\begin{tabular}{cccccc}
\hline Parâmetros & Média & Desvio & Mediana & Intervalos de Credibilidade \\
\cline { 5 - 6 } e $z_{j}{ }^{\prime} \mathrm{s}$ & a posteriori & padrão $(\mathrm{DP})$ & a posteriori & $2,5 \%$ & $97,5 \%$ \\
\hline$\alpha$ & $-17,81$ & 0,6952 & $-17,83$ & $-19,12$ & $-16,45$ \\
$\gamma$ & 3,644 & 0,1511 & 3,646 & 3,340 & 3,933 \\
$\beta_{1}$ & 1,998 & 0,0588 & 1,998 & 1,883 & 2,114 \\
$\xi_{f}$ & 0,398 & 0,0854 & 0,389 & 0,259 & 0,592 \\
$1 / \xi_{f}$ & 2,620 & 0,5539 & 2,570 & 1,688 & 3,849 \\
$\mathrm{z}_{24}$ & 3,284 & 0,3769 & 3,264 & 2,603 & 4,081 \\
$\mathrm{z}_{34}$ & 0,233 & 0,0476 & 0,229 & 0,152 & 0,337 \\
$\mathrm{z}_{36}$ & 1,818 & 0,2872 & 1,798 & 1,310 & 2,431 \\
$\mathrm{z}_{37}$ & 2,490 & 0,5655 & 2,436 & 1,541 & 3,741 \\
$\mathrm{z}_{41}$ & 0,264 & 0,1215 & 0,243 & 0,093 & 0,558 \\
$\mathrm{z}_{52}$ & 1,715 & 0,2348 & 1,700 & 1,297 & 2,220 \\
$\mathrm{z}_{56}$ & 2,923 & 0,7389 & 2,846 & 1,707 & 4,577 \\
$\mathrm{z}_{60}$ & 1,937 & 0,4193 & 1,898 & 1,231 & 2,872 \\
$\mathrm{z}_{62}$ & 2,508 & 0,5295 & 2,460 & 1,613 & 3,676 \\
$\mathrm{z}_{64}$ & 2,200 & 0,5514 & 2,147 & 1,284 & 3,427 \\
\hline
\end{tabular}

Pela Tabela 4 pode-se observar, pela média a posteriori de $\beta_{1}$ e correspondente intervalo de credibilidade, que não contém o valor zero, evidências de efeito do sexo na variável resposta. O fato de a média a posteriori de $\beta_{1}$ ser positiva e estar associada aos machos, indica que estes ganharam peso mais rapidamente do que as fêmeas. A variância genética $\xi_{f}$ também apresentou-se significativa e, como sua média a posteriori foi $\xi_{f}=0,398$ ( $\left.\mathrm{DP}=0,0854\right)$, obteve-se o intervalo de credibilidade a $90 \%$ para a distribuição $\Gamma\left(1 / \xi_{f}, 1 / \xi_{f}\right)=\Gamma(1 / 0,398 ; 1 / 0,398)$ de $(0,32 ; 1,81)$. Isso significa que alguns touros são capazes de gerar animais com taxa 
de crescimento quase 6 vezes $(1,81 \approx 6 \times 0,32)$ maior do que a taxa de outros touros.

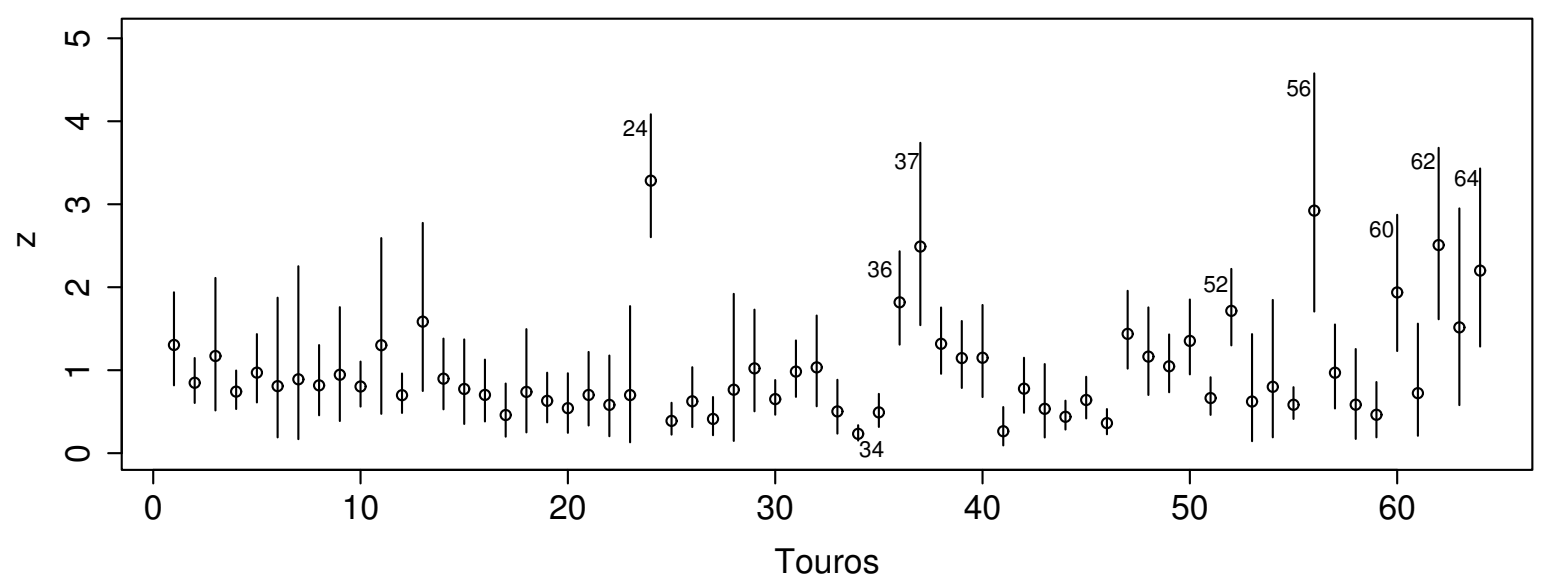

Figura 1 - Médias e intervalos de credibilidade a posteriori dos $z_{j}$ 's associados aos 64 touros Nelore.

Pela análise das médias a posteriori dos $z_{j}, j=1, \ldots, 64$, mostradas na Figura 1, podem-se selecionar os touros geneticamente superiores em termos dos seus descendentes. Como uma ferramenta auxiliar nesse processo de seleção, podem-se, também, utilizar as distribuições a posteriori das classificações atribuídas aos touros. Essas distribuições encontram-se apresentadas, para alguns touros, na Figura 2 e mostram a incerteza associada à classificação de cada um deles. Como valores grandes de $z$ estão associados a classificações de ordem alta, podem-se notar, pela Figura 2, alguns touros superiores tais como, por exemplo, os touros 24, 36, 37, 52, 56, 60, 62 e 64. Das distribuições a posteriori das classificações nota-se uma probabilidade grande de esses touros terem classificações de ordem alta. Por outro lado, os touros 34 e 41 apresentaram probabilidade grande de terem classificações de ordem baixa o que, conseqüentemente, significa pequeno valor de $z$. Para esses touros, desempenho pobre é esperado dos seus descendentes, no sentido que irão levar mais tempo para ganhar 160kg. Alguns touros tais como, por exemplo, os touros 13, 38, 47, 50 e 63, apresentaram desempenho mediano.

A título de ilustração, dois touros foram comparados, dentre os 64 analisados, de modo que um deles tivesse um grande valor de $z$ e o outro um pequeno 

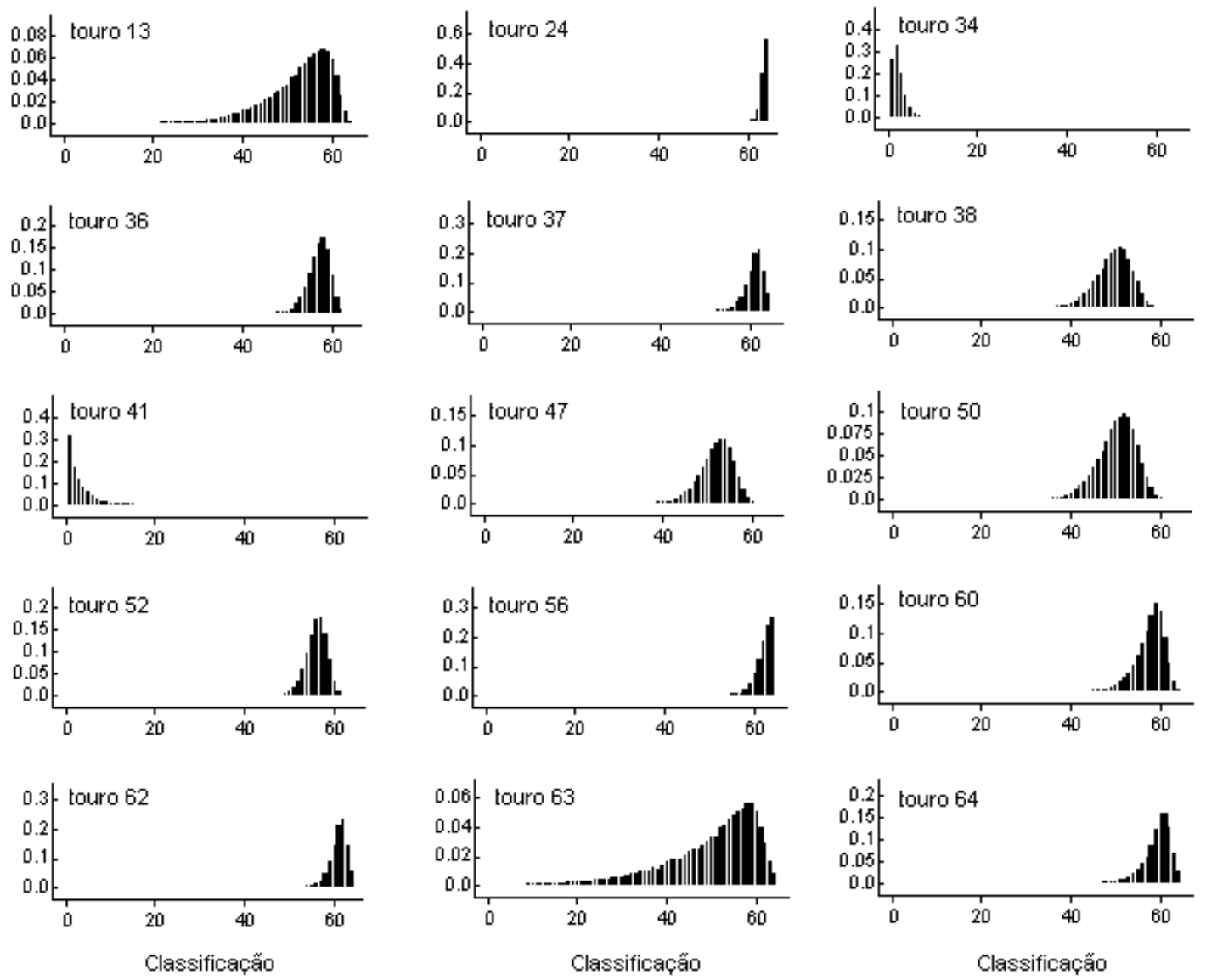

Figura 2 - Distribuições a posteriori das classificações de uma amostra de 16 touros Nelore.

valor de z. Escolheram-se, para essa comparação, os touros $24\left(z_{24}=3,288\right)$ e 34 $\left(z_{34}=0,233\right)$. As curvas de sobrevivência a posteriori, obtidas de (23), encontram-se apresentadas na Figura 3, e mostram que os descendentes do touro 24 ganharam peso mais rapidamente do que aqueles do touro 34. Note que no tempo $t=220$ dias (linha vertical em ambos os gráficos da Figura 3) praticamente todos os descendentes do touro 24 já haviam atingido o peso desejado, enquanto que, muitos dos descendentes do touro 34 permaneciam com ganho de peso inferior ao desejado. Portanto, touros com valores de $z$ grandes são desejáveis uma vez que quando $z$ cresce as curvas de sobrevivência a posteriori dos seus descendentes decrescem mais rapidamente significando que o ganho desejado de peso dos seus descendentes são 
atingidos mais rapidamente. Os descendentes do touro 24 apresentaram, portanto, melhor desempenho do que os do touro 34. A Figura 3 mostra, também, que os machos ganharam peso mais rapidamente do que as fêmeas.
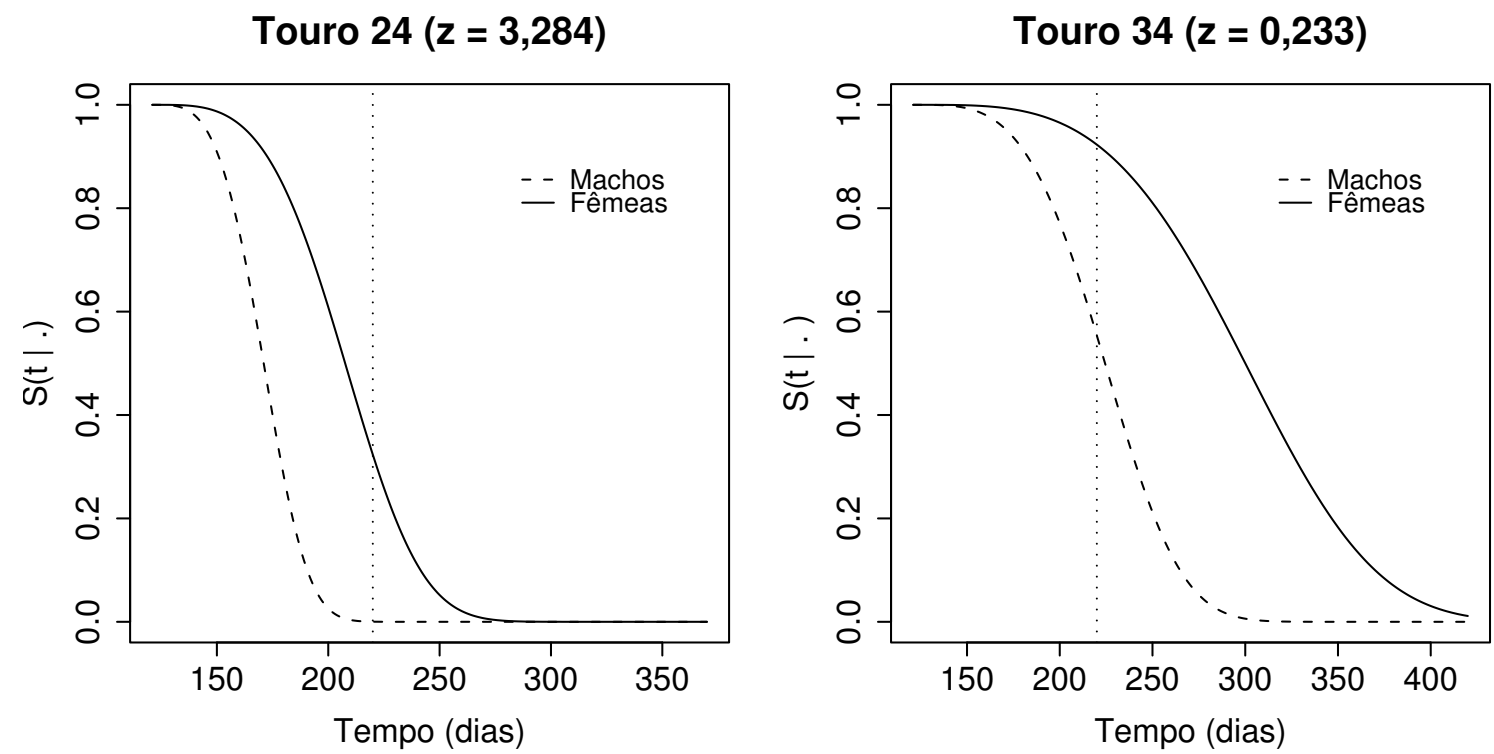

Figura 3 - Curvas de sobrevivência a posteriori para os descendentes machos e fêmeas dos touros Nelore 24 e 34.

\subsubsection{Resultados do estudo de simulação}

Os resultados do estudo de simulação, descrito na seção 3.2.2, realizado para avaliar o impacto nas estimativas dos parâmetros quando o efeito aleatório é ignorado no modelo de fragilidade gama com censura intervalar, são apresentados a seguir.

Na Figura 4 estão apresentados os gráficos de caixas ("boxplots") para as estimativas do parâmetro $\beta_{1}$ associado à covariável. Verifica-se que as estimativas do parâmetro $\beta_{1}$ ficam mais próximas do valor 7,0 usado na simulação quando se considera o efeito aleatório no modelo, e fica subestimado em caso contrário. Observa-se, também, que o vício na estimação torna-se menos acentuado à medida 
que a variância genética $\xi$ decresce. Para os demais parâmetros tal fato não foi observado, obtendo-se estimativas muito semelhantes na presença, ou não, do efeito aleatório.
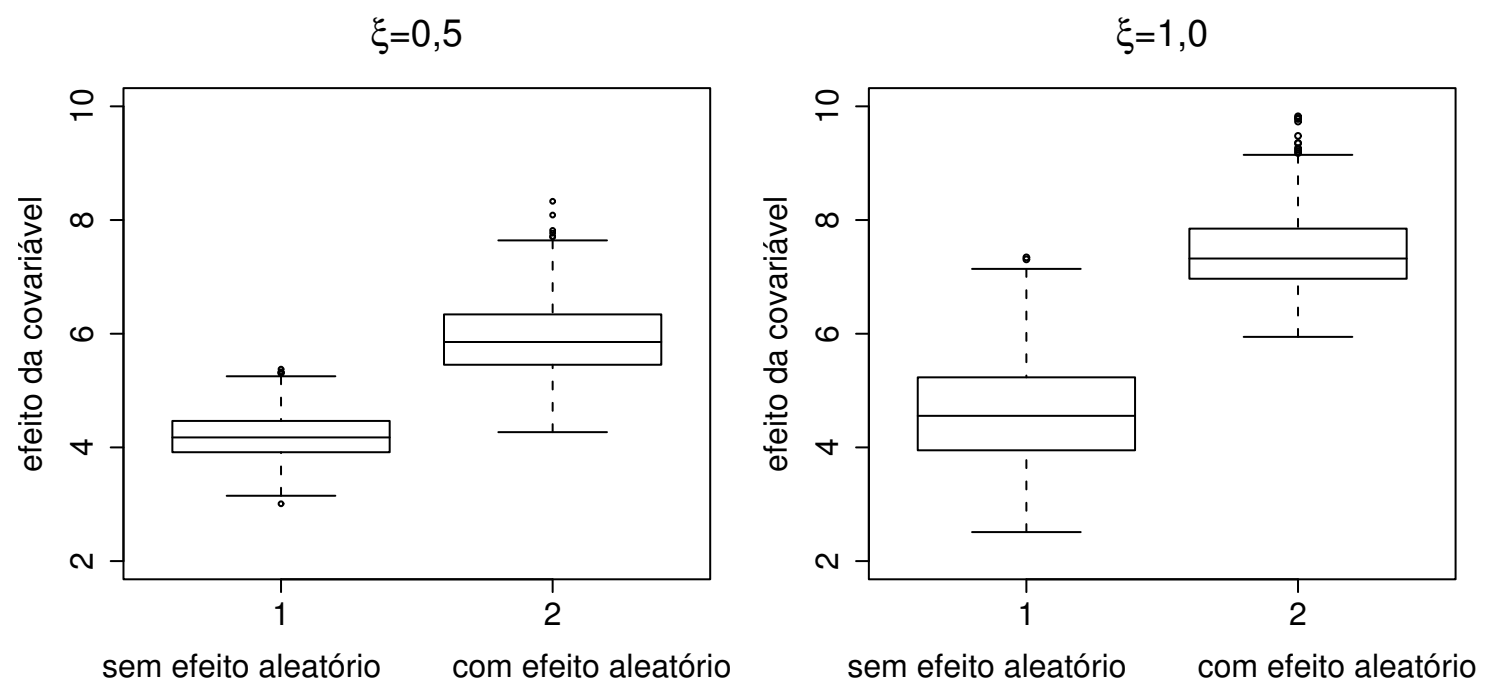

Figura 4 - Gráficos de caixas das estimativas do parâmetro $\beta_{1}$ obtidas em 500 simulações considerando-se o modelo de fragilidade gama com censura intervalar sem, e com, efeito aleatório.

Diversos autores, dentre eles, Gail et al. (1984), Lagakos \& Shoenfeld (1984), Struthers \& Kalbfleish (1986), Bretagnolle \& Huber-Carol (1988), Neuhaus et al. (1992) e Henderson \& Oman (1999) discutiram a incorporação do efeito aleatório em modelos de sobrevivência com dados sem censura intervalar e o seu efeito na estimação dos efeitos das covariáveis. Eles mostraram que ignorar o efeito aleatório pode ocasionar vícios nos efeitos das covariáveis. Dados com censura intervalar não foram considerados por esses autores. Contudo, com os resultados obtidos nessa seção, têm-se evidências de que as conclusões são similares.

\subsubsection{Resultados do modelo de curvas de crescimento com efeitos aleatórios}

Na Tabela 5 são apresentadas estatísticas descritivas para os pesos dos animais registrados em três idades. Os valores da variável peso ao nascer variaram 
de 15 a 46kg com uma média de 30,3kg ( $\mathrm{DP}=3,47)$. O peso médio na desmama foi de 176,5 (DP $=23,69)$, sendo 100 e 289kg os valores mínimo e máximo observados, respectivamente. Para o peso observado no sobreano obteve-se um valor mínimo de $170 \mathrm{~kg}$ e um máximo de $470 \mathrm{~kg}$ com peso médio de $272,6 \mathrm{~kg}(\mathrm{DP}=43,35)$. Pode-se observar, ainda, que a variância dos pesos cresce à medida que o tempo aumenta. A variabilidade dos pesos ao nascer é comparativamente muito menor do que a observada no desmame. Os pesos apresentaram distribuições de freqüência simétricas e é, portanto, razoável a suposição de que eles tenham distribuição Normal.

Tabela 5. Estatísticas resumo para os pesos observados nos descendentes de 64 touros da raça Nelore.

\begin{tabular}{lcrrrrr}
\hline \multicolumn{1}{c}{ Peso } & № de descendentes & Média & DP & Mínimo & Máximo & Mediana \\
\hline ao nascer & 6602 & 30,3 & 3,47 & 15 & 46 & 30 \\
na desmama & 6602 & 176,5 & 23,69 & 100 & 289 & 175 \\
no sobreano & 6602 & 272,6 & 43,35 & 170 & 470 & 266 \\
\hline
\end{tabular}

Na Tabela 6 são apresentadas as médias a posteriori, obtidas pelo método MCMC, dos parâmetros $b, k, \beta_{1}$ (coeficiente associado ao efeito fixo sexo) e das variâncias $\sigma_{a}^{2}, \sigma_{f}^{2}$ e $\sigma_{e}^{2}$. Foi observada uma grande contribuição para os pesos $W(t)$, em relação à variância total, do efeito genético paterno bem como do efeito de animal, em torno de $45 \%$ e $39 \%$, respectivamente. A média a posteriori do efeito do sexo, $\beta_{1}$, mostrou que machos ganharam peso mais rapidamente do que as fêmeas.

Tabela 6. Parâmetros e desvios padrões a posteriori obtidos pelo método MCMC.

\begin{tabular}{cccccc}
\hline$b$ & $k$ & $\beta_{1}$ & $\sigma_{a}^{2}$ & $\sigma_{f}^{2}$ & $\sigma_{e}^{2}$ \\
\hline $7,7(0,043)$ & $0,0135(3,3 \mathrm{e}-5)$ & $49,21(0,637)$ & $432,4(9,82)$ & $492,5(93,53)$ & $166,0(2,05)$ \\
\hline
\end{tabular}

Na Figura 5 e Anexo E, podem-se observar as médias e intervalos de credibilidade a posteriori $\operatorname{dos} f_{j}$ associados aos 64 touros Nelore. Como o efeito 
genético paterno foi aditivamente incorporado ao modelo, valores grandes e positivos de $f_{j}(j=1, \ldots, 64)$ são desejáveis. Vê-se, ainda, claramente que alguns touros têm performances superiores tais como, por exemplo, os touros 24, 56, 60, 62 e 64 .

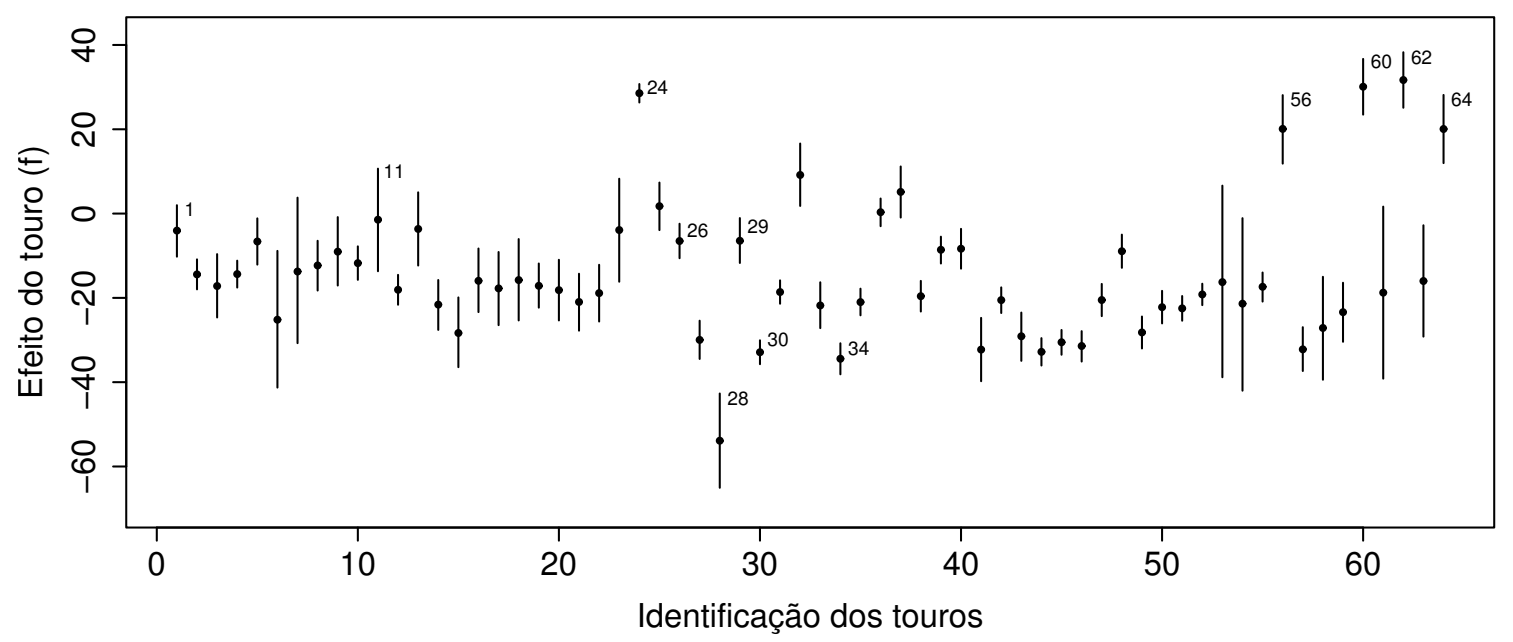

Figura 5 - Médias e intervalos de credibilidade a posteriori dos $f_{j}$ 's associados aos 64 touros Nelore.

A partir das distribuições a posteriori das classificações dos touros, apresentadas na Figura 6, observam-se probabilidades grandes de esses touros serem classificados em posições de ordem alta. O oposto pode ser verificado, por exemplo, para os touros 28, 30 e 34 em que probabilidades grandes estão associadas a classificações de ordem baixa. Para esses touros desempenho pobre é esperado dos animais gerados por eles no sentido de que irão demorar mais tempo para ganhar peso. Alguns touros tais como, por exemplo, os touros 1, 11, 26 e 29, apresentaram probabilidade grande de serem classificados em posições intermediárias de modo que desempenho mediano é esperado dos animais gerados por eles.

Para ilustrar, foram escolhidos dois touros, dentre os 64 analisados, de modo que um deles tenha um grande valor de $f$ e o outro um pequeno valor de $f$. Os touros escolhidos foram o $24\left(f_{24}=28,55\right)$ e o $34\left(f_{34}=-34,44\right)$. Para esses touros, e 

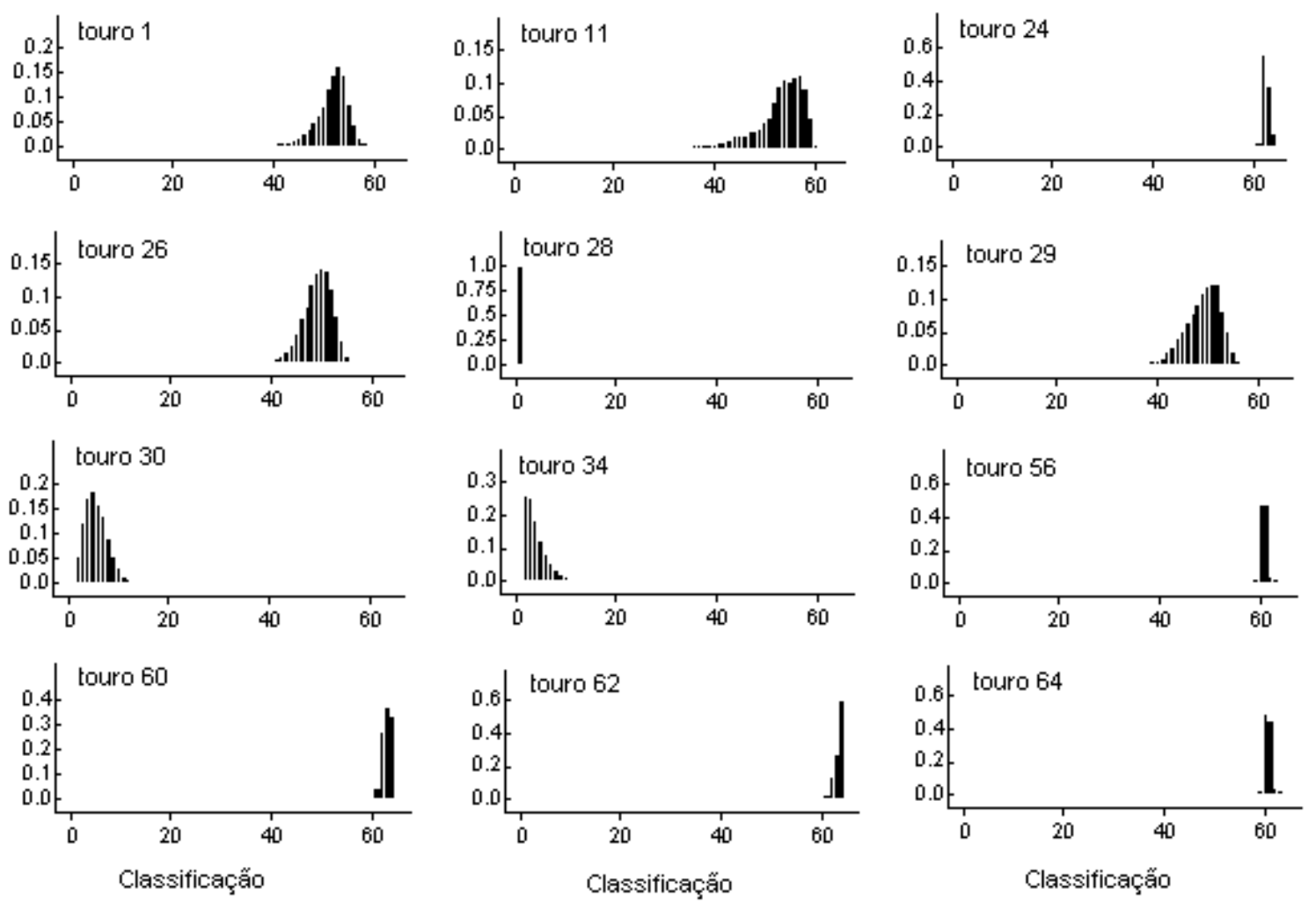

Figura 6 - Distribuições a posteriori das classificações de uma amostra de 12 touros Nelore.

substituindo-se em $(22)$ os valores a posteriori de $A_{i}(i=1, \ldots, 6602)$, foram obtidos os tempos $T_{i}$ para os animais atingirem 190kg. Dos resultados apresentados na Tabela 7 observa-se que os animais descendentes do touro 24 atingiram 190kg mais rapidamente do que os descendentes do touro 34. Os animais machos gerados pelo touro 24 necessitaram um tempo médio de 158,7 dias $(\mathrm{DP}=7,35)$ para alcançarem $190 \mathrm{~kg}$, enquanto que, aqueles gerados pelo touro 34, necessitaram de, em média, 207,6 dias $(\mathrm{DP}=14,4)$. As fêmeas demoraram mais tempo para atingir os $190 \mathrm{~kg}$, sendo observado um tempo médio de 198,5 dias $(\mathrm{DP}=15,22)$ para aquelas geradas pelo touro 24 e 248,7 dias $(\mathrm{DP}=40,60)$ para aquelas descendentes do touro 34 . Não mais do que 186 dias para os machos e 253 dias para as fêmeas foram necessários para que os animais gerados pelo touro 24 atingissem 190kg. Para o touro 34, esses valores foram de 268 e 533 dias, respectivamente. Portanto, animais descendentes 
do touro 24 apresentaram melhor desempenho do que os do touro 34 no sentido de que ganharam peso mais rapidamente.

Tabela 7. Estatísticas resumo para os tempos, em dias, até os descendentes dos touros 24 e 34 da raça Nelore alcançarem 190kg.

\begin{tabular}{cccccc}
\hline Touro & № de descendentes por sexo & Tempo médio & DP & Mínimo & Máximo \\
\hline \multirow{2}{*}{24} & Machos $=196$ & 158,7 & 7,35 & 137,5 & 185,2 \\
& Fêmeas $=264$ & 198,5 & 15,22 & 163,8 & 252,2 \\
\multirow{2}{*}{34} & Machos $=82$ & 207,6 & 14,40 & 170,9 & 267,8 \\
& Fêmeas $=77$ & 248,7 & 40,60 & 202,3 & 532,3 \\
\hline
\end{tabular}

Foram selecionados também, para cada um desses dois touros, três descendentes machos. Suas curvas de crescimento a posteriori encontram-se apresentadas na Figura 7. Dessa figura, observa-se que as taxas de crescimento dos animais gerados pelo touro 24 são maiores do que as dos animais gerados pelo touro 34 evidenciando, assim, a superioridade, no sentido de ganho de peso mais rápido, dos animais descendentes do touro 24 .
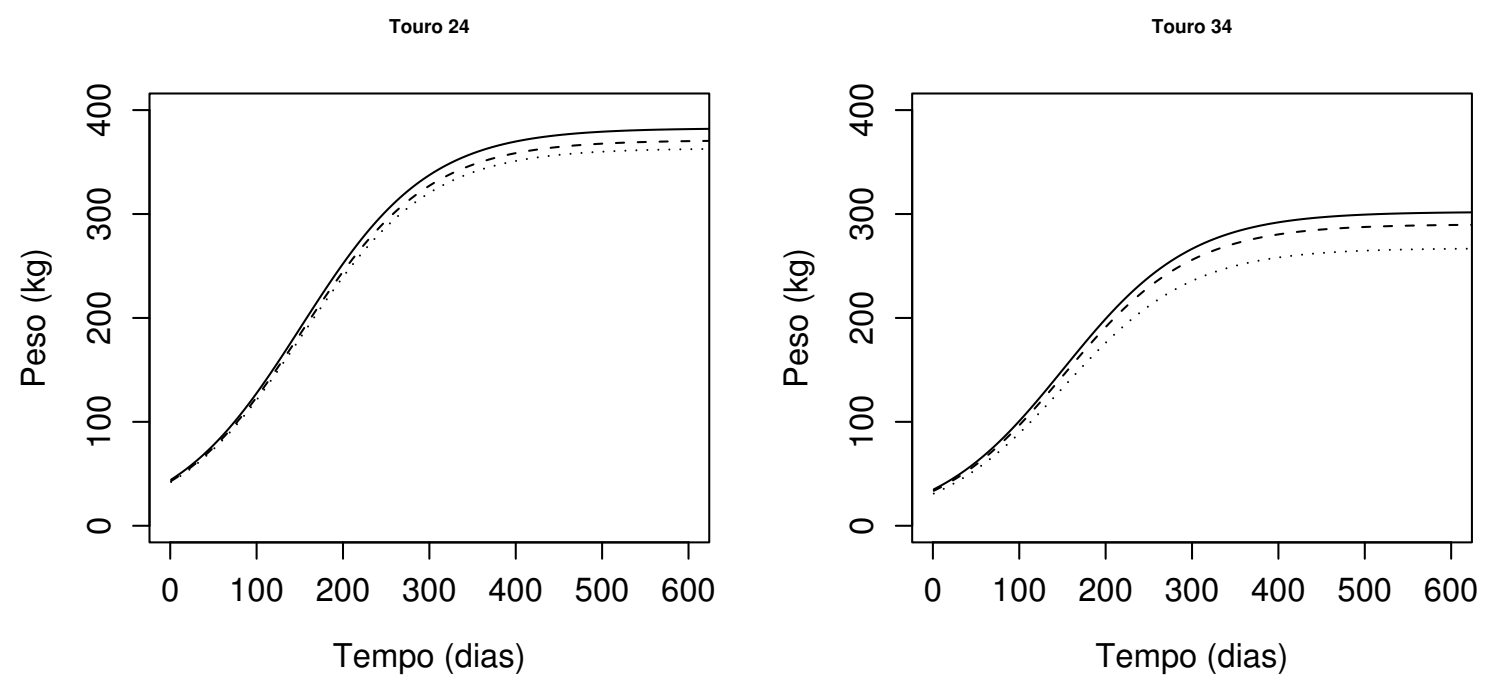

Figura 7 - Curvas de crescimento a posteriori para três descendentes machos dos touros Nelore 24 e 34 . 
Pode-se observar, pelos resultados apresentados até aqui, que praticamente todos os touros que se destacaram como os melhores quando o modelo de fragilidade gama com censura intervalar foi usado, também se destacaram quando da utilização do modelo de curvas de crescimento com efeitos aleatórios. Esse fato, motivou, então, a realização de um estudo para a comparação de ambos os modelos usados como critérios de seleção, apresentado em 4.3.

\subsection{Estudo realizado com bovinos Canchim}

Dos 4509 animais da raça Canchim observados nesse estudo, gerados por 241 touros e 1687 vacas e nascidos entre os anos de 1959 e 1999, tem-se que 53,47\% eram fêmeas e, conseqüentemente, 46,53\% machos. O número de descendentes por touro variou de 2 a 93. Dentre os 241 touros, 88 tiveram no máximo 10 descendentes. O número de partos por vaca variou de 1 a 10, tendo, a idade das mesmas nos partos, variado de 756 a 6674 dias. Para apenas 59 delas houve registros de mais do que 6 partos como pode ser observado na Tabela 8.

Tabela 8. Distribuição de freqüências do número de descendentes de 1687 vacas Canchim.

\begin{tabular}{lcccccccccc}
\hline Número de descendentes & 1 & 2 & 3 & 4 & 5 & 6 & 7 & 8 & 9 & 10 \\
\hline Número de vacas & 567 & 377 & 276 & 193 & 145 & 70 & 37 & 15 & 6 & 1 \\
\hline
\end{tabular}

No período do nascimento até a desmama, 1583 animais $(35,1 \%)$ atingiram um ganho de peso de $175 \mathrm{~kg}$ sendo 894 machos e 689 fêmeas. Pela Tabela 9 pode-se observar a distribuição de freqüências do número de nascimentos por mês e estação do ano. Nota-se que cerca de $82 \%$ dos animais nasceram no inverno ou primavera, $5,4 \%$ no verão e $12,85 \%$ no outono.

Observa-se, ainda, pela Tabela 10, que os pesos ao nascer dos animais variaram de 20 a $60 \mathrm{~kg}$ com uma média de $35,4 \mathrm{~kg}(\mathrm{DP}=5,6)$. O peso médio na desmama foi de $196,5 \mathrm{~kg}(\mathrm{DP}=38,7)$, sendo 90 e $342 \mathrm{~kg}$ os valores mínimo e máximo 
observados. Foi também observada uma grande variabilidade da idade na desmama dos animais, sendo alguns desmamados aos 98 dias e, outros, aos 355 dias após o nascimento. O desmame de cerca de $91 \%$ dos animais ocorreu em idades variando de 180 a 280 dias.

Tabela 9. Distribuição de freqüências do número de nascimentos por mês e estação do ano dos descendentes de 1687 vacas e 241 touros Canchim.

\begin{tabular}{lcccccccccccc}
\hline \multicolumn{3}{c}{ Verão } & \multicolumn{3}{c}{ Outono } & \multicolumn{4}{c}{ Inverno } & \multicolumn{3}{c}{ Primavera } \\
dez & jan & fev & mar & abr & mai & jun & jul & ago & set & out & nov \\
\hline 100 & - & 144 & 176 & 129 & 274 & 712 & 735 & 707 & 703 & 570 & 259 \\
\hline
\end{tabular}

Tabela 10. Estatísticas resumo dos pesos e idades observadas nos descendentes de 241 touros da raça Canchim.

\begin{tabular}{lcccccc}
\hline \multicolumn{1}{c}{ Variável } & Descendentes & Média & DP & Mínimo & Máximo & Mediana \\
\hline peso ao nascer & 4509 & 35,4 & 5,6 & 20 & 60 & 35 \\
peso na desmama & 4509 & 196,5 & 38,7 & 90 & 342 & 197 \\
idade na desmama & 4509 & 233,3 & 30,2 & 98 & 355 & 235 \\
\hline
\end{tabular}

Os resultados do ajuste do modelo de fragilidade gama com censura intervalar apresentado em 3.2.1, considerando-se as covariáveis sexo, estação de nascimento e idade da vaca no parto bem como os efeitos aleatórios de touro e vaca, representando, respectivamente, os efeitos genéticos compartilhados pelos descendentes do mesmo touro e os efeitos genéticos compartilhados pelos descendentes da mesma vaca e expresso por:

$$
S\left(t \mid \mathbf{x}_{i j}, z_{j}, z_{v}\right)=\exp \left\{-\left(z_{j}+z_{v}\right) \exp \left\{\alpha+\boldsymbol{\beta}^{\prime} \mathbf{x}_{i j}\right\} t^{\gamma}\right\}
$$

ou, eqüivalentemente por

$$
\lambda\left(t \mid \mathbf{x}_{i j}, z_{j}, z_{v}\right)=\left(z_{j}+z_{v}\right) \exp \left\{\alpha+\boldsymbol{\beta}^{\prime} \mathbf{x}_{i j}\right\} \gamma t^{\gamma-1}
$$


são apresentados na Tabela 11. Os efeitos aleatórios de touro, $z_{j}, j=1, \ldots, 241$, e de vaca, $z_{v}, v=1, \ldots, 1687$, foram combinados aditivamente e, então, atuam multiplicativamente nas taxas de riscos individuais conforme descrito na seção 2.2.3 sobre modelos de fragilidade aditivos propostos por Petersen (1998).

Tabela 11. Estatísticas resumo das distribuições a posteriori dos parâmetros do modelo de fragilidade gama com censura intervalar - bovinos Canchim.

\begin{tabular}{lcccc}
\hline \multicolumn{5}{c}{ Modelo de fragilidade gama com censura intervalar } \\
& & & \multicolumn{2}{c}{ Intervalos de Credibilidade } \\
\cline { 3 - 4 } Parâmetros & Média a posteriori & Desvio padrão (DP) & $2,5 \%$ & $97,5 \%$ \\
\hline$\alpha:$ constante & $-39,45$ & 1,1880 & $-41,42$ & $-37,07$ \\
$\gamma:$ parâm. de forma - Weibull & 6,658 & 0,2121 & 6,209 & 6,999 \\
$\beta_{1}:$ machos & 0,635 & 0,0584 & 0,521 & 0,751 \\
$\beta_{2}:$ outono & 0,416 & 0,1860 & 0,052 & 0,787 \\
$\beta_{3}:$ inverno & 0,998 & 0,1665 & 0,681 & 1,330 \\
$\beta_{4}:$ primavera & 0,724 & 0,1693 & 0,396 & 1,075 \\
$\beta_{5}:(750,1650]$ dias & 0,316 & 0,1542 & $-0,003$ & 0,608 \\
$\beta_{6}:(1650,2550]$ dias & 0,511 & 0,1454 & 0,203 & 0,784 \\
$\beta_{7}:(2550,3450]$ dias & 0,699 & 0,1497 & 0,391 & 0,988 \\
$\beta_{8}:(3450,4500]$ dias & 0,376 & 0,1549 & 0,064 & 0,670 \\
$\xi_{f}:$ var. genética (touro) & 2,203 & 0,4144 & 1,466 & 3,096 \\
$\xi_{v}:$ var. genética (vaca) & 0,499 & 0,1347 & 0,218 & 0,773 \\
$1 / \xi_{f}$ & 0,470 & 0,0905 & 0,323 & 0,682 \\
$1 / \xi_{v}$ & 2,190 & 0,7752 & 1,294 & 4,572 \\
\hline
\end{tabular}

Pelos resultados apresentados na Tabela 11 pode-se observar pelo intervalo de credibilidade de $\beta_{1}$, que não contém o valor zero, evidências de efeito do sexo na variável resposta. A média a posteriori de $\beta_{1}$, associada aos machos, é positiva e mostra, portanto, que os machos ganharam peso mais rapidamente do que as fêmeas. De modo análogo, podem-se observar evidências de efeito das covariáveis estação de nascimento e idade da vaca no parto. Assim, animais nascidos no inverno e primavera, respectivamente, e gerados por vacas cuja idade no parto encontravam-se entre 2550 e 3450 dias, apresentaram uma maior propensão em ganharem peso mais rapidamente. É importante notar aqui que, dos animais sob estudo, em torno de $82 \%$ deles nasceram no inverno ou primavera (mais acentuadamente entre os meses de 
junho e outubro). Além disso, muitos dos touros sob estudo somente apresentaram descendentes nascidos nesse período o que pode, em um certo sentido, ter favorecido essas duas estações do ano na análise estatística aqui apresentada. Por outro lado, as vacas recebem, em geral, uma suplementação alimentar durante o inverno devido às condições de pastagens não muito favoráveis nessa época do ano o que conseqüentemente enriquece a amamentação e pode, portanto, justificar um ganho de peso mais acentuado dos animais nascidos nesse período.

Pela Tabela 11 observa-se, ainda, que a variância genética devida aos touros foi de $\xi_{f}=2,203(\mathrm{DP}=0,4144)$ o que, considerando-se a distribuição $\Gamma\left(1 / \xi_{f}, 1 / \xi_{f}\right)=\Gamma(1 / 2,203 ; 1 / 2,203)$, produz um intervalo de credibilidade a $90 \%$ de $(0,011 ; 2,758)$. Isso significa que os valores de $z_{j}$ podem variar significativamente entre os touros e, portanto, descendentes de touros com valores de $z$ grandes irão ganhar peso mais rapidamente do que os descendentes dos touros com valores de $z$ pequenos. Para as vacas, a variância genética foi de $0,499(\mathrm{DP}=0,1347)$ e o correspondente intervalo de credibilidade a $90 \%$ para a distribuição $\Gamma(1 / 0,499 ; 1 / 0,499)$ de $(0,26 ; 1,94)$. Assim, há evidências da ocorrência de valores de $z_{v}$ diferentes entre as vacas significando, portanto, que algumas delas serão capazes de gerar descendentes com taxa de crescimento cerca de 8 vezes maior $(1,94 \approx 8 \times 0,26)$ do que as de outras vacas.

Na Figura 8 observam-se as médias a posteriori $\operatorname{dos} z_{j}, j=1, \ldots, 241$, e respectivos intervalos de credibilidade. Médias a posteriori grandes de $z$ com intervalos de credibilidade estreitos são desejáveis e sendo assim, alguns touros se destacaram dos demais. Na Figura 9 são apresentadas as distribuições a posteriori das classificações de uma amostra de 12 touros, incluindo os quatro que se destacaram pela Figura 8. Verifica-se que:

- os touros 9, 208, 221 e 234 apresentaram médias a posteriori de $z$ maiores do que 5 e probabilidade grande de serem classificados em posições de ordem alta;

- os touros 14, 22, 28 e 60 apresentaram probabilidade grande de serem classifi- 
cados em posições intermediárias, o que significa que seus descendentes terão um desempenho mediano em termos de ganho de peso;

- os touros 87, 123, 129 e 146 apresentaram probabilidade grande de serem classificados em posições de ordem baixa e, portanto, desempenho pobre é esperado dos descendentes desses touros, no sentido que irão levar mais tempo para ganhar $175 \mathrm{~kg}$.

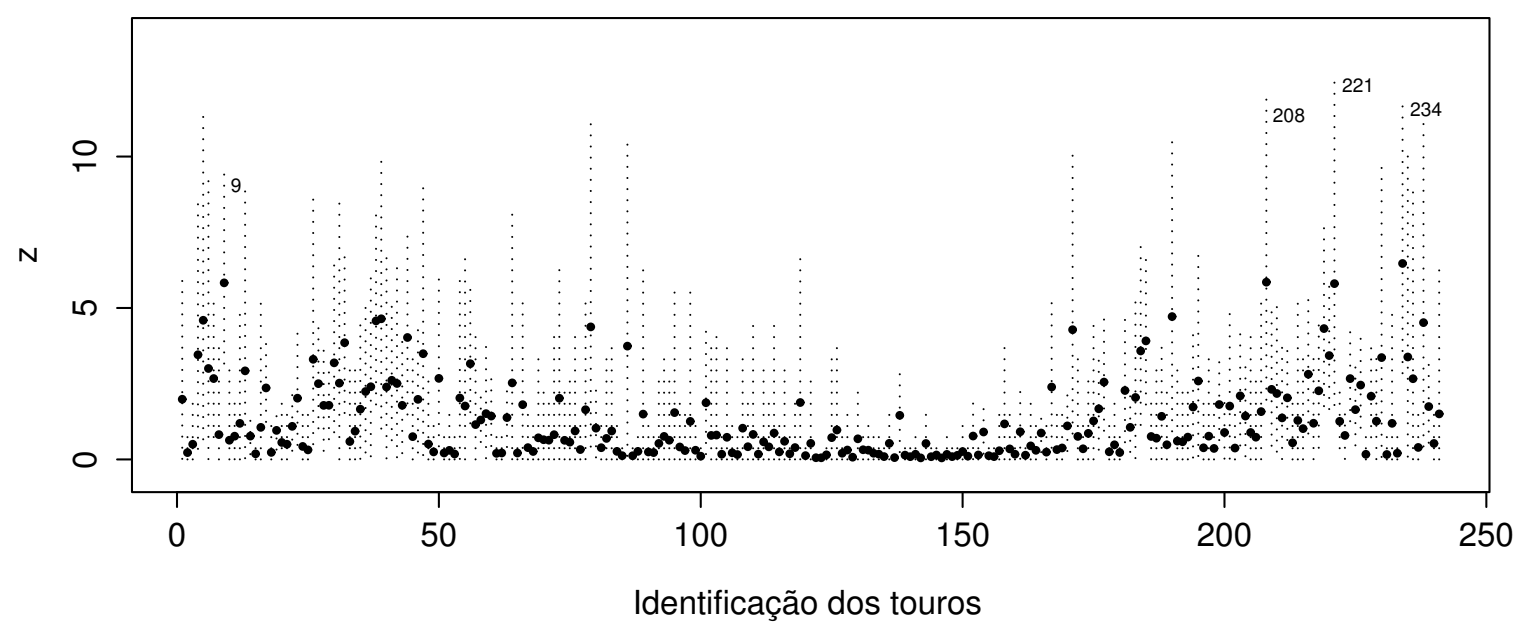

Figura 8 - Médias e intervalos de credibilidade a posteriori dos $z_{j}$ 's associados aos 241 touros Canchim.

Para ilustrar o uso do modelo ajustado, as curvas de sobrevivência a posteriori para descendentes machos e fêmeas nas 4 estações do ano são apresentadas na Figura 10. Para as curvas apresentadas foram considerados os descendentes do touro $234\left(z_{234}=6,47\right)$ e da vaca $1504\left(z_{1504}=1,216\right)$, cuja idade em um dos 3 partos registrados nesse estudo encontrava-se entre 2550 e 3450 dias. A partir dessa figura, pode-se observar que os machos atingiram um ganho de peso de $175 \mathrm{~kg}$ em torno de 250 dias (quando as curvas atingem valores muito próximos a zero) e as fêmeas em torno de 300 dias. Pode-se ainda observar, para ambos os sexos, que tais curvas decrescem mais rapidamente no inverno e primavera o que significa que os animais analisados nesse estudo e nascidos nessas estações ganharam peso mais rapidamente do que os nascidos nas outras duas estações (outono e verão). 

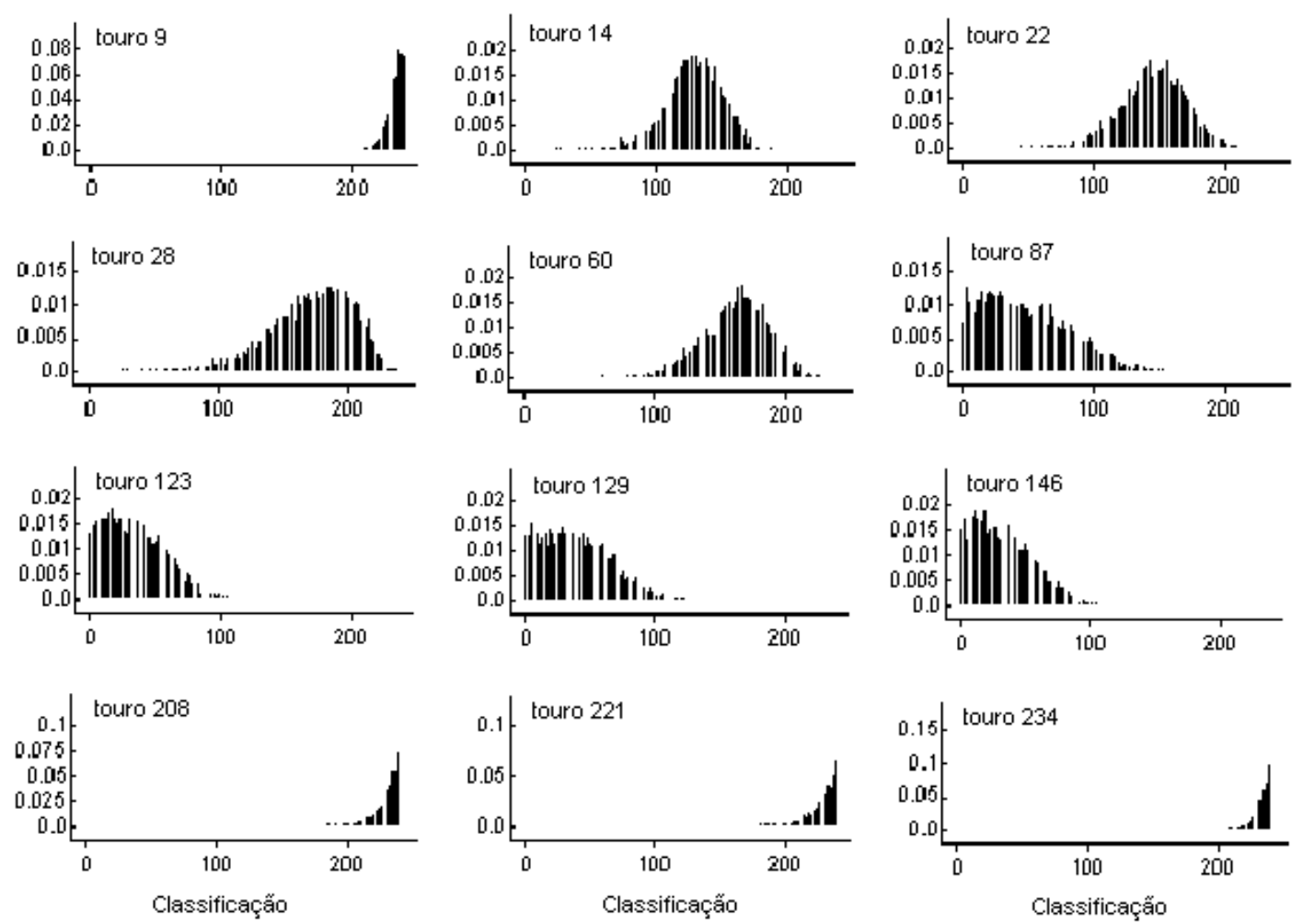

Figura 9 - Distribuições a posteriori das classificações de 12 touros Canchim.
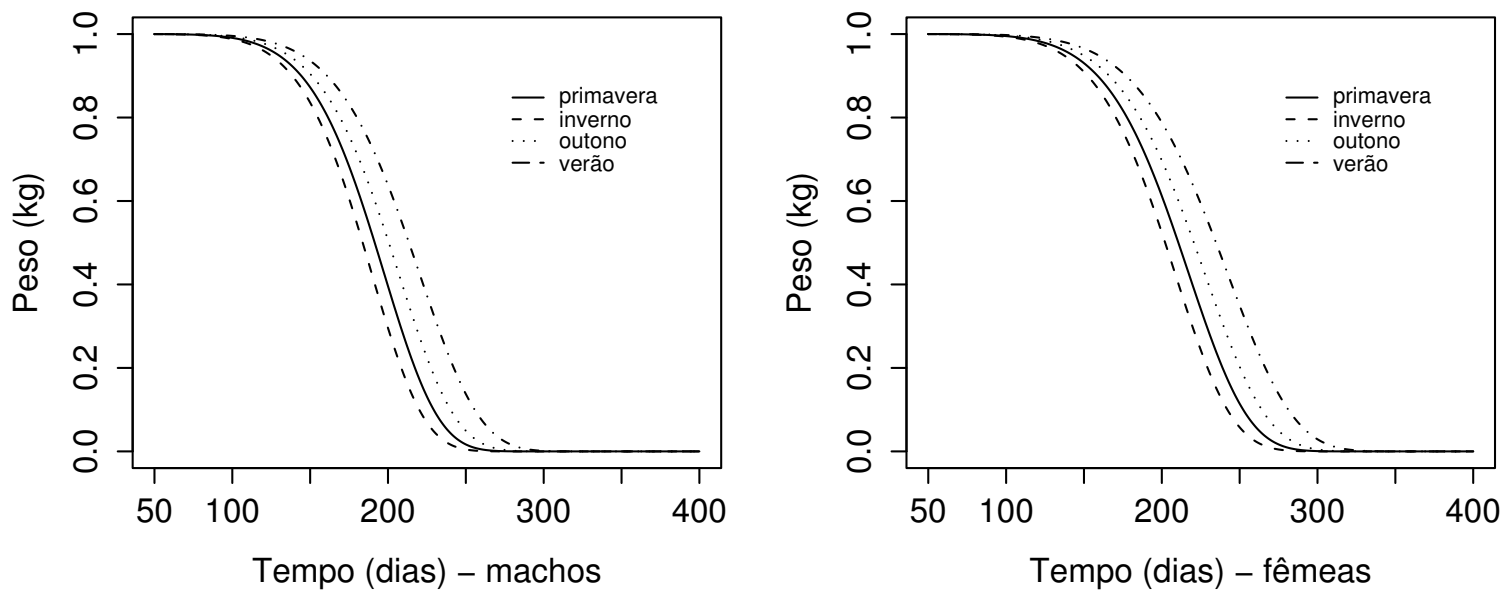

Figura 10 - Curvas de sobrevivência a posteriori dos descendentes machos e fêmeas do touro 234 e da vaca 1504 da raça Canchim nas quatro estações do ano. 
A Figura 11 mostra as curvas de sobrevivência a posteriori para os machos e fêmeas nascidos no inverno e descendentes do touro 234 e da vaca 1504 com diferentes idades no parto. Pode-se observar que os animais ganham peso mais rapidamente se a idade da vaca no parto encontrar-se entre 2550 e 3450 dias. Tal ganho de peso é menos acentuado quando a idade da vaca no parto é superior a 4500 dias. Entre algumas categorias de idades como, por exemplo, entre as categorias $[750,1650]$ e $(3450,4500]$ dias, praticamente não se observam diferenças entre o ganho de peso dos animais.
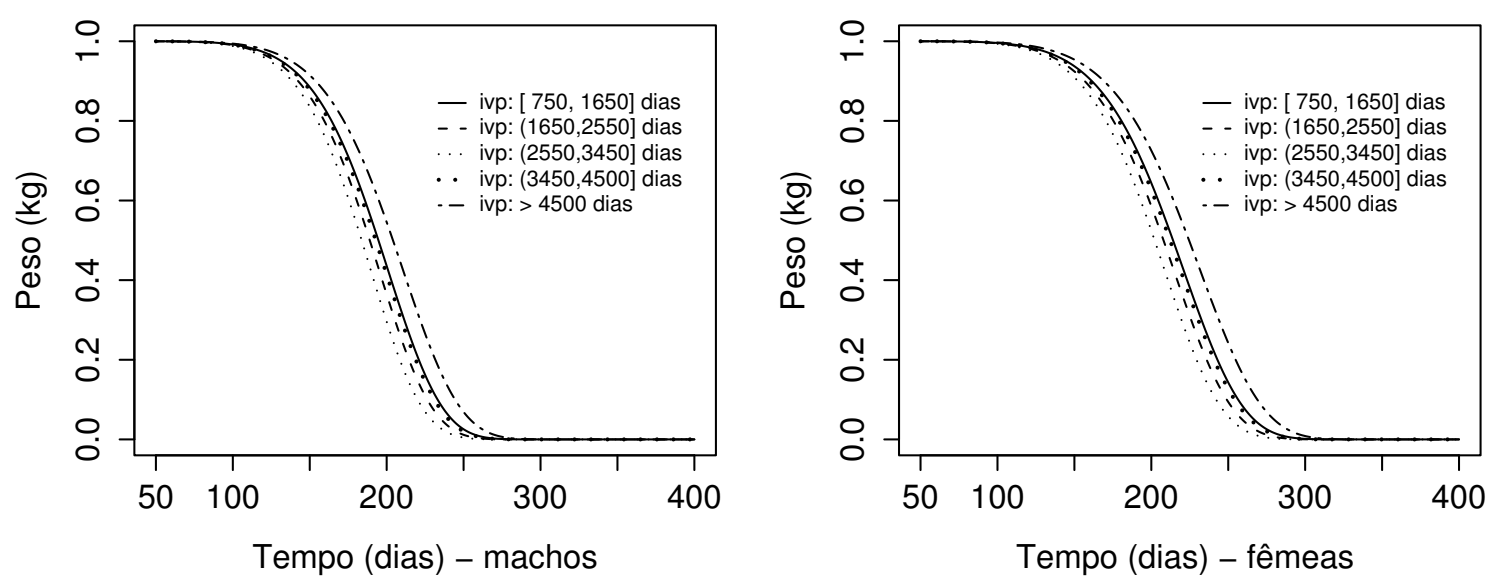

Figura 11 - Curvas de sobrevivência a posteriori dos machos e fêmeas, nascidos no inverno, descendentes do touro 234 e da vaca 1504 da raça Canchim considerando-se diferentes idades da vaca no parto.

O modelo de curvas de crescimento com efeitos aleatórios não foi ajustado para os dados desse estudo devido aos pesos dos animais terem sido observados somente em duas idades, nascimento e desmama. Para o ajuste do referido modelo pesos em mais do que duas idades são requeridos. O programa usado no ajuste do modelo de fragilidade gama encontra-se no Anexo $\mathrm{H}$. 


\subsection{Comparação dos critérios de seleção}

Uma vez que dois critérios para a seleção de touros foram propostos, deseja-se fazer uma comparação entre eles. O objetivo da comparação é o de avaliar se ambos os critérios, ou seja, o modelo de fragilidade gama com censura intervalar e o modelo de curvas de crescimento com efeitos aleatórios, quando adequados aos dados, classificam corretamente os touros bem como se são eqüivalentes, ou seja, se concordam, quanto às classificações atribuídas aos touros. Para essa finalidade, um estudo de simulação foi realizado e os resultados são apresentados a seguir.

\subsubsection{Comparação dos critérios de seleção por meio de simulação}

Os resultados de uma, dentre 20 simulações realizadas com os parâmetros e suposições descritas em 3.2.4, são apresentados a seguir. A Figura 12 mostra as 3000 observações (1000 em cada tempo) simuladas para os 1000 animais nos tempos $t=0,220$ e 600 dias. Nota-se que a simulação realizada levou em conta o fato de que as variâncias crescem ao longo do tempo, como foi observado nos dados reais.

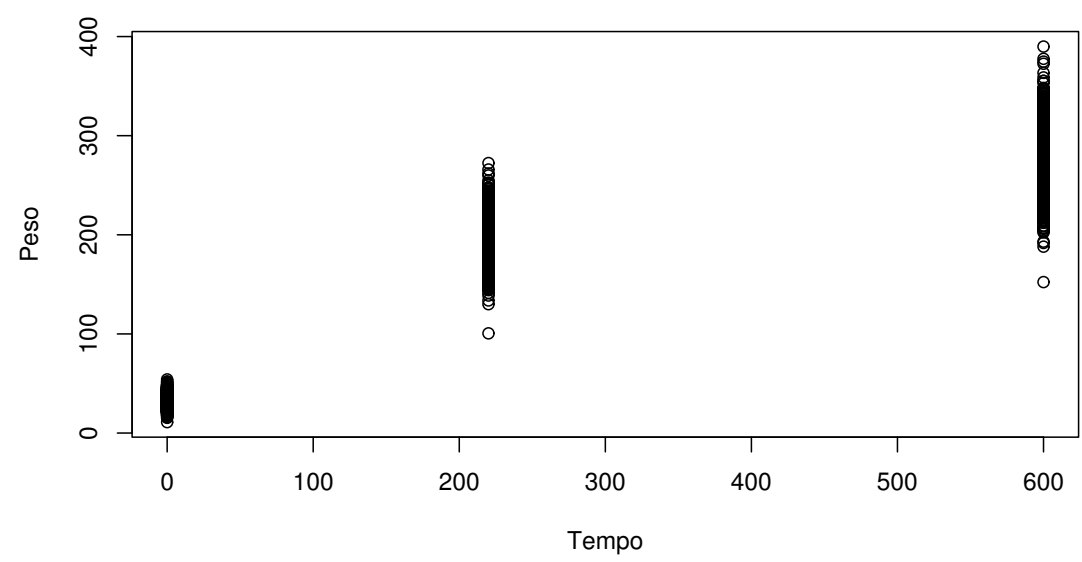

Figura 12 - Pesos simulados para 1000 animais nos tempos 0, 220 e 600 dias.

Os resultados obtidos para o modelo de fragilidade gama com censura intervalar e para o modelo de curvas de crescimento são apresentados na Tabela 12. 
Tabela 12. Estatísticas resumo das distribuições a posteriori dos parâmetros do modelo de curvas de crescimento e do modelo de fragilidade gama e $\operatorname{dos} f_{j}$ 's e $z_{j}$ 's obtidos em uma das simulações.

\begin{tabular}{cccc}
\hline \multicolumn{2}{c}{ Modelo de curvas de crescimento } & \multicolumn{2}{c}{ Modelo de fragilidade gama } \\
Parâmetros e $f_{j}^{\prime}$ 's & Média a posteriori (DP) & Parâmetros e $z_{j}$ 's & Média a posteriori (DP) \\
\hline$b$ & $7,466(0,0401)$ & $\alpha$ & $-14,04(2,0520)$ \\
$k$ & $0,013(2,8 \mathrm{e}-5)$ & $\gamma$ & $3,023(0,4478)$ \\
$\sigma_{a}^{2}$ & $743,8(33,87)$ & $\xi_{f}$ & $0,400(0,2273)$ \\
$\sigma_{f}^{2}$ & $298,8(178,0)$ & $1 / \xi_{f}$ & $3,198(1,5980)$ \\
$\sigma_{e}^{2}$ & $24,91(0,792)$ & - & - \\
$f_{1}$ & $-6,55(2,723)$ & $z_{1}$ & $0,703(0,1836)$ \\
$f_{2}$ & $-19,0(2,740)$ & $z_{2}$ & $0,452(0,1264)$ \\
$f_{3}$ & $-24,4(2,740)$ & $z_{3}$ & $0,346(0,0995)$ \\
$f_{4}$ & $27,2(2,743)$ & $z_{4}$ & $2,366(0,5679)$ \\
$f_{5}$ & $-2,98(2,726)$ & $z_{5}$ & $0,702(0,1838)$ \\
$f_{6}$ & $-1,35(2,730)$ & $z_{6}$ & $0,899(0,2262)$ \\
$f_{7}$ & $19,63(2,742)$ & $z_{7}$ & $1,596(0,3855)$ \\
$f_{8}$ & $9,26(2,715)$ & $z_{8}$ & $1,169(0,2896)$ \\
$f_{9}$ & $9,11(2,702)$ & $z_{9}$ & $1,167(0,2896)$ \\
$f_{10}$ & $-2,43(2,692)$ & $z_{10}$ & $0,853(0,2137)$ \\
\hline
\end{tabular}

A partir da Tabela 12 pode-se observar, pela comparação dos valores $f_{j}$ e $z_{j}, j=1, \ldots, 10$, a existência de uma concordância entre as classificações dos touros uma vez que, valores grandes de $f$ correspondem a valores grandes de $z$ e vice-versa. Na Tabela 13 são apresentadas tais classificações podendo-se notar que ambos os modelos são critérios eficientes para a seleção dos touros. A correlação entre a classificação verdadeira e a obtida pelo modelo de curvas de crescimento foi igual a 0,9878 e, com o modelo de fragilidade gama, igual a 0,9757. Entre os dois modelos a correlação foi de 0,9749. Nas 20 simulações realizadas esse comportamento se manteve sendo a correlação média observada igual a 0,95 $(\mathrm{DP}=0,015)$.

Resultados similares foram obtidos usando-se o mesmo procedimento de simulação e análise, mas considerando-se 20 touros com 50 descendentes cada, ao invés de 10 touros com 100 descendentes cada. A Figura 13 mostra as classificações obtidas em ambas as situações, ou seja, para 10 e 20 touros, respectivamente. Em 
Tabela 13. Classificações obtidas para os 10 touros usando-se o modelo de curvas de crescimento (modelo I) e o modelo de fragilidade gama com censura intervalar (modelo II).

\begin{tabular}{lcccccccccc}
\hline \multicolumn{1}{c}{ Touro } & 1 & 2 & 3 & 4 & 5 & 6 & 7 & 8 & 9 & 10 \\
\hline Classificação verdadeira & 3 & 2 & 1 & 10 & 5 & 6 & 9 & 8 & 7 & 4 \\
Classificação obtida por meio do modelo I & 3 & 2 & 1 & 10 & 5 & 5 & 9 & 8 & 7 & 5 \\
Classificação obtida por meio do modelo II & 3 & 2 & 1 & 10 & 5 & 6 & 9 & 8 & 7 & 4 \\
\hline
\end{tabular}

ambos os casos obteve-se uma correlação grande e positiva entre as classificações, isto é, iguais a 0,9749 e 0,9751, respectivamente.

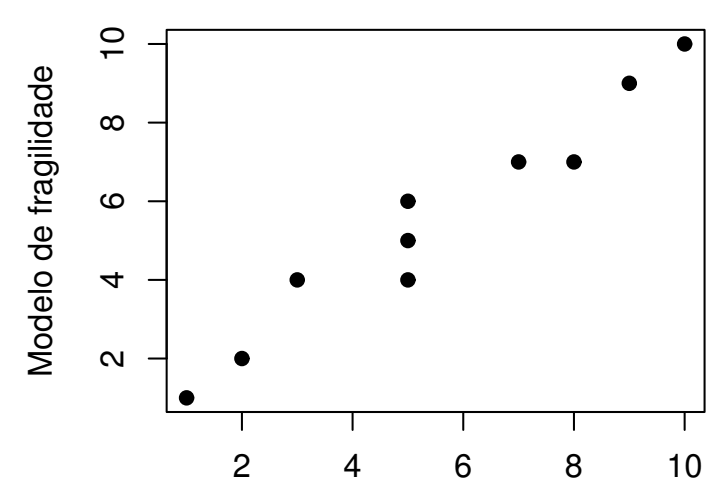

a) Classificação: curvas de crescimento

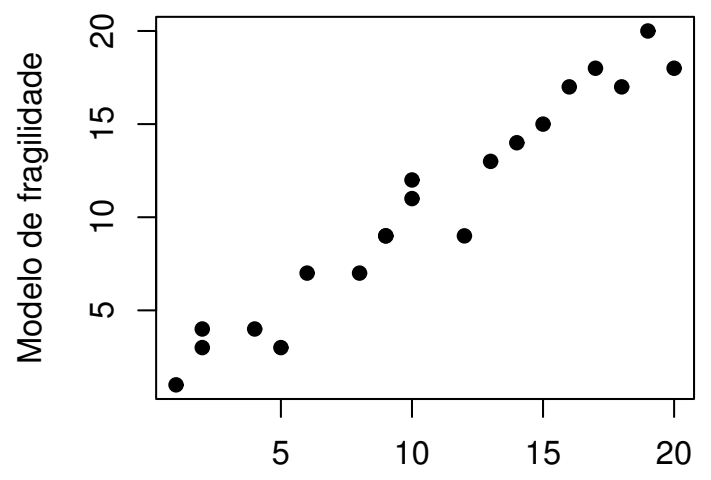

b) Classificação: curvas de crescimento

Figura 13 - Classificações dos touros obtidas em uma das simulações realizadas com 10 e 20 touros, respectivamente.

Considerando-se a simulação com 10 touros apresentada anteriormente e que o peso ao nascer está em torno de $30 \mathrm{~kg}$, foram obtidos, por meio da expressão (22), os tempos $t_{i}, i=1, \ldots, 1000$, até um ganho de peso de $160 \mathrm{~kg}$. A distribuição de freqüências desses tempos e correspondente distribuição Weibull ajustada aos mesmos, usando-se o procedimento gráfico descrito na seção 3.2.4, são apresentadas na Figura 14. A partir dessa figura, nota-se que os tempos apresentam distribuição assimétrica à esquerda. A distribuição Normal considerando-se $\mu$ igual à média dos 
tempos até um ganho de peso de $160 \mathrm{~kg}$ e $\sigma^{2}$ igual a variância dos mesmos, também é apresentada na Figura 14. Observa-se que ela não se ajusta tão bem aos dados quanto à Weibull devido à assimetria observada. A suposição de que os tempos até um ganho de peso de 160kg seguem a distribuição Weibull parece, portanto, razoável para os dados simulados.

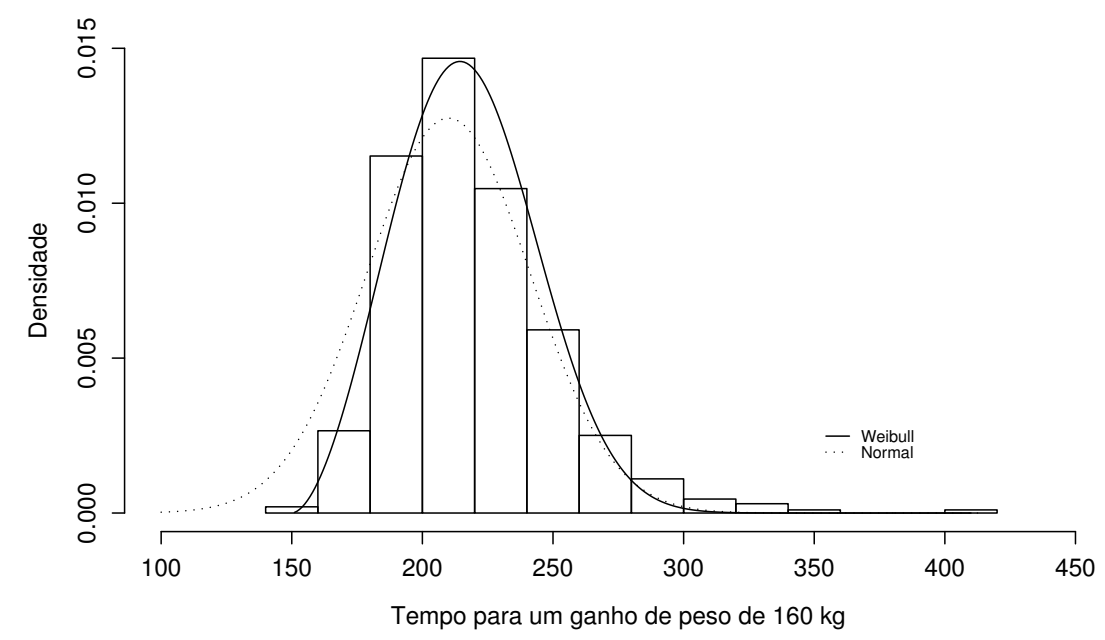

Figura 14 - Distribuição dos tempos até um ganho de peso de 160kg.

Com relação à comparação dos modelos pode-se concluir, pelos resultados obtidos por meio de simulação, que há fortes evidências de que o modelo de curvas de crescimento com efeitos aleatórios e o de fragilidade gama com censura intervalar podem ser usados, em geral, para selecionar os mesmos melhores touros, desde que, é claro, as suposições assumidas para um, ou outro, estejam satisfeitas. Embora as classificações não coincidam exatamente, há uma forte tendência de que os touros que foram classificados nas melhores posições por um modelo também serão pelo outro. A escolha por um dos modelos dependerá, portanto, das informações que se tenham disponíveis bem como dos custos em obtê-las. Para o modelo de curvas de crescimento com efeitos aleatórios necessita-se, para cada animal, de um número maior de informações sobre o peso ao longo do tempo. No modelo de fragilidade gama com censura intervalar menos informação é requerida, porém praticamente 
nada existe na literatura para a verificação da qualidade do modelo ajustado. Estudos adicionais nesse sentido necessitam, portanto, ser realizados. 


\section{CONCLUSÕES}

Nesse trabalho foram propostos dois modelos os quais podem ser usados como critérios para a seleção de bovinos. São eles, o modelo de fragilidade gama para dados de sobrevivência com censura intervalar e o modelo de curvas de crescimento com efeitos aleatórios. O primeiro modelo é usado quando a variável resposta de interesse é o tempo, no período do nascimento até a desmama, para um ganho de peso pré-especificado e, o segundo, quando pesos são observados ao longo do tempo, ou seja, em algumas idades específicas.

A partir dos modelos propostos, de suas aplicações a dados reais e dos estudos de simulações, as seguintes conclusões foram obtidas:

i) o modelo de fragilidade gama mostrou ser um critério de seleção adequado às situações em que se deseja estudar a variável resposta tempo até um ganho de peso específico e em que: a) os tempos de interesse (variável resposta), embora não observados diretamente, ocorrem em intervalos de tempo, b) é conhecido que o evento de interesse ocorreu para alguns indivíduos e para outros não, c) agrupamentos naturais ou artificias existem e estes induzem a uma provável associação entre os tempos dos indivíduos pertencentes a cada agrupamento e, d) a variável resposta não segue a distribuição Normal;

ii) o modelo de curvas de crescimento com efeitos aleatórios foi proposto como um critério de seleção alternativo e sua utilização somente é possível quando o peso do animal for observado em várias idades (pelo menos três idades e que não sejam muito próximas) para que se possa modelar o crescimento adequadamente. Este modelo é, portanto, um critério que, quando comparado ao 
anterior, demanda uma quantidade maior de informações disponíveis;

iii) ambos os modelos propostos apresentaram-se como bons critérios de seleção e, em sendo adequados aos dados, um estudo de simulação mostrou que ambos os modelos selecionam, de um modo geral, os mesmos melhores touros. A escolha por um dos dois modelos dependerá, em parte, das informações que se tenham disponíveis bem como dos custos em obtê-las;

iv) se os pesos dos animais em diversas idades encontrarem-se disponíveis seria recomendável o ajuste de ambos os modelos considerando-se os efeitos fixos bem como os efeitos aleatórios julgados relevantes ao problema. Estando os modelos adequados aos dados, os touros selecionados devem ser aqueles comuns a ambos os modelos;

v) os estudos com bovinos Nelore e Canchim, utilizados nesse trabalho a título de ilustração, mostraram como os modelos propostos podem ser utilizados e seus resultados interpretados e foram úteis para que os programas escritos no WinBUGS fossem implementados de forma satisfatória. 
ANEXOS 
Anexo A - Distribuição de freqüências do número de descendentes dos 64 touros Nelore por grupo de manejo na desmama.

\begin{tabular}{|c|c|c|c|c|c|c|c|c|c|c|c|c|}
\hline Grupo de manejo & 1 & 2 & 3 & 4 & 5 & 6 & 7 & 11 & 12 & 13 & 14 & 15 \\
\hline № de descendentes & 80 & 40 & 42 & 58 & 54 & 24 & 7 & 94 & 57 & 120 & 56 & 73 \\
\hline Grupo de manejo & 16 & 17 & 18 & 19 & 20 & 21 & 22 & 23 & 24 & 25 & 26 & 27 \\
\hline № de descendentes & 67 & 68 & 43 & 51 & 37 & 145 & 41 & 114 & 39 & 77 & 98 & 115 \\
\hline Grupo de manejo & 28 & 29 & 30 & 31 & 32 & 33 & 34 & 35 & 36 & 37 & 38 & 39 \\
\hline № de descendentes & 148 & 129 & 69 & 137 & 156 & 119 & 115 & 81 & 176 & 90 & 154 & 72 \\
\hline Grupo de manejo & 40 & 41 & 42 & 43 & 44 & 45 & 46 & 47 & 48 & 49 & 50 & 51 \\
\hline № de descendentes & 86 & 130 & 106 & 65 & 138 & 88 & 45 & 51 & 75 & 28 & 48 & 81 \\
\hline Grupo de manejo & 52 & 53 & 54 & 55 & 56 & 57 & 58 & 59 & 61 & 62 & 63 & 64 \\
\hline № de descendentes & 225 & 77 & 128 & 63 & 80 & 26 & 14 & 20 & 35 & 59 & 62 & 57 \\
\hline Grupo de manejo & 65 & 66 & 71 & 72 & 73 & 74 & 75 & 76 & 77 & 78 & 79 & 80 \\
\hline № de descendentes & 80 & 46 & 60 & 26 & 38 & 55 & 78 & 48 & 66 & 62 & 1 & 57 \\
\hline Grupo de manejo & 81 & 82 & 83 & 84 & 85 & 86 & 87 & 88 & 89 & 90 & 91 & 92 \\
\hline № de descendentes & 38 & 20 & 28 & 50 & 25 & 46 & 23 & 52 & 40 & 77 & 51 & 61 \\
\hline Grupo de manejo & 93 & 94 & 95 & 96 & 97 & 98 & 99 & 100 & 101 & 102 & 103 & 104 \\
\hline № de descendentes & 25 & 39 & 3 & 75 & 117 & 68 & 68 & 93 & 21 & 23 & 23 & 22 \\
\hline Grupo de manejo & 106 & 107 & 108 & 109 & 110 & 111 & & & & & & \\
\hline № de descendentes & 44 & 35 & 1 & 52 & 5 & 40 & & & & & & \\
\hline
\end{tabular}

Anexo B - Distribuição de freqüências do número de descendentes dos 64 touros Nelore por grupo de manejo no sobreano.

\begin{tabular}{cccccccccccccc}
\hline Grupo de manejo & 1 & 2 & 3 & 4 & 5 & 6 & 7 & 8 & 9 & 10 & 11 & 12 & 13 \\
№ de descendentes & 174 & 228 & 209 & 396 & 244 & 466 & 466 & 270 & 283 & 464 & 221 & 113 & 85 \\
Grupo de manejo & 14 & 15 & 16 & 17 & 18 & 19 & 20 & 21 & 22 & 23 & 24 & 25 & 27 \\
№ de descendentes & 64 & 194 & 186 & 210 & 333 & 80 & 173 & 304 & 337 & 259 & 177 & 27 & 66 \\
Grupo de manejo & 28 & 29 & 30 & 31 & 32 & 33 & 34 & 35 & 41 & 42 & 43 & 72 & \\
№ de descendentes & 111 & 68 & 90 & 57 & 21 & 66 & 75 & 18 & 33 & 20 & 13 & 1 & \\
\hline
\end{tabular}


Anexo C - Distribuição de freqüências do número de descendentes dos 64 touros Nelore.

\begin{tabular}{ll}
\hline Identificação do touro & Número de descendentes \\
\hline $53 / 5461 / 7 / 6 / 63 / 112358$ & $3 / 4 / 6 / 7 / 11 / 13$ \\
$28 / 18 / 1317 / 155664 / 9 / 316$ & $16 / 22 / 27 / 31 / 32 / 36$ \\
$41 / 2032 / 59 / 2122 / 62 / 60$ & $37 / 39 / 43 / 47 / 48 / 49$ \\
$1 / 37 / 814 / 43 / 25 / 33$ & $56 / 57 / 61 / 62 / 65 / 70$ \\
$5 / 29 / 19 / 57 / 40 / 27$ & $71 / 74 / 78 / 79 / 95 / 99$ \\
$26 / 50 / 10 / 48 / 47 / 49$ & $127 / 135 / 136 / 137 / 142 / 153$ \\
$34 / 12 / 38 / 46 / 2 / 55$ & $159 / 162 / 165 / 169 / 174 / 179$ \\
$36 / 44 / 39 / 4 / 35 / 42$ & $194 / 200 / 208 / 211 / 220 / 235$ \\
$51 / 45 / 30 / 31 / 52 / 24$ & $251 / 252 / 260 / 296 / 337 / 460$ \\
\hline
\end{tabular}


Anexo D - Médias e intervalos de credibilidade a posteriori dos $z_{j}$ 's, associados aos 64 touros Nelore, obtidos pelo modelo de fragilidade gama com censura intervalar.

\begin{tabular}{|c|c|c|c|c|c|c|c|}
\hline Touro & $\mathrm{z}_{j}$ a posteriori & $\mathrm{z}_{j(0,05)}$ & $\mathrm{z}_{j(0,95)}$ & Touro & $\mathrm{z}_{j}$ a posteriori & $\mathrm{z}_{j(0,05)}$ & $\mathrm{z}_{j(0,95)}$ \\
\hline 1 & 1,3050 & 0,8177 & 1,9390 & 33 & 0,5035 & 0,2358 & 0,8847 \\
\hline 2 & 0,8494 & 0,6053 & 1,1470 & 34 & 0,2336 & 0,1521 & 0,3374 \\
\hline 3 & 1,1710 & 0,5152 & 2,1120 & 35 & 0,4921 & 0,3162 & 0,7147 \\
\hline 4 & 0,7427 & 0,5321 & 0,9963 & 36 & 1,8180 & 1,3080 & 2,4330 \\
\hline 5 & 0,9716 & 0,6115 & 1,4350 & 37 & 2,4930 & 1,5430 & 3,7400 \\
\hline 6 & 0,8078 & 0,1904 & 1,8740 & 38 & 1,3180 & 0,9569 & 1,7560 \\
\hline 7 & 0,8897 & 0,1692 & 2,2530 & 39 & 1,1470 & 0,7860 & 1,5930 \\
\hline 8 & 0,8177 & 0,4568 & 1,3030 & 40 & 1,1500 & 0,6765 & 1,7860 \\
\hline 9 & 0,9438 & 0,3877 & 1,7600 & 41 & 0,2643 & 0,0934 & 0,5561 \\
\hline 10 & 0,8047 & 0,5615 & 1,1040 & 42 & 0,7787 & 0,4870 & 1,1500 \\
\hline 11 & 1,3010 & 0,4740 & 2,5920 & 43 & 0,5346 & 0,1893 & 1,0740 \\
\hline 12 & 0,6996 & 0,4848 & 0,9601 & 44 & 0,4390 & 0,2850 & 0,6329 \\
\hline 13 & 1,5860 & 0,7496 & 2,7750 & 45 & 0,6411 & 0,4187 & 0,9206 \\
\hline 14 & 0,8982 & 0,5284 & 1,3810 & 46 & 0,3627 & 0,2282 & 0,5317 \\
\hline 15 & 0,7741 & 0,3523 & 1,3710 & 47 & 1,4390 & 1,0190 & 1,9570 \\
\hline 16 & 0,7018 & 0,3822 & 1,1280 & 48 & 1,1640 & 0,7015 & 1,7570 \\
\hline 17 & 0,4602 & 0,1991 & 0,8395 & 49 & 1,0470 & 0,7344 & 1,4310 \\
\hline 18 & 0,7402 & 0,2506 & 1,4950 & 50 & 1,3540 & 0,9495 & 1,8520 \\
\hline 19 & 0,6302 & 0,3713 & 0,9699 & 51 & 0,6647 & 0,4618 & 0,9150 \\
\hline 20 & 0,5430 & 0,2454 & 0,9632 & 52 & 1,7160 & 1,2990 & 2,2210 \\
\hline 21 & 0,7031 & 0,3338 & 1,2200 & 53 & 0,6229 & 0,1447 & 1,4350 \\
\hline 22 & 0,5825 & 0,2041 & 1,1770 & 54 & 0,7994 & 0,1910 & 1,8470 \\
\hline 23 & 0,7004 & 0,1312 & 1,7720 & 55 & 0,5836 & 0,4128 & 0,7956 \\
\hline 24 & 3,2880 & 2,6030 & 4,0840 & 56 & 2,9230 & 1,7070 & 4,5770 \\
\hline 25 & 0,3894 & 0,2237 & 0,6072 & 57 & 0,9696 & 0,5387 & 1,5510 \\
\hline 26 & 0,6234 & 0,3146 & 1,0360 & 58 & 0,5854 & 0,1720 & 1,2550 \\
\hline 27 & 0,4129 & 0,2168 & 0,6767 & 59 & 0,4624 & 0,1910 & 0,8574 \\
\hline 28 & 0,7639 & 0,1479 & 1,9200 & 60 & 1,9390 & 1,2310 & 2,8730 \\
\hline 29 & 1,0250 & 0,5047 & 1,7300 & 61 & 0,7230 & 0,2096 & 1,5610 \\
\hline 30 & 0,6517 & 0,4638 & 0,8813 & 62 & 2,5110 & 1,6140 & 3,6800 \\
\hline 31 & 0,9831 & 0,6786 & 1,3590 & 63 & 1,5150 & 0,5792 & 2,9500 \\
\hline 32 & 1,0340 & 0,5652 & 1,6590 & 64 & 2,2040 & 1,2850 & 3,4310 \\
\hline
\end{tabular}


Anexo E - Médias e intervalos de credibilidade a posteriori dos $f_{j}$ 's, associados aos 64 touros Nelore, obtidos pelo modelo de curvas de crescimento com efeitos aleatórios.

\begin{tabular}{|c|c|c|c|c|c|c|c|}
\hline Touro & $f_{j}$ a posteriori & $f_{j(0,05)}$ & $f_{j(0,95)}$ & Touro & $f_{j}$ a posteriori & $f_{j(0,05)}$ & $f_{j(0,95)}$ \\
\hline 1 & $-4,03$ & $-10,23$ & 1,99 & 33 & $-21,80$ & $-27,18$ & $-16,30$ \\
\hline 2 & $-14,43$ & $-17,98$ & $-10,86$ & 34 & $-34,44$ & $-38,13$ & $-30,77$ \\
\hline 3 & $-17,19$ & $-24,65$ & $-9,61$ & 35 & $-21,00$ & $-24,14$ & $-17,81$ \\
\hline 4 & $-14,36$ & $-17,55$ & $-11,17$ & 36 & 0,32 & $-2,99$ & 3,57 \\
\hline 5 & $-6,62$ & $-12,11$ & $-1,13$ & 37 & 5,14 & $-0,94$ & 11,18 \\
\hline 6 & $-25,18$ & $-41,28$ & $-8,84$ & 38 & $-19,60$ & $-23,24$ & $-15,97$ \\
\hline 7 & $-13,75$ & $-30,74$ & 3,78 & 39 & $-8,59$ & $-11,85$ & $-5,47$ \\
\hline 8 & $-12,31$ & $-18,26$ & $-6,45$ & 40 & $-8,33$ & $-13,07$ & $-3,62$ \\
\hline 9 & $-9,03$ & $-17,07$ & $-0,83$ & 41 & $-32,27$ & $-39,77$ & $-24,74$ \\
\hline 10 & $-11,76$ & $-15,72$ & $-7,77$ & 42 & $-20,53$ & $-23,59$ & $-17,51$ \\
\hline 11 & $-1,45$ & $-13,68$ & 10,66 & 43 & $-29,11$ & $-34,94$ & $-23,48$ \\
\hline 12 & $-18,08$ & $-21,63$ & $-14,54$ & 44 & $-32,80$ & $-36,05$ & $-29,55$ \\
\hline 13 & $-3,64$ & $-12,33$ & 5,04 & 45 & $-30,53$ & $-33,49$ & $-27,61$ \\
\hline 14 & $-21,60$ & $-27,60$ & $-15,74$ & 46 & $-31,42$ & $-35,11$ & $-27,89$ \\
\hline 15 & $-28,33$ & $-36,44$ & $-19,84$ & 47 & $-20,51$ & $-24,33$ & $-16,69$ \\
\hline 16 & $-15,95$ & $-23,37$ & $-8,28$ & 48 & $-8,93$ & $-12,87$ & $-4,99$ \\
\hline 17 & $-17,75$ & $-26,47$ & $-9,11$ & 48 & $-28,20$ & $-32,00$ & $-24,42$ \\
\hline 18 & $-15,77$ & $-25,35$ & $-6,04$ & 50 & $-22,21$ & $-26,06$ & $-18,33$ \\
\hline 19 & $-17,14$ & $-22,32$ & $-11,85$ & 51 & $-22,49$ & $-25,42$ & $-19,56$ \\
\hline 20 & $-18,16$ & $-25,35$ & $-10,95$ & 52 & $-19,19$ & $-21,72$ & $-16,64$ \\
\hline 21 & $-20,97$ & $-27,78$ & $-14,25$ & 53 & $-16,26$ & $-38,83$ & 6,62 \\
\hline 22 & $-18,87$ & $-25,61$ & $-12,15$ & 54 & $-21,38$ & $-42,02$ & $-1,08$ \\
\hline 23 & $-3,90$ & $-16,17$ & 8,27 & 55 & $-17,37$ & $-20,88$ & $-13,98$ \\
\hline 24 & 28,55 & 26,35 & 30,73 & 56 & 20,09 & 11,85 & 28,10 \\
\hline 25 & 1,75 & $-3,92$ & 7,35 & 57 & $-32,21$ & $-37,35$ & $-26,95$ \\
\hline 26 & $-6,51$ & $-10,59$ & $-2,40$ & 58 & $-27,14$ & $-39,42$ & $-15,00$ \\
\hline 27 & $-29,97$ & $-34,49$ & $-25,45$ & 59 & $-23,39$ & $-30,42$ & $-16,41$ \\
\hline 28 & $-53,88$ & $-65,05$ & $-42,66$ & 60 & 30,09 & 23,47 & 36,69 \\
\hline 29 & $-6,45$ & $-11,72$ & $-1,06$ & 61 & $-18,76$ & $-39,16$ & 1,65 \\
\hline 30 & $-32,89$ & $-35,73$ & $-30,06$ & 62 & 31,68 & 25,10 & 38,27 \\
\hline 31 & $-18,62$ & $-21,39$ & $-15,86$ & 63 & $-16,00$ & $-29,19$ & $-2,78$ \\
\hline 32 & 9,15 & 1,80 & 16,62 & 64 & 20,06 & 11,97 & 28,14 \\
\hline
\end{tabular}


Anexo F - Fluxograma e programa usado no WinBugs - versão 1.3 para o ajuste do modelo de fragilidade gama com censura intervalar - estudo dos bovinos Nelore.

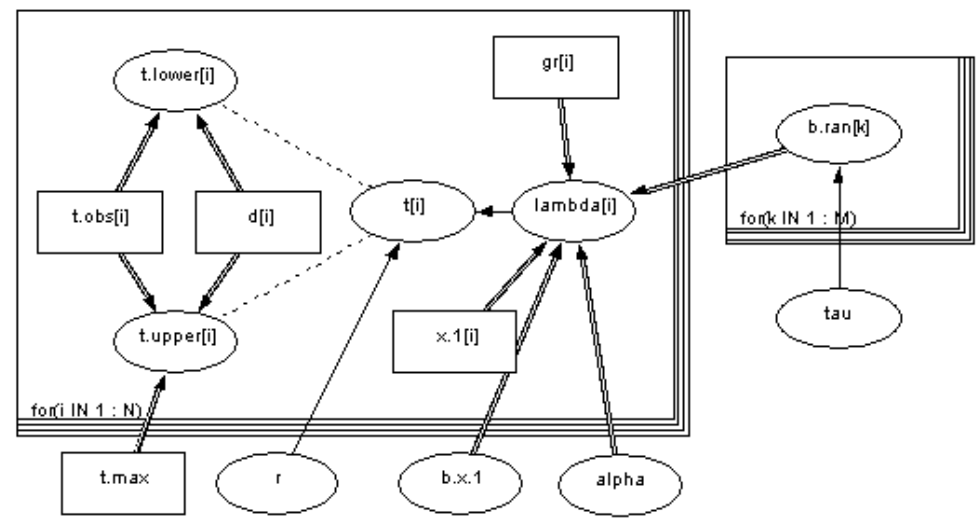

\# construindo os limites inferiores e superiores dos intervalos

model \{

for $(i$ in $1: N)\{$

t.lower $[i]<-(1-d[i]) *$ t.obs $[i]$

for $(i$ in $1: N)\{$

t.upper $[i]<-d[i] * t . o b s[i]+(1-d[i]) * t . \max$

\}

\# assumindo a distribuicao Weibull para os tempos Ti pertencentes aos intervalos [Li, Ui] for $(i$ in $1: N)\{$

t[i] $\operatorname{dweib}(r$, lambda[i])I(t.lower [i],t.upper [i])

\}

\# especificando prioris para os parâmetros

$r \sim \operatorname{dgamma}(1,1.0 \mathrm{E}-4)$

alpha $\sim \operatorname{dnorm}(0.0,1.0 \mathrm{E}-6)$

b.x.1 $\sim \operatorname{dnorm}(0.0,1.0 \mathrm{E}-6)$

\# especificando um dos parâmetros da Weibull em função dos efeitos fixos e aleatórios

for $(i$ in $1: N)\{$

lambda $[i]<-b \cdot \operatorname{ran}[g r[i]] * \exp (a l p h a+b \cdot x \cdot 1 * x \cdot 1[i])$

\}

\# assumindo prioris gama para os efeitos aleatórios

for $(\mathrm{k}$ in $1: \mathrm{M})\{$

b.ran $[\mathrm{k}] \sim \operatorname{dgamma}(\mathrm{tau}, \mathrm{tau})$

tau dgamma $(0.001,0.001)$

qsi<-1/tau

\} 
Anexo G - Programa usado no WinBugs - versão 1.3 para o ajuste do modelo de curvas de crescimento com efeitos aleatórios - estudo dos bovinos Nelore.

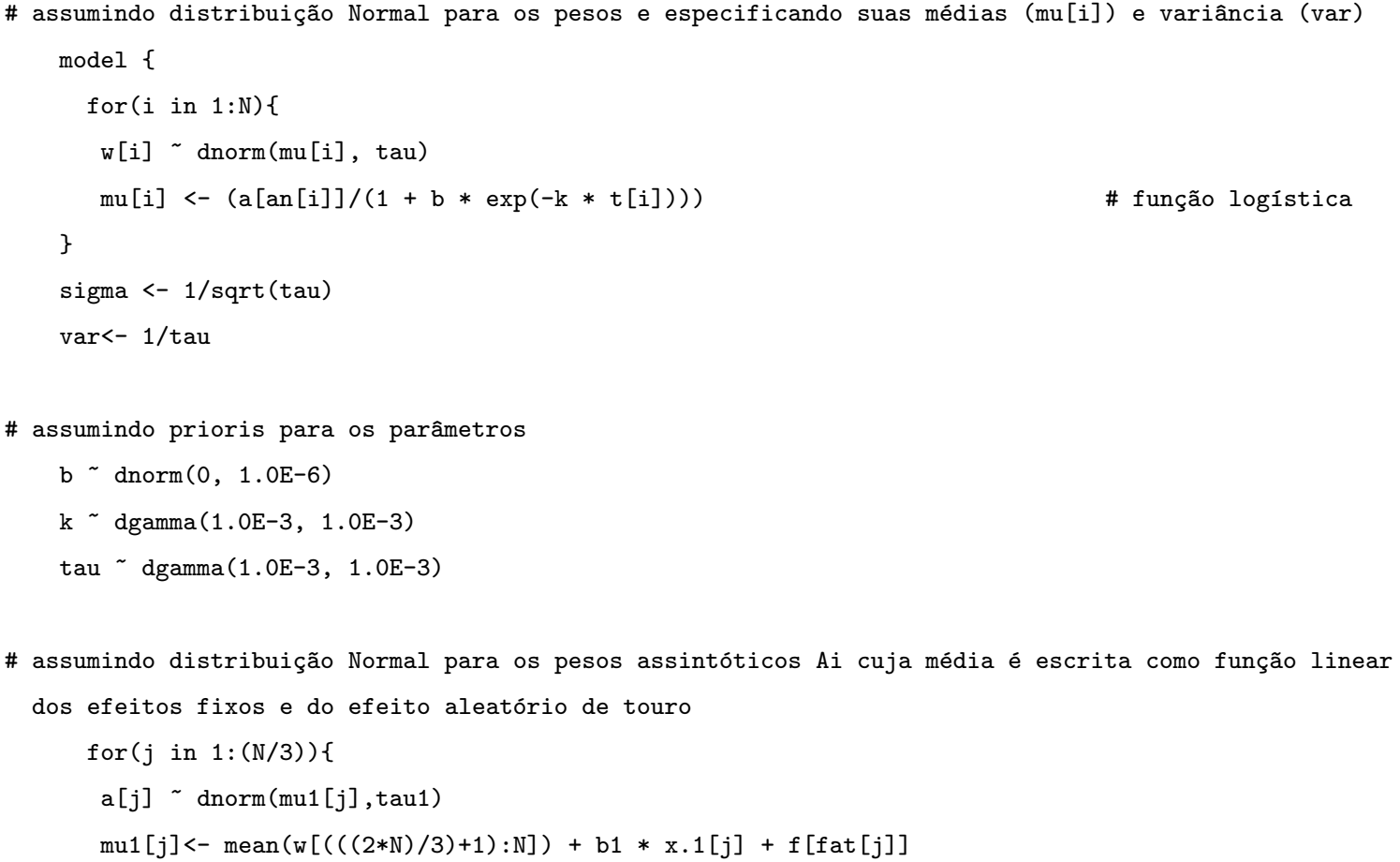

\# assumindo distribuição Normal para os pesos assintóticos Ai cuja média é escrita como função linear dos efeitos fixos e do efeito aleatório de touro

\# assumindo distribuição Normal para o efeito aleatório de touro

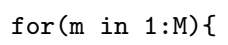

\# assumindo prioris para os parâmetros e obtendo as variâncias a posteriori de Ai (var1) e do efeito aleatório de touro (var2)

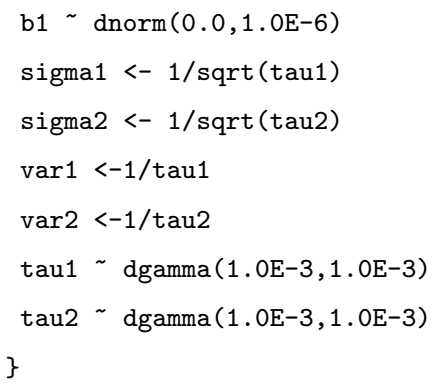


Anexo H - Programa usado no WinBugs - versão 1.3 para o ajuste do modelo de fragilidade gama com censura intervalar - estudo dos bovinos Canchim.

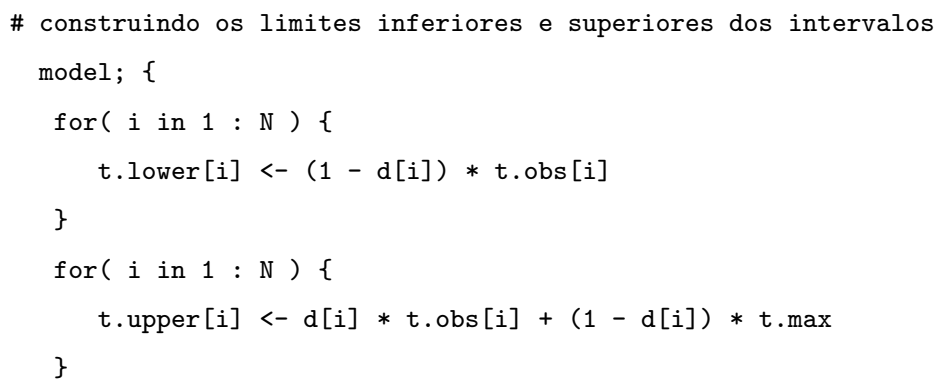

\# assumindo prioris gama para o efeito aleatório de touro e de vaca for $(\mathrm{k}$ in $1: \mathrm{M})\{$

b.ran $[\mathrm{k}] \sim \operatorname{dgamma}(\mathrm{tau}, \mathrm{tau})$ 
Anexo H - Continuação do programa usado no WinBugs - versão 1.3 para o ajuste do modelo de fragilidade gama com censura intervalar - estudo dos bovinos Canchim.

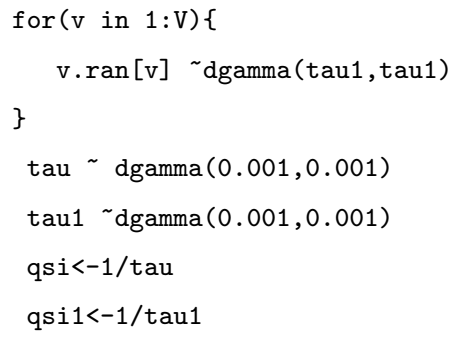


Anexo I - Programa escrito em R - versão 1.5 para simular os dados usados no estudo de simulação realizado para verificar o efeito nas covariáveis causado pela presença ou ausência do efeito aleatório.

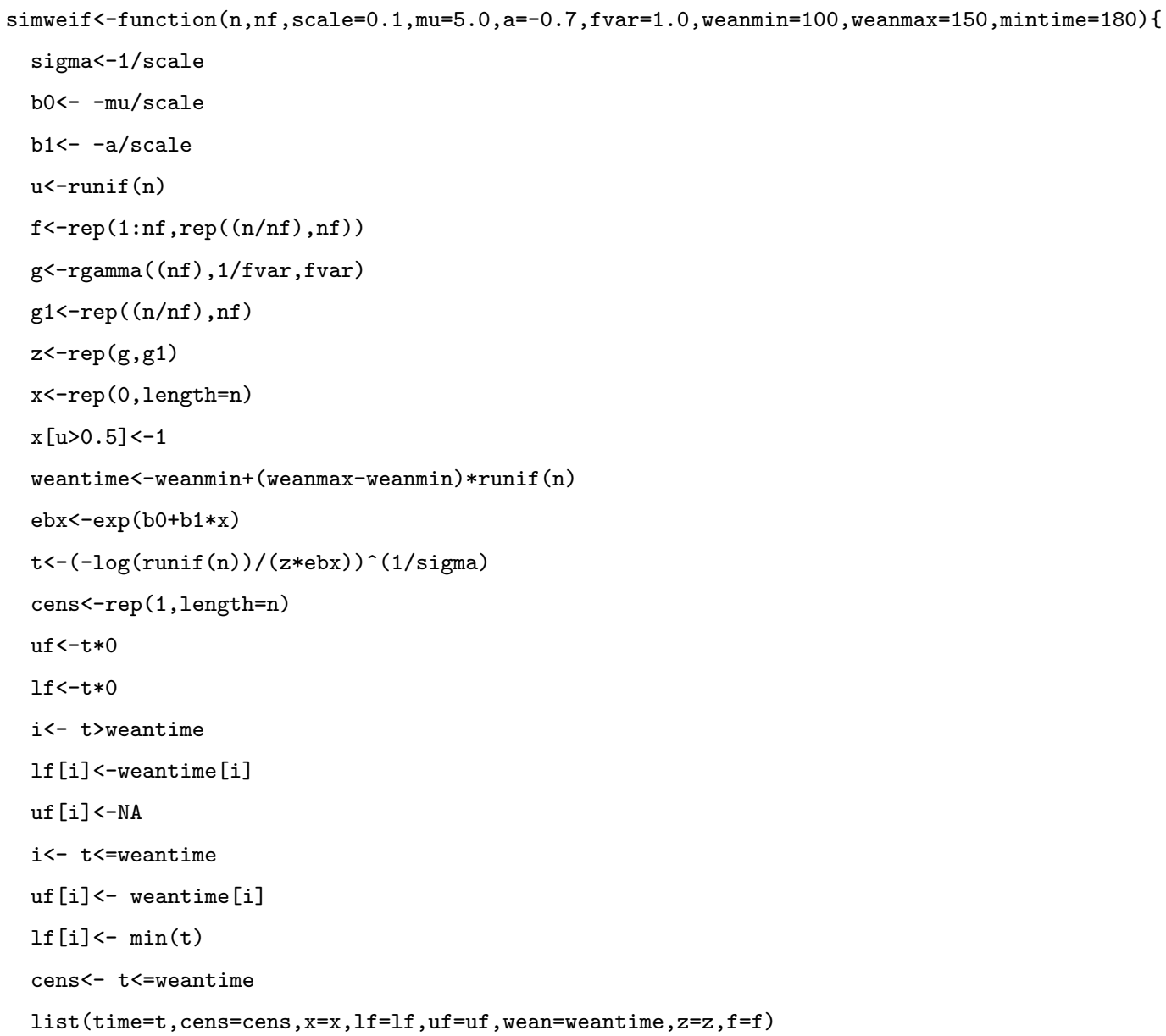


Anexo J - Programa escrito em R - versão 1.5 para estimação dos parâmetros do modelo de fragilidade gama com censura intervalar na ausência do efeito aleatório.

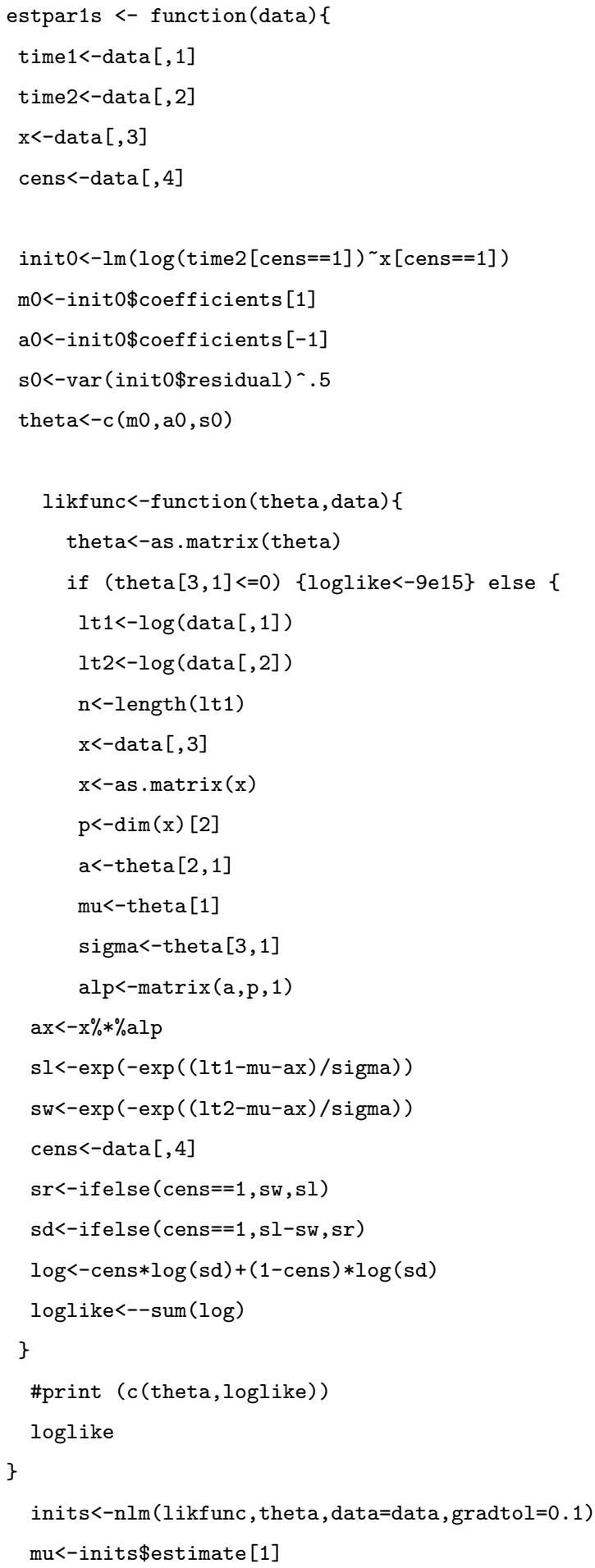


Anexo J - Continuação do programa escrito em $\mathrm{R}$ - versão 1.5 para estimação dos parâmetros do modelo de fragilidade gama com censura intervalar na ausência do efeito aleatório.

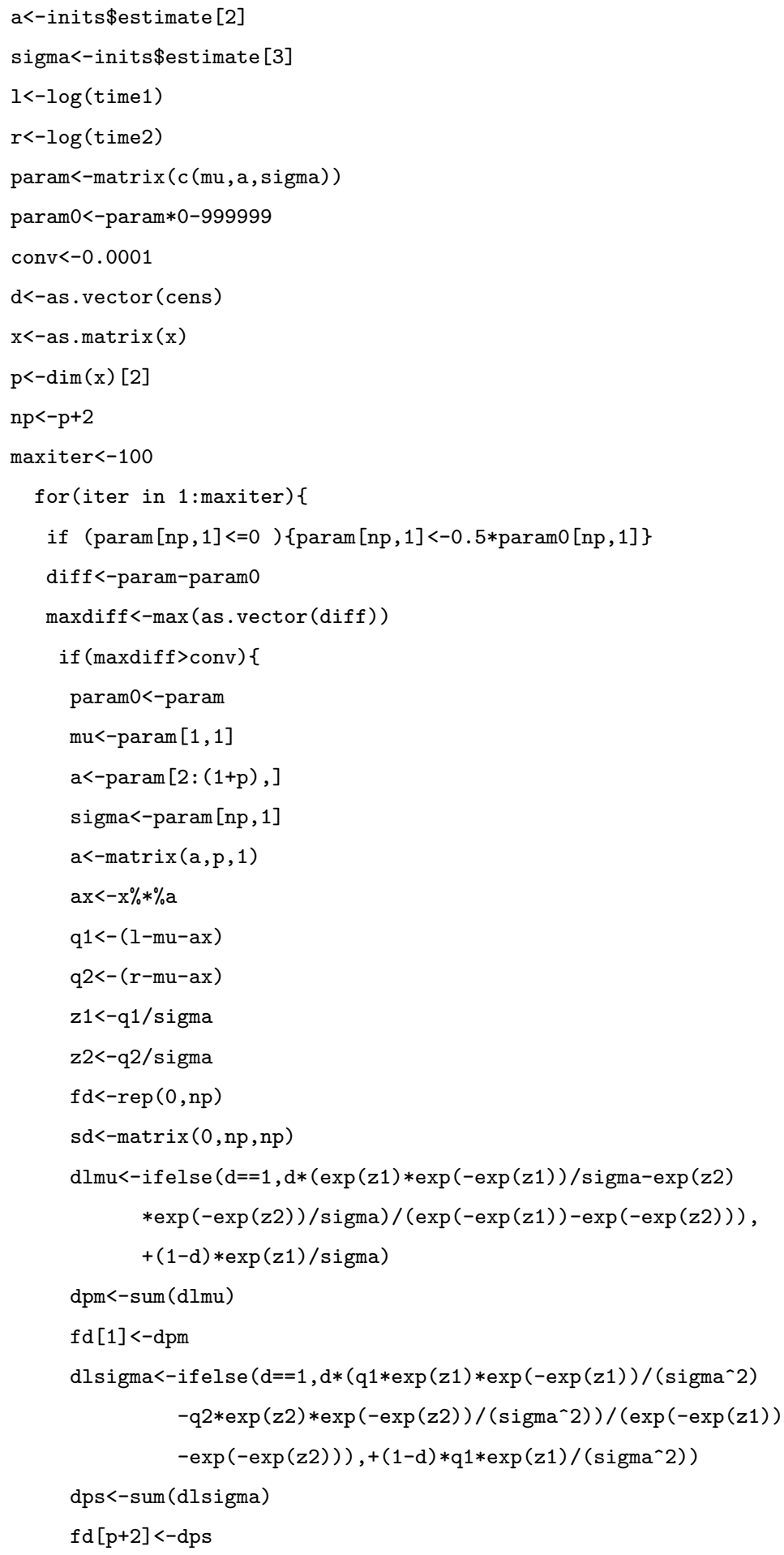


Anexo J - Continuação do programa escrito em R - versão 1.5 para estimação dos parâmetros do modelo de fragilidade gama com censura intervalar na ausência do efeito aleatório.

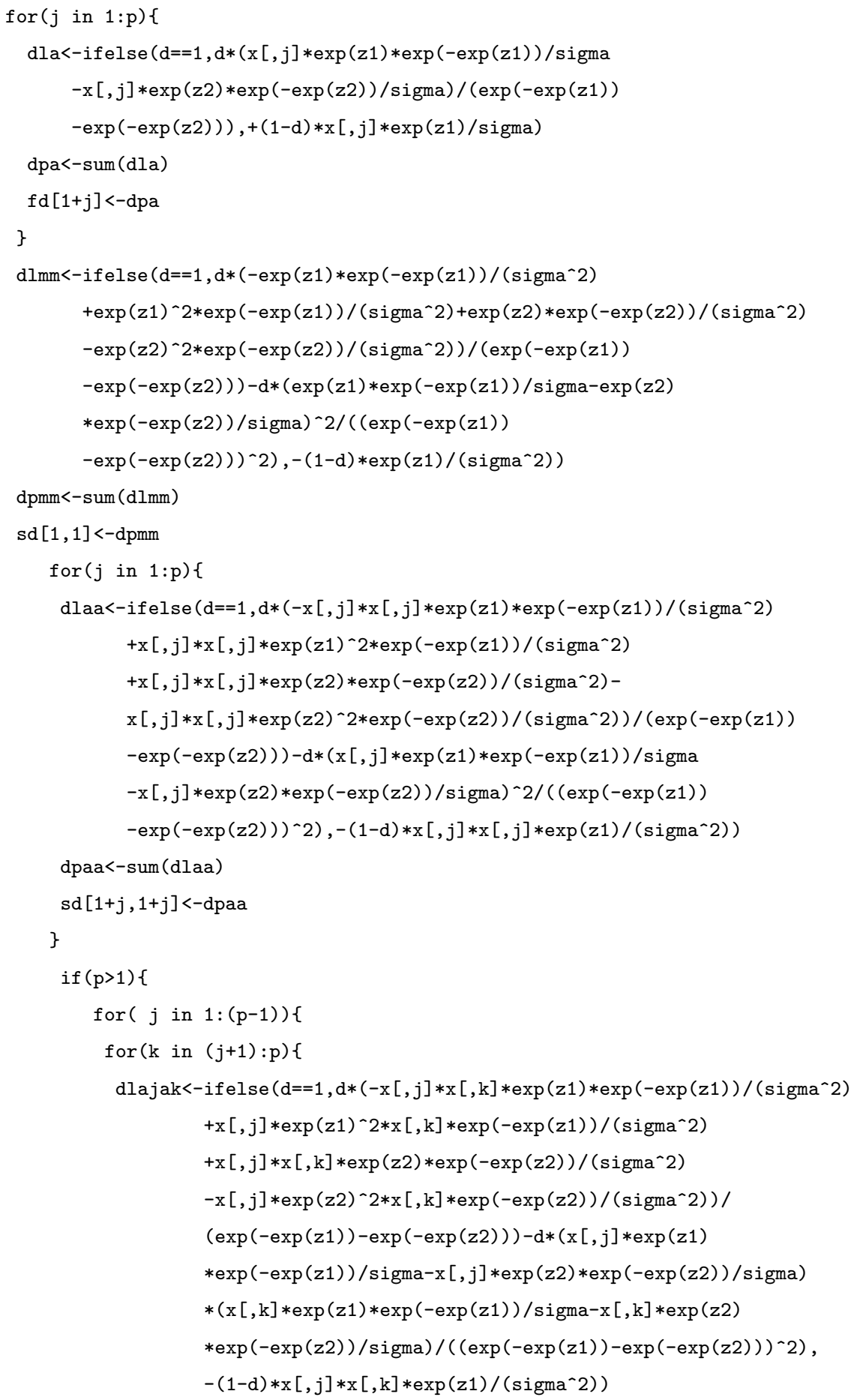


Anexo J - Continuação do programa escrito em R - versão 1.5 para estimação dos parâmetros do modelo de fragilidade gama com censura intervalar na ausência do efeito aleatório.

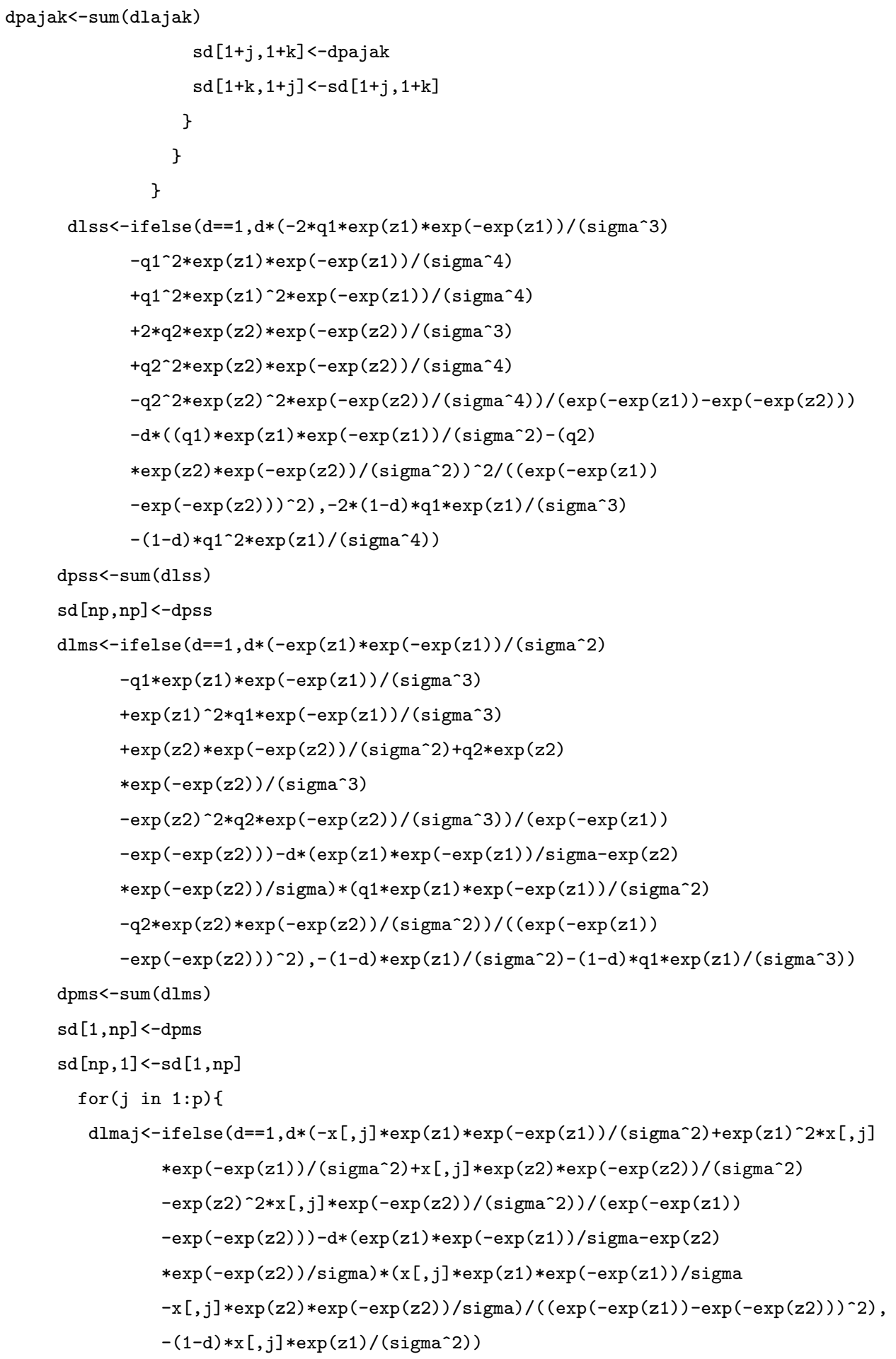


Anexo J - Continuação do programa escrito em R - versão 1.5 para estimação dos parâmetros do modelo de fragilidade gama com censura intervalar na ausência do efeito aleatório.

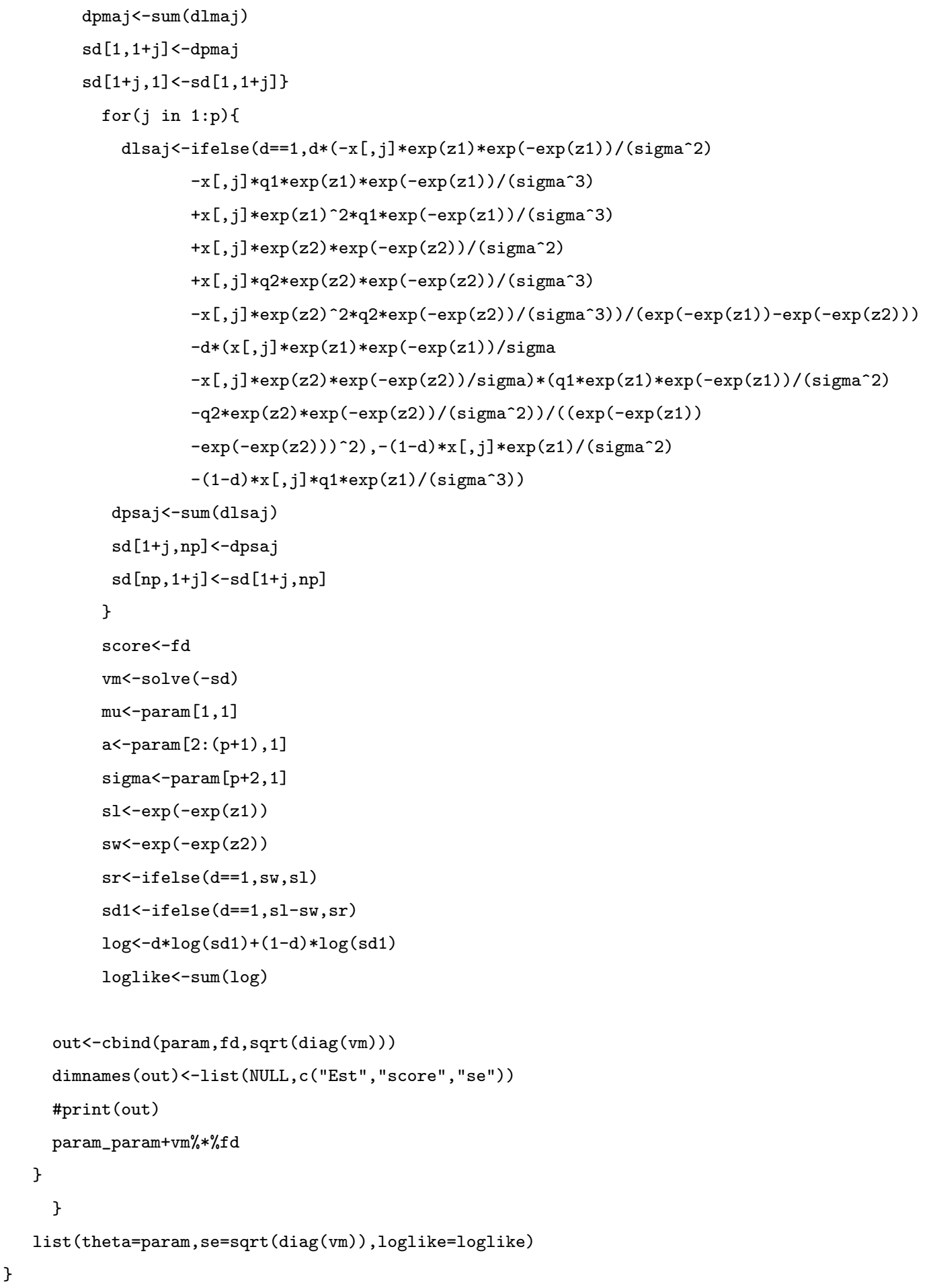


Anexo K - Programa escrito em R - versão 1.5 para a estimação dos parâmetros do modelo de fragilidade gama com censura intervalar, considerando-se $z$ conhecido.

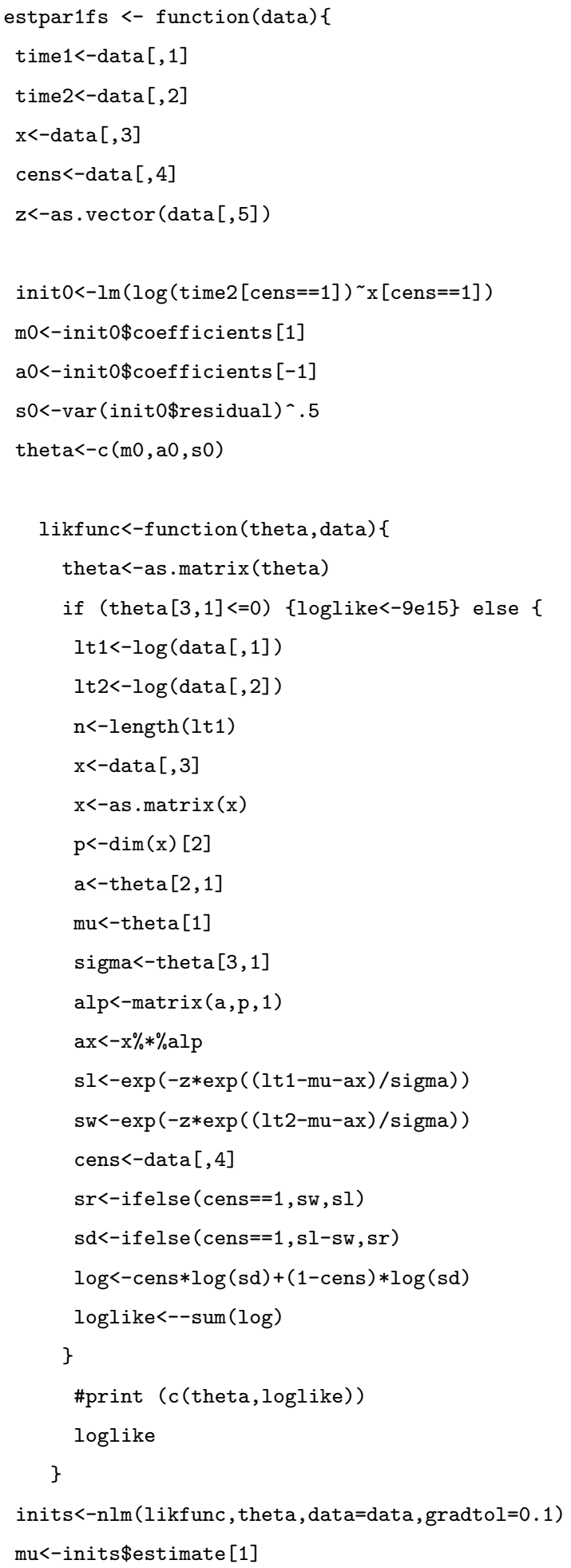


Anexo K - Continuação do programa escrito em R - versão 1.5 para a estimação dos parâmetros do modelo de fragilidade gama com censura intervalar considerando-se $z$ conhecido.

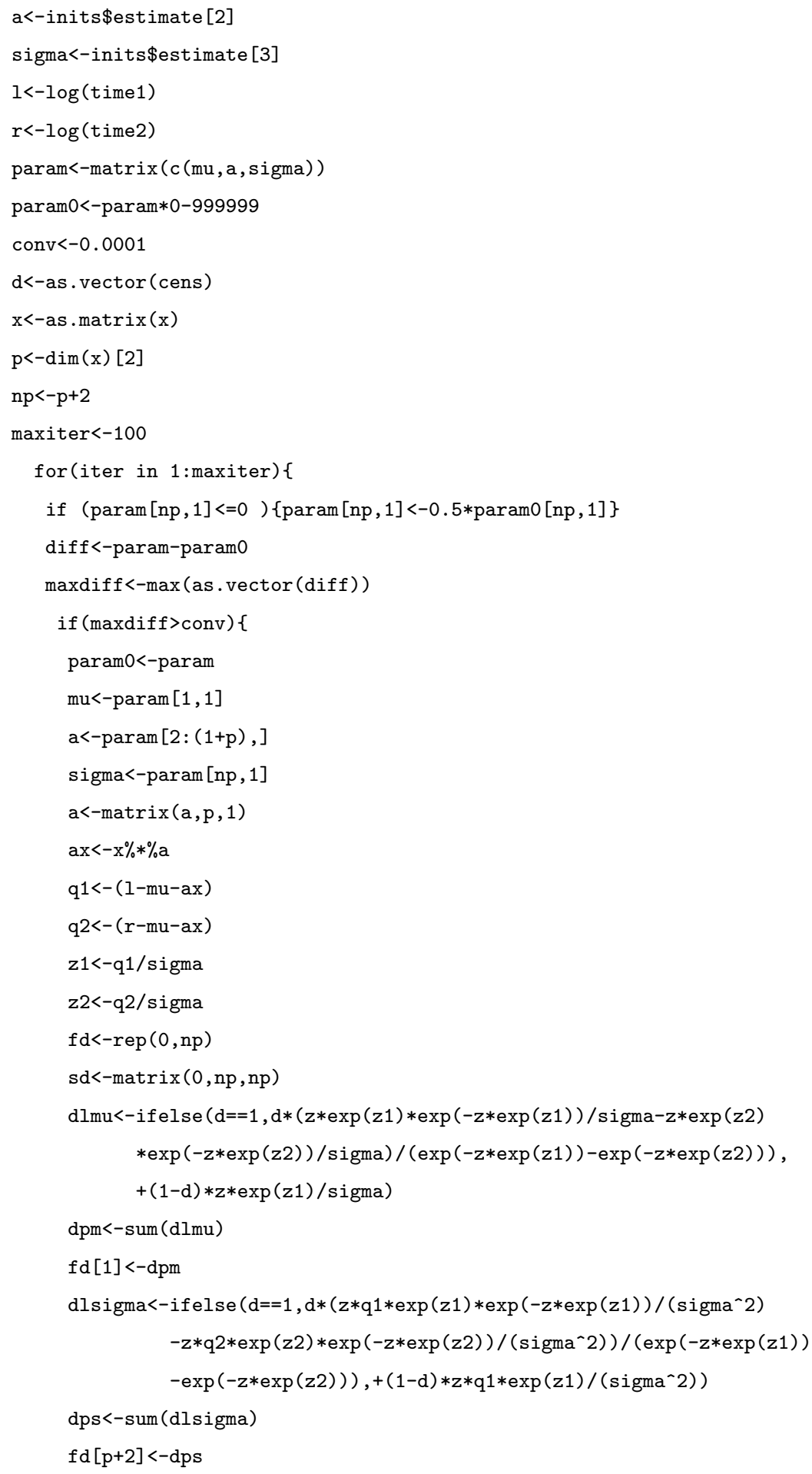


Anexo K - Continuação do programa escrito em R - versão 1.5 para a estimação dos parâmetros do modelo de fragilidade gama com censura intervalar, considerando-se $z$ conhecido.

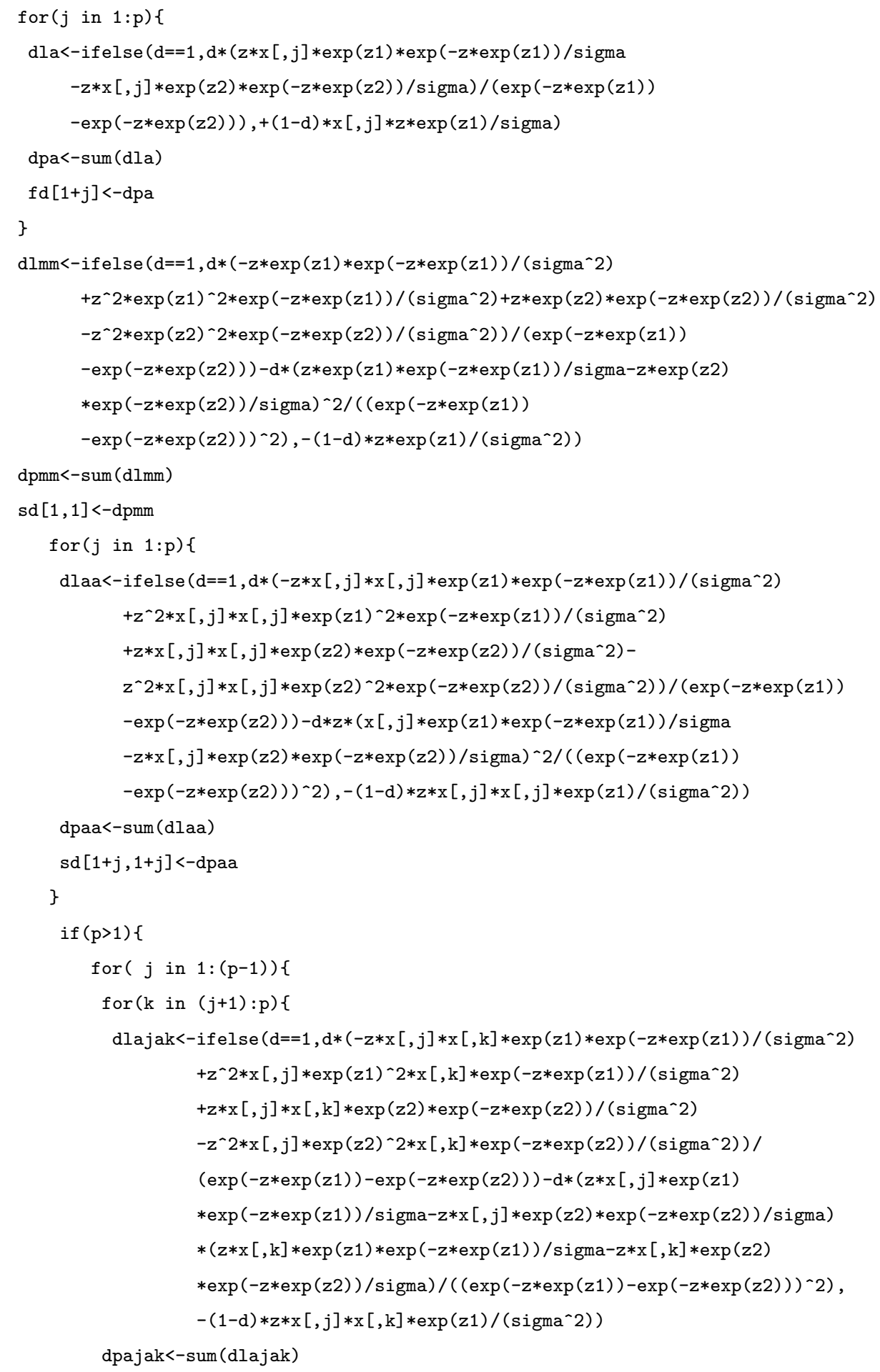


Anexo K - Continuação do programa escrito em R - versão 1.5 para a estimação dos parâmetros do modelo de fragilidade gama com censura intervalar, considerando-se $z$ conhecido.

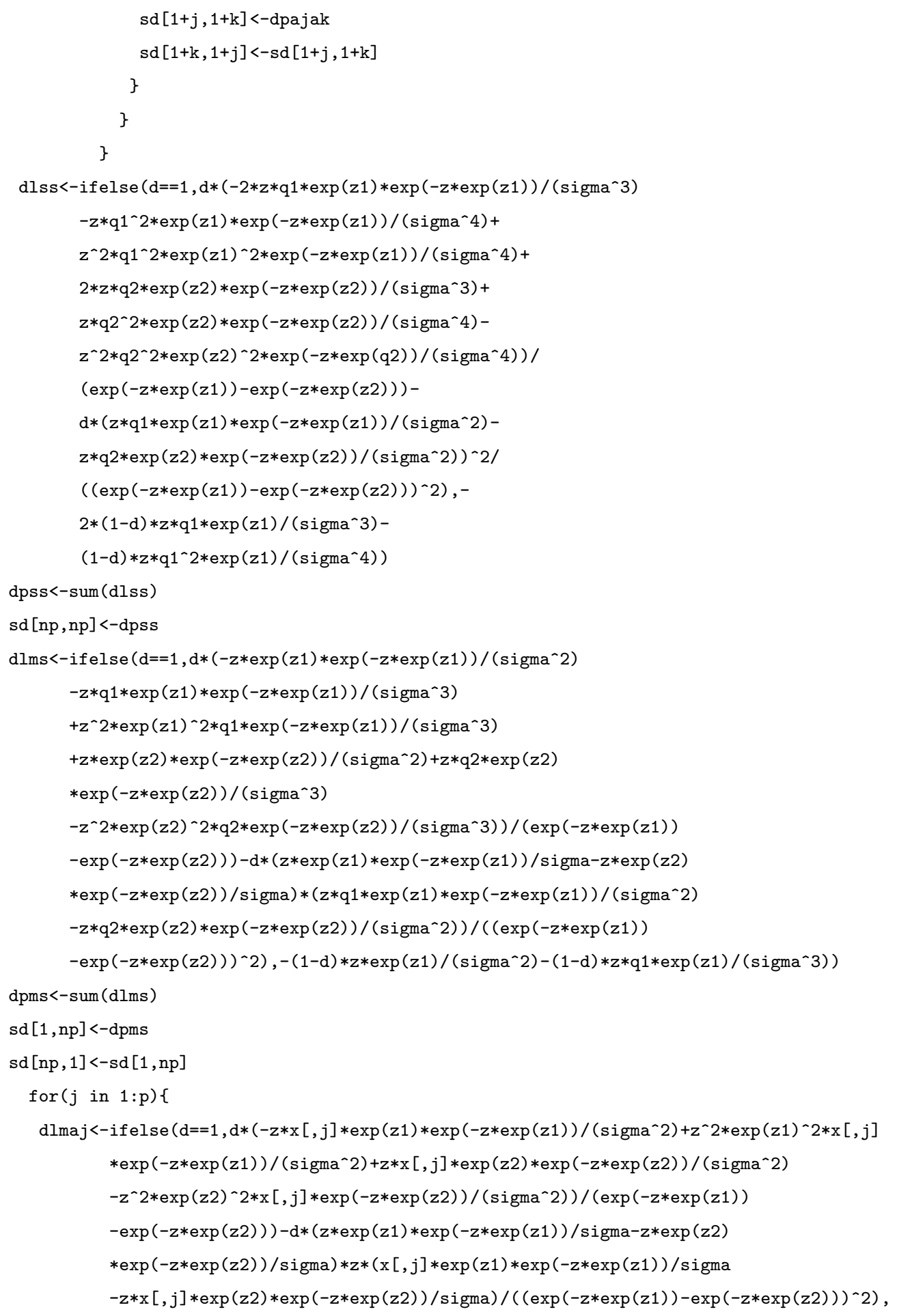


Anexo K - Continuação do programa escrito em R - versão 1.5 para a estimação dos parâmetros do modelo de fragilidade gama com censura intervalar, considerando-se $z$ conhecido.

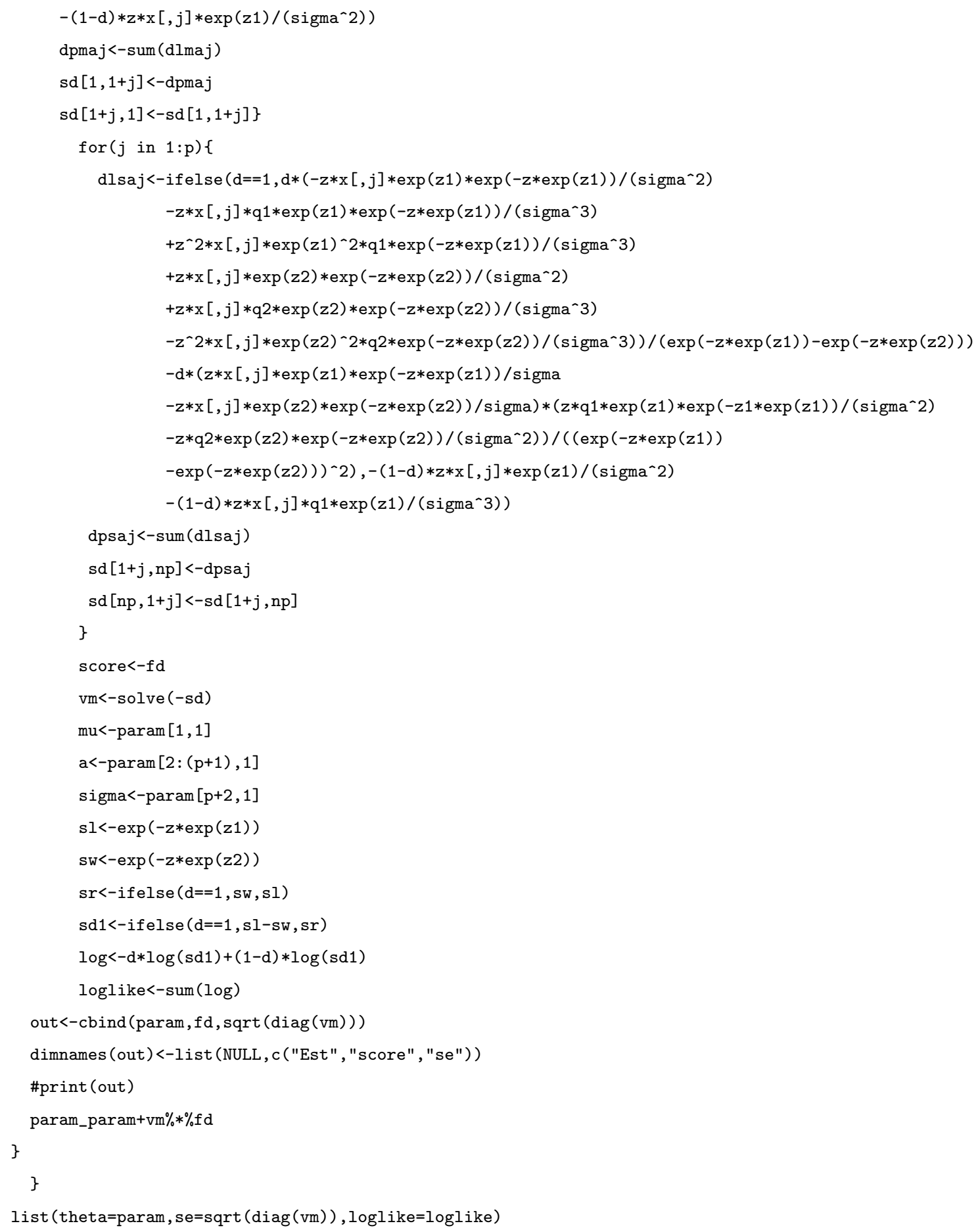


Anexo L - Programa escrito em R para simular e obter as estimativas dos parâmetros em $\mathrm{n}=500$ simulações realizadas para verificar o efeito nas covariáveis causado pela presença e ausência do efeito aleatório no modelo de fragilidade gama com censura intervalar.

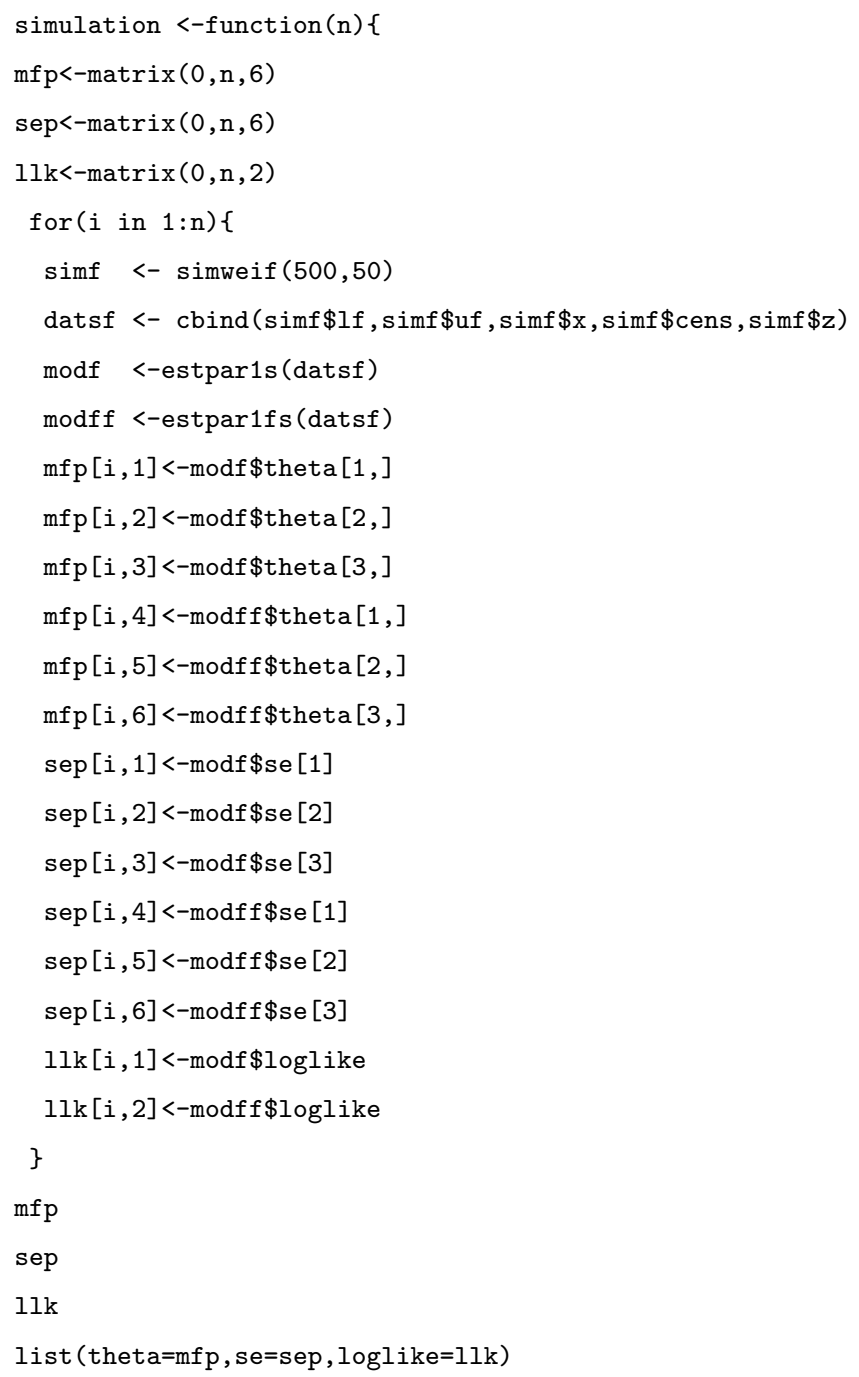

Obs.: Para executar essa simulação fazem-se necessários os programas: simweif apresentado no Anexo I, estpar1s apresentado no Anexo J e estpar1fs apresentado no Anexo K. O pacote estatístico R possui a função survreg a qual produz os resultados da função estpar1s. 
Anexo M - Programa usado no R - versão 1.5 para a simulação dos pesos usados na comparação dos resultados obtidos pelo modelo de fragilidade gama com censura intervalar e o de curvas de crescimento com efeitos aleatórios.

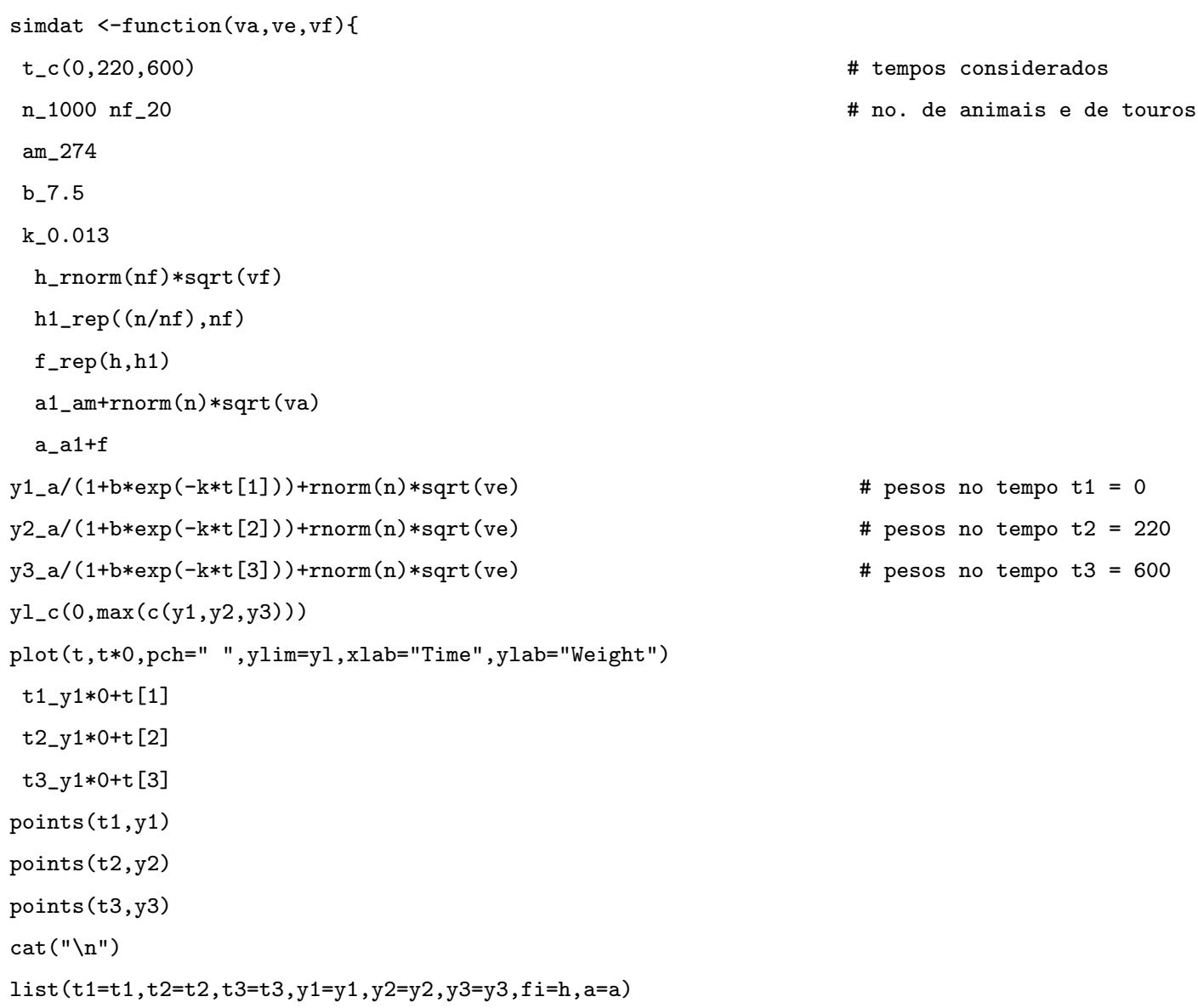

\# tempos considerados

\# no. de animais e de touros

\# pesos no tempo t1 $=0$

\# pesos no tempo t2 $=220$

$\#$ pesos no tempo t3 $=600$ 


\section{REFERÊNCIAS BIBLIOGRÁFICAS}

ALBUQUERQUE, L.G.; FRIES, L.A. Selection for reducing ages of marketing units in beef catlle. In: WORLD CONGRESS ON GENETICS APPLIED TO LIVESTOCK PRODUCTION 6., Armidale, 1998. Proceedings. Armidale: NSW, 1998. v.27, p.235-238.

ANDERSEN, P.K.; KLEIN, J.P.; KNUDSEN, K.M.; PALACIOS, R.T. Estimation of variance in Cox model with shared gamma frailty. Biometrics, v.53, p.14751484, Dec. 1997.

BRETAGNOLLE, J.; HUBER-CAROL, C. Effects of omitting covariates in Cox's model for survival data. Scandinavian Journal of Statistics, v.15, p.125-138, 1988.

CLAYTON, D. A model for association in bivariate life tables and its application in epidemiological studies of familial tendency in chronic disease incidence. Biometrika, v.65, n.1, p.141-151, 1978.

COMMENGES, D.; ANDERSEN, P.K. Score test of homogeneity for survival data. Lifetime Data Analysis, v.1, p.145-156, 1995.

COX, D.R. Regression Models and life tables. Journal of Royal Statistical Society. Series B, v.39, p.1-38, 1972.

COX, D.R. Partial likelihood. Biometrika, v. 62, n.2, p.269-276, Mar. 1975. 
DEMPSTER A.; LAIRD N.; RUBIN D. Maximum likelihood from imcomplete data via the EM-algorithm. Journal of the Royal Statistical Society. Series B, v.39, p.1-38, 1977.

FAUCETT, C.L.; THOMAS, D.C. Simultaneously modelling censored survival data and repeatedly measured covariates: a Gibbs sampling approach. Statistics in Medicine, v.15, p.1663-1686, 1996.

FINKELSTEIN, D.M. A proportional hazards model for interval-censored failure time data. Biometrics, v.42, p.845-854, 1986.

FINKELSTEIN, D.M.; SCHOENFELD, D.A. Combining mortality and longitudinal measures in clinical trials. Statistics in Medicine, v.18, p.1341-1354, 1999.

GAIL M.H.; WIEAND, S.; PIANTADOSI, S. Biased estimates of treatment effect in randomized experiments with nonlinear regressions and omitted covariates. Biometrics, v.71, p.431-444, 1984.

GILKS, W. R.; RICHARDSON, S.; SPIEGELHALTER, D.J. Markov chain Monte Carlo in practice. London: Chapman \& Hall, 1996. 486p.

GLIDDEN, D.V. Checking the adequacy of the gamma frailty model for multivariate failure times. Biometrika, v.86, n.2, p.381-393, 1999.

HENDERSON, R.; Oman, P. Effect of frailty on marginal regression estimates in survival analysis. Journal of the Royal Statistical Society. Series B, v.61, p.367-379, 1999.

HENDERSON, R.; DIGGLE, P.; DOBSON, A. Joint modelling of longitudinal measurements and event time data. Bioestatistics, 2001./No prelo/

HOGAN, J.W.; LAIRD, N.M. Mixture models for the joint distribution of repeated measures and event times. Statistics in Medicine, v.16, p.239-257, 1997a. 
HOGAN, J.W.; LAIRD, N.M. Model-based approaches to analysing incomplete longitudinal and failure time data. Statistics in Medicine, v.16, p.259-272, 1997b.

HOUGAARD, P. A class of multivariate failure time distributions. Biometrika, v.73, n.3, p.671-678, 1986.

HOUGAARD, P. Analysis of multivariate survival analysis. New York: Springer-Verlag, 2000. 542p.

HOUGAARD, P.; HARVALD, B.; HOLM, N.V. Measuring the similarities between the lifetimes of adult Danish twins born between 1881-1930. Journal of the American Statistical Association, v.87, p.17-24, 1992.

JOHANSEN, S. An extension of Cox's regression model. International Statistical Review, v.51, p.165-174, 1983.

KAPLAN, E.L.; MEIER, P. Non-parametric estimation from incomplete observations. Journal of American Statistical Association, v.53, p.457-481, 1958.

KLEIN, J.P. Semiparametric estimation of random effects using Cox model based on the EM algorithm. Biometrics, v.48, p.795-806, Sept. 1992.

KLEIN, J.P.; MOESCHBERGER M. L. Survival analysis: techniques for censored and truncated data. New York: Springer-Verlag, 1997. 502p.

LAGAKOS S.W.; SHOENFELD, D. Properties of proportional hazards score tests under misspecified regression models. Biometrics, v.40, p.1037-1048, 1984.

LAWLESS, J.F. Statistical models and methods for lifetime data. New York: John Wiley, 1982. 580p.

LEE, E. Statistical Methods for survival data analysis. Belmont: Lifetime Learning, 1980. 557p. 
LIANG, K.Y.; SELF, S.; BANDEEN-ROCHE, K.J.; ZEGER, S.L. Some recent developments for regression analysis of multivariate failure time data. Lifetime Data Analysis, v.1, p.403-415, 1995.

LIN, D.Y.; WEI, L.J.; YING, Z. Checking the Cox model with cumulative sums of martingale-based residuals. Biometrika, v.80, p.557-572, 1993.

LINDSEY, J. C.; RYAN, L. M. Tutorial in biostatistics methods for interval-censored data. Statistics in Medicine, v.17, p.219-238, 1998.

McGILCHRIST, C.A. REML estimation for survival models with frailty. Biometrics, v.49, p.221-225, Mar. 1993.

NEUHAUS, J.M.; HAUCK, W.W.; KALBFLEISH, J.D. The effects of mixture distribution misspecification when fitting mixed-effects logistic models. Biometrics, v.79, n.4, p.755-762, 1992.

NIELSEN, G.G.; GILL, R.D.; ANDERSEN, P.K.; SØRENSEN, T.I.A. A counting process approach to maximum likelihood estimation in frailty models. Scandinavian Journal of Statistics, v.19, p.25-43, 1992.

OAKES, D. A model for association in bivariate survival data. Journal Royal Statistical Society. Series B, v.44, p.414-422, 1982.

PAIK, M.C.; TSAI, W.Y.; OTTMAN, R. Multivariate survival analysis using piecewise gamma frailty. Biometrics, v.50, p.975-988, Dec. 1994.

PEROTTO, D.; CUE, R. I.; LEE, J. Comparison of nonlinear functions for describing the growth curve of three genotypes of dairy cattle. Canadian Journal of Animal Science, v.72, p.773-782, 1992.

PETERSEN, J.H. An additive frailty model for correlated life times. Biometrics, v.54, p.646-661, June 1998. 
PETO, R. Experimental survival curves for interval-censored data. Applied Statistics, v.22, p.86-91, 1973.

SPIEGELHALTER, D.; THOMAS A.; BEST, N. User manual WinBUGS version 1.3. www.mrc-bsu.cam.ac.uk/bugs. (20 nov. 2002)

STRUTHERS C.A.; KALBFLEISH, J.D. Misspecified proportional hazards models. Biometrics, v.73, n.2, p.363-369, 1986.

TURNBULL, B. W. The empirical distribution function with arbitrary grouped, censored and truncated data. Journal of the Royal Statistical Society, Series B, v.38, p.290-295, 1976.

WULFSOHN, M.S.; TSIATIS, A.A. A joint model for survival and longitudinal data measurement with error. Biometrics, v.53, p.330-339, Mar. 1997. 